\title{
Exploring the scaling-up of sustainable land management in the Central highlands of Ethiopia
}

\author{
Meskerem Abi Teka
}
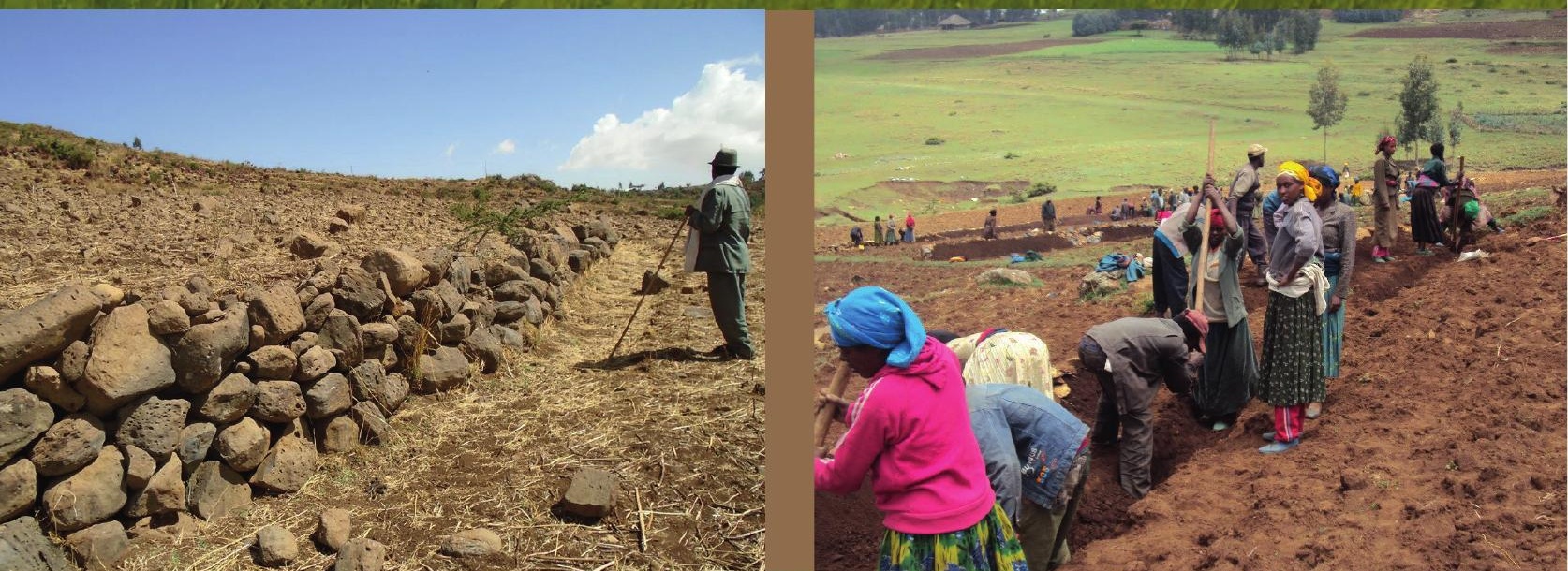



\section{Propositions}

1. In order to foster resilient farming in the Ethiopian highlands, sustainable land management practices must be planned and implemented in a more integrated and participatory way.

(this thesis)

2. The productive capacity of smallholder farmers and their food security can only be sustainably increased if farmers' intrinsic motivation to improve their livelihood is enhanced.

(this thesis)

3. Improving the post-harvest processing and distribution system of food is even more important for food security than increasing agricultural productivity.

4. Corruption, caused by lack of good governance and leadership, is the main threat to poverty and food insecurity in developing countries.

5. Sharing a scientific paper through social networks has more impact than publishing in open-access journals.

6. A career in academia will be more successful when time invested is in balance with time dedicated to family life.

Propositions belonging to the thesis entitled,

"Exploring the scaling-up of sustainable land management in the central highlands of Ethiopia"

Meskerem Abi Teka

Wageningen, 12 June 2019 

Exploring the scaling-up of sustainable land management in the Central highlands of Ethiopia 


\section{Thesis committee}

\section{Promotor}

Prof. Dr P.J.M. Oosterveer

Professor of Environmental Policy

Wageningen University \& Research

\section{Co-promotor}

Dr C.A. Kessler

Assistant Professor at the Soil Physics and Land Management group Wageningen University \& Research

\section{Other members}

Prof. Dr C. Leeuwis, Wageningen University \& Research

Prof. Dr J. Nyssen, Ghent University, Belgium

Dr E.M.A. Smaling, Wageningen University \& Research

Dr C. van Beek, SoilCares Foundation, Wageningen, the Netherlands

This research was conducted under the auspices of the Research School for SocioEconomic and Natural Sciences of the Environment (SENSE) 


\section{Exploring the scaling-up of sustainable land management in the Central highlands of Ethiopia}

\section{Meskerem Abi Teka}

\section{Thesis}

submitted in fulfilment of the requirements for the degree of doctor

at Wageningen University

by the authority of the Rector Magnificus

Prof. Dr A.P.J. Mol

in the presence of the

Thesis Committee appointed by the Academic Board

to be defended in public

on Wednesday 12 June 2019

at time 11 a.m. in the Aula. 
Meskerem Abi Teka

Exploring the scaling-up of sustainable land management in the Central highlands of Ethiopia,

147 pages.

PhD thesis, Wageningen University, Wageningen, the Netherlands (2019)

With references, with summary in English

ISBN: 978-94-6343-943-5

DOI: https://doi.org/10.18174/475460 


\section{Table of contents}

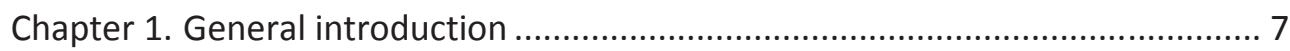

Chapter 2. Understanding the spontaneous spreading of stone bunds in Ethiopia: Implications for sustainable land management 19

Chapter 3. How farmers' characteristics influence spontaneous spreading of stone bunds in the Highlands of Ethiopia: a case study in the Girar Jarso woreda.

Chapter 4. Adapting the current mass mobilization approach in Ethiopia to enhance its impact on sustainable land management.

Chapter 5. Towards an enabling policy and institutional environment for scaling-up sustainable land management in the central highlands of Ethiopia..... 77

Chapter 6. Synthesis. .95

Appendices 109

Literature cited 117

English summary 135

Acknowledgements 139

About the author. 143

Certificate of the Netherlands Research School for the Socio-economic and Natural Sciences of the Environment (SENSE) 145 


\section{Dedication}

This thesis is dedicated to my beloved parents, Abi Teka and Shewaye Adugna Thank you 


\section{General introduction}

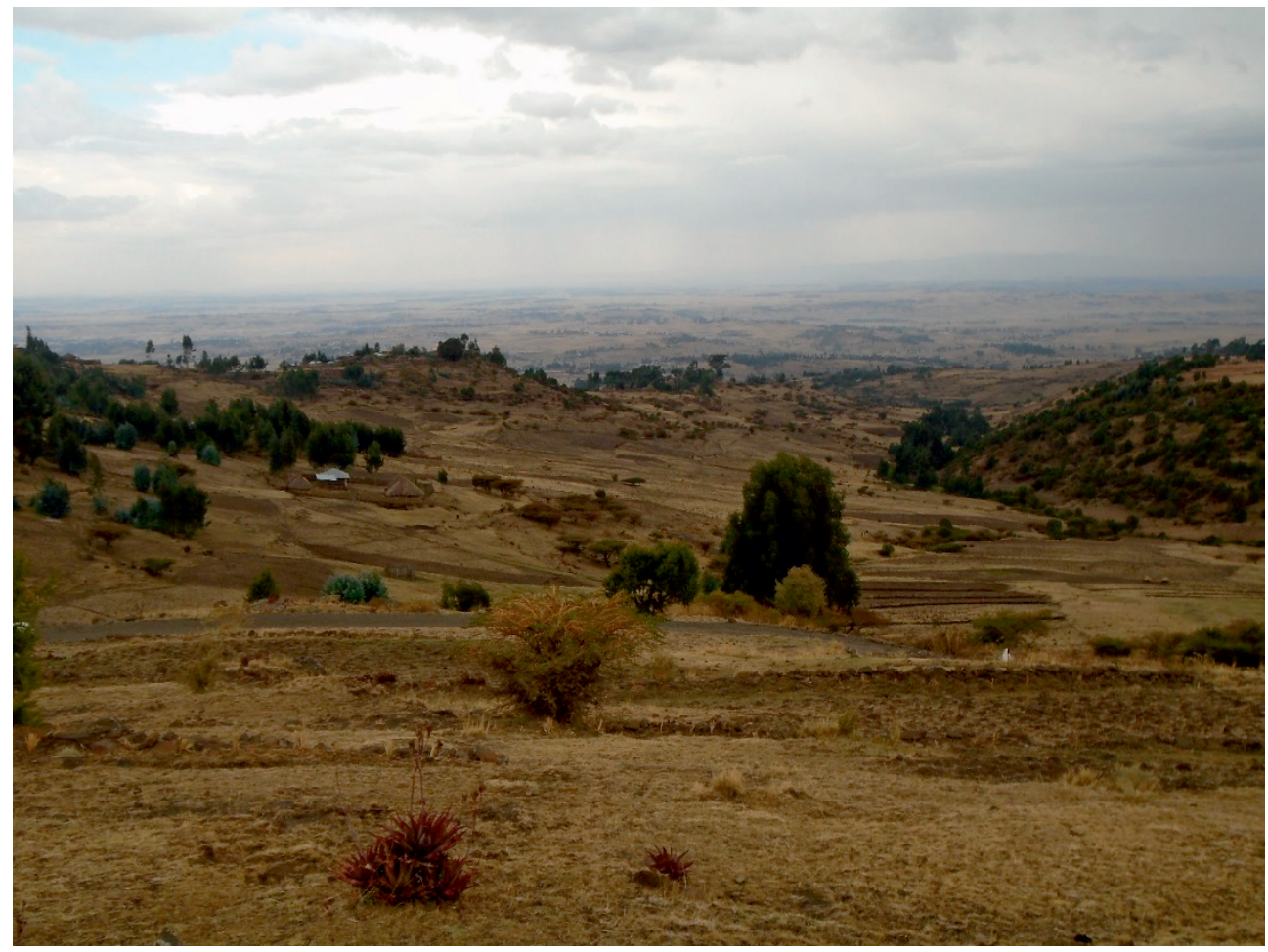




\subsection{Land degradation in the Highlands of Ethiopia}

More than $85 \%$ of Ethiopia's population inhabit rural areas and primarily depend on livelihoods that draw income from land resources (MoARD, 2010; CSA, 2013). The vast majority of the Ethiopian rural population are smallholder subsistence farmers and they predominantly practice rain-fed agricultural production (Tadesse \& Belay, 2004; Anley et al., 2007). Agriculture is the backbone of Ethiopia's economy and food provision (MoARD, 2010; Gebrehiwot \& van der Veen, 2013). The sector accounts for about $42 \%$ of the country's Gross Domestic Product (GDP), 90\% of export revenues and $85 \%$ of employment (Adego et al., 2018; CSA, 2018). However, agriculture in Ethiopia is characterized by low productivity (Weldemariam et al., 2013; Abebe \& Sewnet, 2014), and consequently cannot cover the food requirements of the country's population (Adimassu et al., 2014). Factors attributing to the low level of agricultural productivity and food insecurity in Ethiopia include land degradation, climatic change and variability, low application of inputs and political instability (Anley et al., 2007; Abi \& Tolossa, 2015; Miheretu \& Yimer, 2017).

Land degradation refers to a long-term decline in the productivity of the land due to human activities, exacerbated by natural processes (Taddese, 2001; Bhan, 2013; Tesfahunegn, 2018), and includes all the processes that reduce the productive capacity of land resources and their ability to perform essential functions (Hurni, 1993; Taddese, 2001; Hurni et al., 2010). These processes include soil erosion, soil nutrient depletion, reduced availability of soil water, deforestation and loss of soil biodiversity (Hurni et al., 2010; Lanckriet et al., 2015; Tesfahunegn, 2018). Soil erosion by water is the most widespread and severe form of land degradation constraining agricultural production and food security of smallholder farmers (Haileslassie et al., 2005; Tamene \& Vlek, 2008; Gebremichael et al., 2015). It triggers loss of fertile top soil during heavy rainfall, especially on bare and unprotected farmlands, and results in long-term decline and seasonal shortages in household food production (Haileslassie et al., 2005; Gebremichael et al., 2015). Likewise, declining soil productivity has exacerbated declining crop yields, which, in turn, undermine food security of the rural poor (Sonneveld \& Keyzer, 2003).

The problem of land degradation is particularly persistent in the highlands of Ethiopia, where the majority of the country's population lives and depends on farming (Amsalu \& de Graaff, 2007; Mengistu et al., 2015; Adego et al., 2018). The Ethiopian highlands cover about $65 \%$ of the total area of the country, $90 \%$ of its arable lands, house $90 \%$ of the human population and $60 \%$ of the livestock population (Hurni et al., 2010). The cause of land degradation in the highlands of Ethiopia is basically intensive cultivation on steep and fragile farmlands with unsustainable land management practices (Shiferaw \& Holden, 1998; Asrat et al., 2004; Tamene \& Vlek, 2008). Soil characteristics, rugged topographic settings, erosive rainfall and a cropping pattern dominated by cereals make the Ethiopian highlands 
vulnerable to soil erosion (Hurni, 1993; Lanckriet et al., 2015). In this regard, it has been estimated that more than 1.5 billion tons of topsoil is eroded from the highlands of Ethiopia every year (Taddese, 2001; Tamene \& Vlek, 2008), which could have provided billions of extra tons of food crops to the national agricultural production (Taddese, 2001). These food crops, such as cereals and pulses, are crucial to the food security of smallholder farmers and their households in Ethiopia (CSA, 2018).

Moreover, changes in rainfall amounts and patterns (too much or too little), together with an increase in temperature, seriously threaten agricultural productivity and food security in the highlands of Ethiopia (Hurni et al., 2010; Gebrehiwot \& van der Veen, 2013). Changes in rainfall and temperature enhance the probability of crop failures and the proliferation of weeds and insects, to eventually reduce crop yields (Araya \& Stroosnijder, 2011; Liniger et al., 2011) and food availability (Adimassu et al., 2014; Abi \& Tolossa, 2015). In addition, recurrent drought and erratic rainfall distribution have adverse effects on soil productivity and soil water holding capacity for crop production (Mengistu et al., 2015). The core argument of this research is that Sustainable Land Management (SLM) is required in Ethiopia to reverse the problem of land degradation and increase the country's economic growth and food security.

\subsection{Sustainable land management (SLM) in Ethiopia}

Over the last decades, SLM has become a major international response to tackle accelerating land degradation. In Ethiopia as well, SLM has become important and has received increasing emphasis in the country's development agenda that aims at bringing sustainable agriculture and food security among subsistence smallholder farmers (Yirga et al., 2014; Nedessa et al., 2015). The government of Ethiopia, in collaboration with several consortia of development partners, such as World Food Program, World Bank and African Development Bank, has made huge investments in promoting SLM practices over the past decades (Shiferaw \& Holden, 1998; Osman \& Sauerborn, 2001; Bewket, 2007). Public interventions in soil conservation were initiated after the occurrence of the 1970s and 1980s devastating drought and famines in particular (Hurni, 1993; Osman \& Sauerborn, 2001). Over decades, massive soil and water conservation activities were designed and implemented in highly degraded areas and in food deficit areas, mainly through food-forwork programs (Shiferaw \& Holden, 1998; Asrat et al., 2004; Moges \& Taye, 2017). Construction of physical structures such as bunds, terraces and check dams in cultivated fields, as well as planting trees on hillside areas, were given due emphasis over the years (Bewket, 2007). However, the efforts have not been widespread and did not bring the expected changes (Moges \& Taye, 2017). 
Likewise, between 1995 and 2009, SLM activities were implemented as part of Ethiopia's agricultural extension programs for individual farm-households (Bewket, 2007). Since 2010, guided by the successive Growth and Transformation Plans (GTP I \& II) of Ethiopia, SLM activities are being implemented through community mass mobilization at watershed level (Wolancho, 2015; Adego et al., 2018). The GTPs are a national development framework for five year periods (FDRE, 2010), with the current GTP II (lasting till 2020) being directed to achieving the country's vision of becoming a middle income country by 2025 (FDRE, 2016). Mass mobilization is a strategy pursued to mobilize all land users in a community (men, women and youth) to collectively address soil erosion and declining productivity of farmlands (Danano, 2010; Wolancho, 2015). This strategy aims at scaling-up SLM over a large area (Nedessa et al., 2015) and is crucial to increase the impact of SLM practices beyond the initially targeted area and target groups, as such reaching the majority of farmers (Uvin et al., 2000; Franzel et al., 2004). A good scaling-up strategy may reduce the time lag between technology development and its massive uptake (Gündel et al., 2001). Primarily, a scaling-up strategy is crucial for more effective investments in SLM practices (Tukahirwa et al., 2013). The main SLM practices implemented through mass mobilization in the Ethiopian highlands include physical measures, such as bunds, terraces, check-dams and in-situ soil moisture conservation structures, as well as biological measures, such as planting trees and area enclosures for natural regeneration (Danano, 2010).

Despite the introduction of various SLM practices, farmers' investments in these practices remain limited (Adimassu et al., 2012). In this regard, physical structures are often poorly adopted, hardly maintained and sometimes even removed by farmers (Kassie et al., 2010). As a result, land degradation has continued to be a critical threat to Ethiopian agriculture and to attaining the country's food security targets (Mengistu et al., 2015; Nedessa et al., 2015; Miheretu \& Yimer, 2017). Research over the past decades revealed that adoption and implementation of SLM practices by Ethiopian farmers is constrained by personal, socioeconomic, biophysical and institutional factors (Asrat et al., 2004; Shiferaw et al., 2009; Adimassu et al., 2012; Abebe \& Sewnet, 2014; Teshome et al., 2016a). Personal factors include age, education, perceived effects of erosion and perception of technological attributes (Tadesse \& Belay, 2004; Abebe \& Sewnet, 2014). Among the socio-economic factors identified to constrain adoption were labor, farmland size, social capital, access to information and sources of income (Amsalu \& de Graaff, 2007; Abebe \& Sewnet, 2014; Miheretu \& Yimer, 2017). The biophysical factors (or field characteristics) cover slope, soil type, soil fertility, soil depth, topography and rainfall (Tadesse \& Belay, 2004; Amsalu \& de Graaff, 2007; Shiferaw et al., 2009; Miheretu \& Yimer, 2017). Similarly, a top-down approach, poor extension services, lack of considering farmers' priority needs and farming systems, and a high emphasis on the promotion of physical structures are some of the institutional factors constraining SLM (Bewket, 2007; Shiferaw et al., 2009; Kassie et al., 2010; Weldemariam et al., 2013). 


\subsection{Scaling-up SLM practices in Ethiopia}

The issue of scaling-up SLM practices has received much attention in Ethiopia based on the notion that the practices of successful farmers (i.e. model farmers) need to be spread to other farmers to bring more benefits to the majority of smallholder farmers more quickly (FDRE, 2010, 2016). Scaling-up is the process of increasing the impact of SLM practices that achieved success in a limited area by a small group of people to reach more people over a larger area (Uvin et al., 2000; Carter \& Currie-Alder, 2006). It is also a process of doing more of the same over a larger geographical area (Wigboldus et al., 2016). The most widely used definition of scaling-up is that "Scaling-up leads to bring more quality benefits to more people over a wider geographical area more quickly, more equitably and more lastingly" (IIRR, 2000). According to Gündel et al. (2001), central concepts to this definition include a people centered vision, equity and sustainability, which are also important for SLM.

An enabling institutional and policy environment as well as stakeholders collaboration are important for the process of scaling-up (Mutoko et al., 2014), as they build partnerships, mobilize resources, promote genuine participation of stakeholders and build local institutional capacity in a sustainable manner (Franzel et al., 2004). Both vertical and horizontal scaling-up are often used to explain the scaling-up of SLM practices. Vertical scaling-up involves the coordination between different institutional levels and policy departments to establish an enabling institutional and policy environment and to ensure sustainability (Gündel et al., 2001; Franzel et al., 2004; Aad Kessler, 2006; Tukahirwa et al., 2013). The horizontal scaling-up involves the geographical spreading of SLM practices to reach more farmers (Mutoko et al., 2014). Both are important to motivate more farmers to adopt and implement SLM practices (Aad Kessler, 2006). Raising awareness, changing farmers' mindset, promoting genuine participation and enabling them to become intrinsically motivated to plan and invest in their future is crucial for the horizontal scalingup of SLM practices (Carter \& Currie-Alder, 2006; Kessler et al., 2016). The biggest challenge for SLM in Ethiopia is therefore how to achieve wide-scale impact, at a geographical scale larger than the traditional scale of singular intervention through projects.

\subsection{The Problem and research questions}

In Ethiopia, despite efforts being made to implement SLM practices that have a potential to improve soil fertility and increase productivity, widespread adoption by local farmers has been limited (Anley et al., 2007; Bewket, 2007; Shiferaw et al., 2009; Abebe \& Sewnet, 2014). At the same time, some farmers, often spontaneously, adapt SLM practices to make them fit their farming system and limited available resources such as farmland, labour and 
finance (Bekele \& Drake, 2003; Amsalu \& de Graaff, 2006; Teshome et al., 2016a). This adaptation, i.e. what farmers do with the introduced practices, based on their own knowledge, and how they make them fit to better work in their own local conditions, is very important (Douthwaite et al., 2001; Douthwaite et al., 2009). Farmers' knowledge in this regard is their understanding of how the introduced SLM practices work, and where to implement them on their farm to achieve better results (Meijer et al., 2015). Especially, when farmers adapt the introduced SLM practices to make them fit their farming system, one might conclude that such farmers are committed and intrinsically motivated to implement these practices and to maintain them. This is crucial in halting land degradation and improving productivity (Shiferaw et al., 2009). It also strengthens the potential for successful implementation and continued use of introduced SLM practices (Meijer et al., 2015).

However, in Ethiopia, information is lacking on how local farmers adapt soil conservation technologies, and how effective these are in combating land degradation and fostering SLM. Farmers' adaptation of introduced SLM practices plays a critical role in facilitating scalingup over larger geographical areas (Douthwaite et al., 2001; Millar \& Connell, 2010; Mutoko et al., 2014). This is because scaling-up is not only about adopting the recommended practices, but rather a process of learning to implement these practices, and adapting them to better fit to the local conditions (Millar \& Connell, 2010; Wigboldus et al., 2016). Following IIRR (2000), scaling-up is about people adapting SLM practices to their local contexts and learning from their experiences. Likewise, Franzel et al. (2004) and Carter \& Currie-Alder (2006) indicate that scaling-up involves learning, experimentation, adaptation/modification.

Although much knowledge about adoption in the highlands of Ethiopia is already available (e.g. Amsalu \& de Graaff, 2007; Teshome et al., 2016a; Miheretu \& Yimer, 2017), limited research has been done to better understand which practices spread spontaneously and how these are adapted to fit the farming system. Information is also lacking on how to enhance Ethiopian farmers' awareness and motivation to implement SLM practices in their fields and integrate these into their annual farm planning. Another issue that needs further study is the policy and institutional environment of Ethiopia that can foster or limit the widespread adoption and scaling-up of SLM practices. Therefore, the main purpose of this research is to analyse spontaneous adoption and scaling-up of SLM in the Central Highlands of Ethiopia. As a way to attain this general objective, the research poses the following research questions:

1. How have stone bunds spontaneously spread in the Girar Jarso woreda, and what are their characteristics? 
2. What are the key-factors in household characteristics that explain why some farmers spontaneously implement stone bunds and other farmers do not?

3. How to trigger Ethiopian farmers' motivation and awareness to practice integrated farming in their fields, and to invest in SLM practices in the future?

4. What changes are required in the policy and institutional environment of Ethiopia to enable the scaling-up of SLM practices through a more integrated mass mobilization approach?

\subsection{Definition of terms and concepts}

In this section, I present definitions of the most important terms and concepts used in this thesis.

SLM: refers to the use of suitable technologies or practices that farmers implement on their farmland to satisfy individual and community needs, while simultaneously ensuring the long-term productive potential of the farmland and maintaining environmental functions (Liniger et al., 2011; Schwilch et al., 2014; Nedessa et al., 2015).

Practices (or technologies): refers to a combination of land management activities/techniques and knowledge implemented by farmers in the field to control erosion, improve soil fertility and increase productivity.

Spontaneous spreading: refers to the adoption and implementation of SLM practices based on farmers intrinsic motivation using his/her own resources, as well as knowledge from projects, neighboring farmers or through participation in mass mobilization campaign.

Intrinsic motivation: refers to doing an activity for the inherent satisfaction of the activity itself, driven only by the personal willingness and readiness to undertake action and improve (Aad Kessler, 2006; Deci \& Ryan, 2012).

Integrated farm management: refers to managing the farming system in such a way that it integrates SLM practices with the existing crop production, livestock production and income generation activities, contributing to an increase in farm resilience and food security.

Mass mobilisation campaign: A strategy pursued to mobilize all farmers to make labour available for the implementation of SLM activities (Leta et al., 2018). 
Enabling environment: involves a favourable policy and institutional environment that encourages farmers to invest in SLM practices, and that speeds-up the processes of spreading SLM practices over a wider geographical area (Adimassu et al., 2016).

\subsection{Methodological design}

\subsubsection{Description of the study area}

The study is undertaken in the Central Ethiopian Highlands, specifically in the Girar Jarso woreda of North Shewa zone, Oromia region (Figure 1.1). The woreda is found along the highway to Debre-Markos in the North-western direction at a distance of $112 \mathrm{~km}$ from Addis Ababa, capital city of Ethiopia. The woreda is located between $09^{\circ} 40^{\prime} 00^{\prime \prime} \mathrm{N}-10^{\circ} 00^{\prime} 00^{\prime \prime} \mathrm{N}$ latitude and $38^{\circ} 35^{\prime} 00^{\prime} \mathrm{E}-38^{\circ} 56^{\prime} 30^{\prime \prime} \mathrm{E}$ longitude. The total area of the woreda is about 494 $\mathrm{km}^{2}$. More than $65 \%$ of the area is characterized by steep-slopes and a mountainous topography. The elevation ranges between 1300 and 3419m above sea level (Abi \& Tolossa, 2015; Tolossa et al., 2015; Seyoum, 2016a). The average annual temperature ranges from $11.5^{\circ} \mathrm{C}$ to $35^{\circ} \mathrm{C}$, whereas the average annual rainfall ranges between $801 \mathrm{~mm}$ and $1200 \mathrm{~mm}$, according to meteorological data of Fiche Station. Administratively, the woreda encompasses 17 rural kebeles. The total population of the Girar Jarso woreda in 2017 was 85,606 (CSA, 2013).

Rain-fed mixed farming (crop production and livestock raising) is the main means of living for more than $90 \%$ of the population in the woreda. In addition, small-scale irrigation is practiced in some of the kebeles in the woreda (Abi \& Tolossa, 2015). The main dominant soil type in the woreda are Vertisols, but also Nitosols and Cambisols are found (Seyoum, 2016a). Cereals and pulses are the major food crops grown in the area. In the Girar Jarso woreda, however, land degradation in the forms of soil erosion and soil nutrient decline is a common phenomenon, resulting in declining household food security (Abi \& Tolossa, 2015). Likewise, a study by Tolossa et al. (2015) and Seyoum (2016a) indicates the prevalence of severe land degradation problems in the woreda due to deforestation and reduction of the vegetation cover, expansion of cultivated farmland to marginal areas (e.g. steep slopes), inappropriate land management practices, continuous cultivation with short fallowing periods and over-grazing/free grazing.

In order to tackle the problem of land degradation, various SLM practices have been introduced in the Girar Jarso woreda, especially structural measures such as stone bunds, terraces, diversion ditches, check dams, micro-basin and hillside terraces. Introduced SLM practices are those promoted by different projects (e.g. MERET, Managing Environmental Resources to Enable Transition) and the governmental extension programs. Farmers in the 
woreda also apply some local land management practices on their farms, such as fertilizer applications, contour cultivation, crop rotation, multiple cropping, and construction of traditional diversion ditches and waterways. Unlike the local practices, the introduced practices have standard length, width, and height (Bekele \& Drake, 2003).

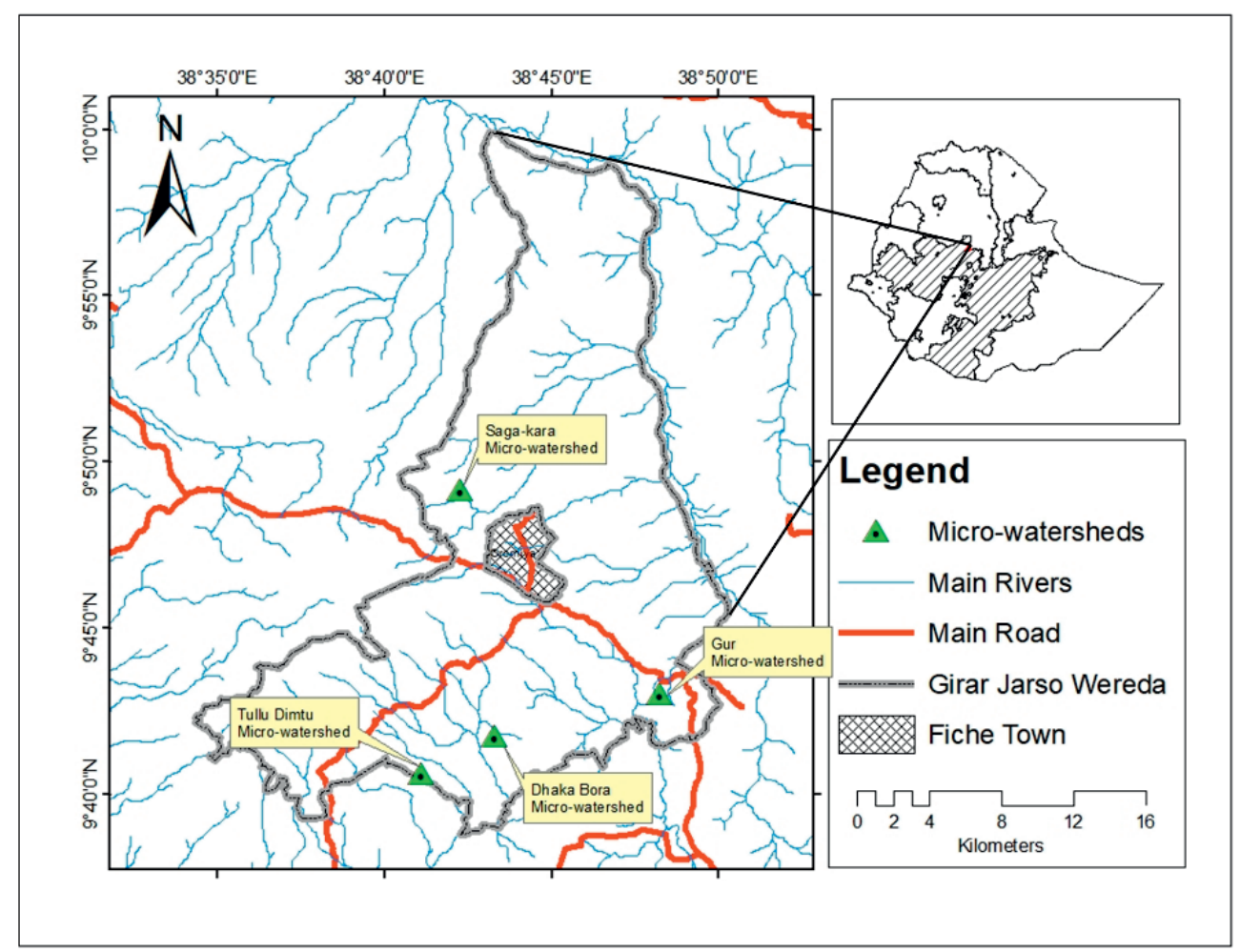

Figure 1.1 Map of Ethiopia, Girar Jarso woreda and the study watersheds

\subsubsection{Methods}

The overall research design of this study is a case study approach consisting of quantitative and qualitative surveys based on a participatory learning process. Participatory research is important to understand farmers' experiences with SLM technologies (Sturdy et al., 2008; de Souza et al., 2012). This method has been widely used by many scholars to identify locally available SLM technologies with their consecutive approaches (e.g. Douthwaite et al., 2009; Liniger et al., 2011; Schwilch et al., 2014; de Vente et al., 2016).

Primary data are collected using a combination of household surveys, interviews, discussions and field observations. For research questions 1 and 2, data are generated using 
household surveys with 80 farmers, focus group discussions and field observations. Data for research question 3 are generated through household surveys with 52 farmers and focus group discussions. For research question 4, institutional data are collected using interviews with 30 key informants. Secondary data are obtained from published and unpublished books, articles, research papers and government documents. Descriptive statistics (e.g. percentages, means and standard deviations) and Principal Component Analysis are used to analyze the quantitative data, whereas content analysis is used to analyze the qualitative data. Similarly, t-test and chi-square tests are used to test significance levels.

\subsection{Thesis outline}

The thesis consists of the introduction and five chapters. Chapter 2 contributes to the understanding of the process of spontaneous spreading, by analysing where stone bunds in the area have been spontaneously implemented (on which plots and farms) and how they look like (their characteristics and effects). The characteristics of farmers who spontaneously implement stone bunds are assessed and further analysed in Chapter 3 . The focus is here on household characteristics that explain differences between farmers who spontaneously implement stone bunds and farmers who do not.

Lessons learned from Chapter 2 and 3 are used in Chapter 4 to develop an adapted (more participatory and more integrated) training approach for the mass mobilisation campaigns, which is tested and validated in the field with a group of farmers. The focus of this adapted training approach is on strengthening farmers' knowledge and awareness about natural resources management, drought mitigation and integrated farm planning. Its validation provides insights in how to trigger farmers' motivation to integrate SLM practices into their farming system, as such providing an opportunity to speed-up the scaling-up of SLM and achieve more sustainable impact.

Chapter 5 analyses the existing institutional and policy environment for SLM implementation and suggests how this environment needs to change to foster scaling-up SLM. In this Chapter, we identify the perceived limitations and opportunities for institutions at the national, regional and local level for scaling-up SLM. The final Chapter discusses the major findings of the thesis, and outlines the main conclusions drawn from the findings. It also draws out the policy and extension implications, science and society contributions and discusses issues for future research. 


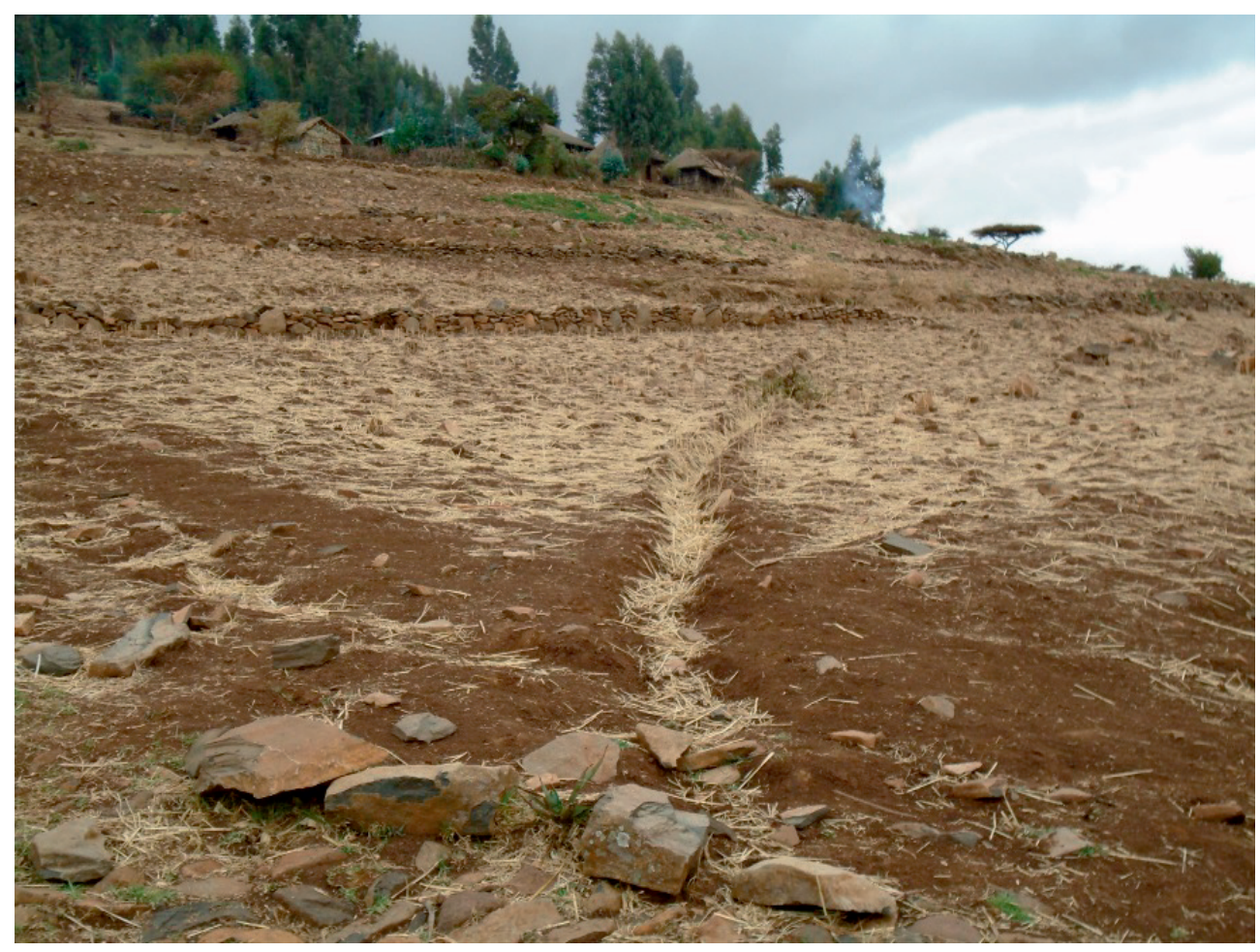




\section{Understanding the spontaneous spreading of stone bunds in Ethiopia: Implications for sustainable land management}

This study deals with the spontaneous spreading of stone bunds in the Central Ethiopian Highlands, i.e. the adoption and implementation of stone bunds by farmers on their own initiative. The study tests the hypothesis that spontaneously implemented stone bunds, as compared to stone bunds implemented by mass mobilization campaigns, are more integrated with other land management practices and lead to higher yields. Data are collected in the Girar Jarso woreda through field observations and household surveys. Descriptive statistics are used to analyze and test the data at 1\% and 5\% probability levels. Results show that stone bunds are spontaneously implemented mainly on farmlands located nearby the homesteads where farmers perceive severe erosion, poor soil fertility and steep slope gradients. Compared to stone bunds implemented by mass mobilization, spontaneously implemented stone bunds are perceived as better maintained, more frequently modified to fit the farming system and better integrated with soil fertility management practices such as applying fertilizer, compost and manure. Particularly, this better integration with other practices is very important, because it makes stone bunds more effective in reducing erosion, leading to beneficial effects on soil moisture and soil productivity, as perceived by farmers. The study, therefore, suggests that the mass mobilization campaign should use a more participatory and integrated approach, in which there is ample space for awareness raising and learning concerning the benefits of integrated farm management, and in which farmers themselves have a leading role in the decision on where to construct stone bunds. Such a strategy will lead to more sustainable impact on soil fertility and food security than the current top-down intervention approach.

Based on:

Abi, M., Kessler, A., Oosterveer, P. \& Tolossa, D. 2018. Understanding the spontaneous spreading of stone bunds in Ethiopia: Implications for Sustainable Land Management. Sustainability, 10 (8). http://doi.org/10.3390/su1008266. 


\subsection{Introduction}

Subsistence agriculture is the main source of livelihood for more than $85 \%$ of Ethiopia's population (CSA, 2015). However, the country faces challenging problems in its struggle to make agriculture sustainable and to achieve food security (Bekele \& Drake, 2003; Asrat et al., 2004). In Ethiopia, land degradation in the form of soil erosion and nutrient depletion seriously threatens agricultural productivity and is a major cause of food insecurity (Amsalu \& de Graaff, 2007; Meijer et al., 2015). The problem is persistent in the Highlands of Ethiopia, where the majority of the country's population lives and depends on farming. Land degradation in the Highlands of Ethiopia is primarily caused by intensive cultivation on steep and fragile farmlands with unsustainable land management practices (Asrat et al., 2004; Tadesse \& Belay, 2004). Furthermore, soil characteristics, topography and the cropping pattern (dominated by cereals) make the Ethiopian Highlands vulnerable to soil erosion (Gete et al., 2006). In this regard, it has been estimated that 42 ton/ha (Hurni, 1993; Bekele \& Drake, 2003) to 179 ton/ha (Shiferaw \& Holden, 1999) of soil is eroded from cultivated land every year. Hence, we can infer that the fate of Ethiopian smallholder agriculture relies on the quest for Sustainable Land Management (SLM).

In Ethiopia, SLM is an important issue and receives emphasis in the country's development agenda, which aims to reverse land degradation, improve agricultural productivity and achieve food security through implementing soil and water conservation practices at a large scale (Snyder et al., 2014). In this regard, many development projects and programs have been initiated and implemented by successive Ethiopian governments in collaboration with several consortia of donors since the 1970s (Hurni, 1993; Snyder et al., 2014; Teshome et al., 2016a). Between 1995 and 2009, the Ethiopian government incorporated SLM practices into agricultural extension packages/programs for individual farm-households (Teshome et al., 2016a). Recently, SLM practices have been promoted and implemented through community mass mobilization at a watershed level, as part of Ethiopia's Growth and Transformation Plans (GTP I and II) (FDRE, 2010, 2016). GTPs are a national development framework for five year periods: GTP I (2010/11 to 2014/15) was directed towards achieving the Millennium Development Goals by 2015 (FDRE, 2010), and GTP II (2015/16 to 2019/20) was directed towards achieving the country's vision of becoming a middle income country by 2025 (FDRE, 2016). The main SLM practices implemented through (community) mass mobilization include physical measures, such as stone/soil bunds, terraces and check-dams, as well as biological measures, such as tree planting and area enclosures (Danano, 2010).

Despite considerable efforts made to promote SLM through different intervention strategies, limited adoption of SLM practices by local farmers is reported in many studies conducted in the Highlands of Ethiopia (for instance, Bekele \& Drake, 2003; Tadesse \& Belay, 2004; Wolka, 2014; Abdela \& Derso, 2015; Adimassu et al., 2016). At the same time, some 
farmers adopt SLM practices spontaneously, on their own initiative. Such farmers often adapt and implement these practices to make them fit to their farming system and limited available resources, and integrate them with other measures by using their own knowledge and family labor (Beshah, 2003; Amsalu \& de Graaff, 2006; Teshome et al., 2016c). However, there is limited research done to better understand which practices spread spontaneously and how these are adapted to fit the farming system. Having more insight into such spontaneous spreading would help to improve current SLM scaling-up strategies and better enable the inclusion of farmers' knowledge and practices into a technology spreading strategy (German et al., 2006).

This study provides insights into how stone bunds have spontaneously spread in the Girar Jarso woreda, the Central Highlands of Ethiopia, as such contributing to the understanding of the process of spontaneous spreading. Stone bunds are chosen because these are widely promoted and implemented on farmlands in the study area. The study further tests the hypothesis that spontaneously implemented stone bunds, as compared to stone bunds implemented by mass mobilization campaigns, are better integrated with other land management measures, and therefore lead to higher yields.

\subsection{Conceptual and Theoretical Frameworks}

\subsubsection{Conceptual framework}

The concept of SLM has emerged as an important global issue due to accelerating land degradation worldwide, including Ethiopia. SLM refers to the use of suitable technologies or practices that farmers implement on their farmland to satisfy individual and community needs, while simultaneously ensuring the long-term productive potential of the farmland and maintaining environmental functions (Hurni, 2000; WOCAT, 2007; Liniger et al., 2011). SLM practices are structural, agronomic, vegetative and management measures used to control soil erosion, reduce nutrient depletion, improve soil conservation and enhance productivity (Shiferaw et al., 2009; Adimassu et al., 2016). Some examples of SLM practices include: terraces, stone/soil bunds, minimum tillage, intercropping, composting, manuring and agroforestry. This study focuses on stone bunds, which, in Ethiopia, can play a crucial role in addressing soil erosion on farmlands (Vancampenhout et al., 2006). Stone bunds are an embankment of stones constructed along the contour line to reduce or stop the velocity of water flowing down-slope, consequently reducing soil erosion (Gebremichael et al., 2005; Vancampenhout et al., 2006) (Figure 2.1).

SLM approaches encompass the ways and means to support and enable farmers to implement, adopt and adapt SLM on the farmland (Hurni, 2000; WOCAT, 2007; Liniger et 
al., 2011). In Ethiopia, the regular government extension program, the food-for-work program and mass mobilization are important approaches for spreading SLM practices (Danano, 2010; Nedessa et al., 2015). Next to project - or program - based SLM approaches, World Overview of Conservation Approaches and Technologies, WOCAT (2007) identifies the "spontaneous" approach, in which farmer-to-farmer learning takes place, often supported by an adequate enabling environment for spreading of SLM practices. Spontaneous spreading can be measured in terms of the distance that a practice has spread, for instance, from the original farmers involved in a project to non-project farmers through existing social networks (German et al., 2006). In this research, the term 'spontaneous spreading' refers to the adoption and implementation of SLM practices based on a farmer's intrinsic motivation using his/her own resources, and using knowledge obtained elsewhere: from project interventions, from neighboring farmers or through participation in mass mobilization campaigns.
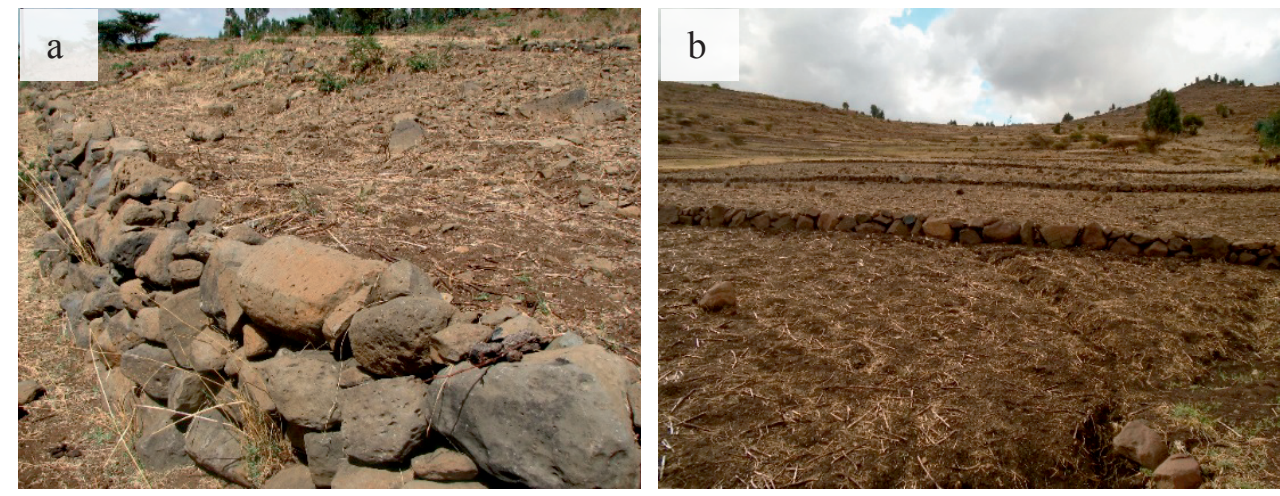

Figure 2.1 Stone bunds on farmlands in the Girar Jarso woreda, Central Ethiopian Highlands. Spontaneously implemented stone bunds (a); and mass mobilization campaign stone bunds (b) (Abi, 2015)

\subsubsection{Theoretical framework}

The diffusion of innovation theory (Rogers, 1995) was used here to better understand how spontaneous spreading takes place, because it describes how knowledge of an innovation, technical information and actual practices spread through-out a population within existing social networks (Rogers, 1983; Straub, 2009). Rogers defines diffusion as the process, by which an innovation is communicated through certain channels over time among the members of a social system (Rogers, 1995). Innovation, in the context of soil conservation, can be defined as a new technology for erosion control or the reduction of soil loss, and/or the integration of a new technology into the farming system (Napier, 1991). It should be noted that we used the term 'innovation and technology (or practices)' synonymously, which is the same as Rogers does. 
Rogers (1995) and Carter Jr et al. (2001) argue that the diffusion process is determined by the characteristics of the technology, the communication channel used to share the information about the technology, and characteristics of these who adopt the technology and the environmental contexts (geographical setting). Concerning the technological characteristics, the farmer's perception of the technology determines its spreading (Adesina \& Zinnah, 1993; Owen et al., 2006). This includes: (1) its relative advantage - the degree to which a technology is viewed as better than the previously used practices, (2) its compatibility - the degree to which a technology is consistent with the farming system, farmer's experiences and needs, (3) its complexity - the degree to which a technology design is perceived as difficult to understand and use, (4) its testability - the degree to which a technology can be experimented with on a limited area, (5) its observability - the degree to which the results of a technology are easily visible to others, and (6) its adaptability - the degree to which a technology is changed or modified by a user to fit the farmer's needs in a process of its implementation (Rogers, 1983). Therefore, as suggested by Rogers, technologies that are perceived by farmers as having greater relative advantages, compatible to the farming system, observable to others, adaptable to fit the farmland condition, and less complex to use, would spread better than other technologies (Rogers, 2002). Among others, observability and compatibility are crucial in terms of triggering spontaneous spreading. Farmers spontaneously implement certain technologies, when they observe the benefits of the technologies in the fields of other farmers, and find it convenient in their farming system (Reij \& Garrity, 2016).

Similarly, access to information about an innovation is a decisive factor for its diffusion (Adesina \& Zinnah, 1993; Prager \& Posthumus, 2010). Access to information enables a farmer to have knowledge about a new technology, how to apply it on the field and what its effect would be in terms of conservation, agricultural productivity, income, etc. (Meijer et al., 2015). In this case, the role of agricultural extension workers and development agents is crucial (Shiferaw \& Holden, 1998; Ntshangase et al., 2018), named the 'change agents' (Rogers, 1983). In addition, Beshah (2003) and Meijer et al. (2015) suggest that information and training play a significant role in the transfer of knowledge of introduced technologies. Access to information triggers farmers to learn and implement a new technology, which is crucial in the process of spontaneous diffusion (Rogers, 1995).

Moreover, Rogers (2002) explains diffusion in terms of a social learning process, through which people talking to people spread an innovation. For instance, individuals may learn about the characteristics of the technology from their neighbors' experiences (Conley \& Udry, 2001; Straub, 2009; Karidjo et al., 2018), particularly when a technology implemented on a neighbor's farmland is visible (Cramb et al., 1999). In addition, Carter Jr et al. (2001) and Peshin et al. (2009) suggest that interpersonal communication (a face-to-face exchange) is highly effective in forming and changing attitudes towards a technology, as it 
increases diffusion of information on available technologies and their benefits. Similarly, Kiptot et al. (2006) point out that farmer-to-farmer diffusion provides a potential alternative mechanism for technology spreading through extension campaigns. Next to this, knowledge about a technology can also be developed through self-testing and self-experimenting the technology (Conley \& Udry, 2001; Vanclay, 2004; Straub, 2009).

Hence, knowledge can be obtained through different ways: through farmer-to-farmer learning, own experimentation, and through sharing experiences about a new technology (Mercer, 2004). Nonetheless, geographical settings, including the topography, soil condition, slope, land size and location, also affect technology use (Meijer et al., 2015); technologies can only be used when they are suitable to local conditions and the farming system (Wejnert, 2002). Literature shows that modifying and adapting technologies to make them fit to local conditions are important for the effectivity of these technologies to tackle environmental problems (Napier, 1991; Mercer, 2004; Shiferaw et al., 2009). Therefore, a thorough understanding of the geographical setting, in which innovations take place, as well as of the technological characteristics and sources of information that farmers use, are important aspects that help to understand spontaneous spreading; these are all addressed in this paper.

\subsection{Research Methodology}

\subsubsection{Description of the study area}

This study was undertaken in the Girar Jarso woreda (similar to district, an official administrative unit), Central Ethiopian Highlands. The total area of the woreda is about 494 $\mathrm{km}^{2}$ with an elevation ranging between 1300 and 3419 m.a.s.I. The woreda encompasses 17 rural kebeles (similar to ward, the lowest official administrative unit) and has a total population of 80,080 people (CSA, 2013). Annual rainfall ranges between $801 \mathrm{~mm}$ to 1200 $\mathrm{mm}$ (according to Fiche Station meteorological data) with annual temperature between 11 ${ }^{\circ} \mathrm{C}$ and $21.8{ }^{\circ} \mathrm{C}$. Rain-fed mixed farming (crop production and livestock raising) is the main means of livelihood for more than $90 \%$ of the population in the woreda, with some smallscale irrigation practiced in some kebeles.

The main soil types found are Vertisols, Nitosols and Cambisols. Vertisols are the dominant soil types in the woreda (Seyoum, 2016b). Cereals are the most important food crop. Soil erosion and soil nutrient depletion severely threaten agricultural production in the woreda (Kassahun, 2006; Abi, 2012; Abi \& Tolossa, 2015; Seyoum, 2016b). Similar to other Ethiopian Highlands, various SLM technologies (structural and biological measures) have been implemented in the study area to curb erosion problems. The structural measures include 
construction of bunds, terraces, diversion ditches, check-dams, micro-basins and hillside terraces. The biological measures comprise enclosure of degraded lands from human and animal interference and tree plantings.

\subsubsection{Sampling techniques}

Given that stone bunds are found widely spread on farmlands in the Girar Jarso woreda, we selected this practice to understand spontaneous spreading. It should be noted that we considered stone bunds implemented on the farmlands over a five-year period (2010-2014). In this period, stone bunds have been intensively implemented at a watershed level through mass mobilization campaign as part of the first GTP of Ethiopia. For the purpose of this study, three watersheds of the Girar Jarso woreda (Gur watershed, Dhaka Bora watershed and Tulu Dimtu watershed) (Figure 2.2) were selected. The respective watersheds are 990 hectares, 570 hectares and 600 hectares in size.

Farmers from each watershed were selected on purpose, using a two-stage sampling technique. In the first stage, farmlands with spontaneously implemented stone bunds were identified based on a snowball sampling approach. Snowball sampling is a non-probabilistic form of sampling in which persons initially chosen for the sample are used as informants to locate other persons having similar characteristics (Bernard, 2011; Neuman, 2014; Leavy, 2017). This type of sampling method is used in cases, where it is hard to identify samples in the population, in this case, in farmers with spontaneously implemented stone bunds. In addition, snowball sampling is appropriate to understand technology spreading in the absence of external intervention or support (German et al., 2006). Accordingly, we selected 40 farmers ( 20 from the Gur watershed, 10 from the Dhaka Bora watershed and 10 from the Tulu Dimtu watershed) with spontaneously implemented stone bunds. The difference in the number of farmers chosen from the Gur watershed was based on the difference in its size (larger than the Dhaka Bora and Tulu Dimtu watersheds) and the large number of farmers living in the watershed. In the next stage, we compared the plots of these 40 selected farmers (called spontaneous adopting farmers or SFs) with other nearby plots where stone bunds were implemented by farmers participating in the mass mobilization campaign (called non-spontaneous adopting farmers or NSFs). Subsequently, we selected 20 NSFs from the Gur watershed, 10 from the Dhaka Bora watershed and 10 from the Tulu Dimtu watershed based on purposive sampling technique. Hence, in total, 80 farmers were selected for household surveys: 40 SFs and 40 NSFs. 


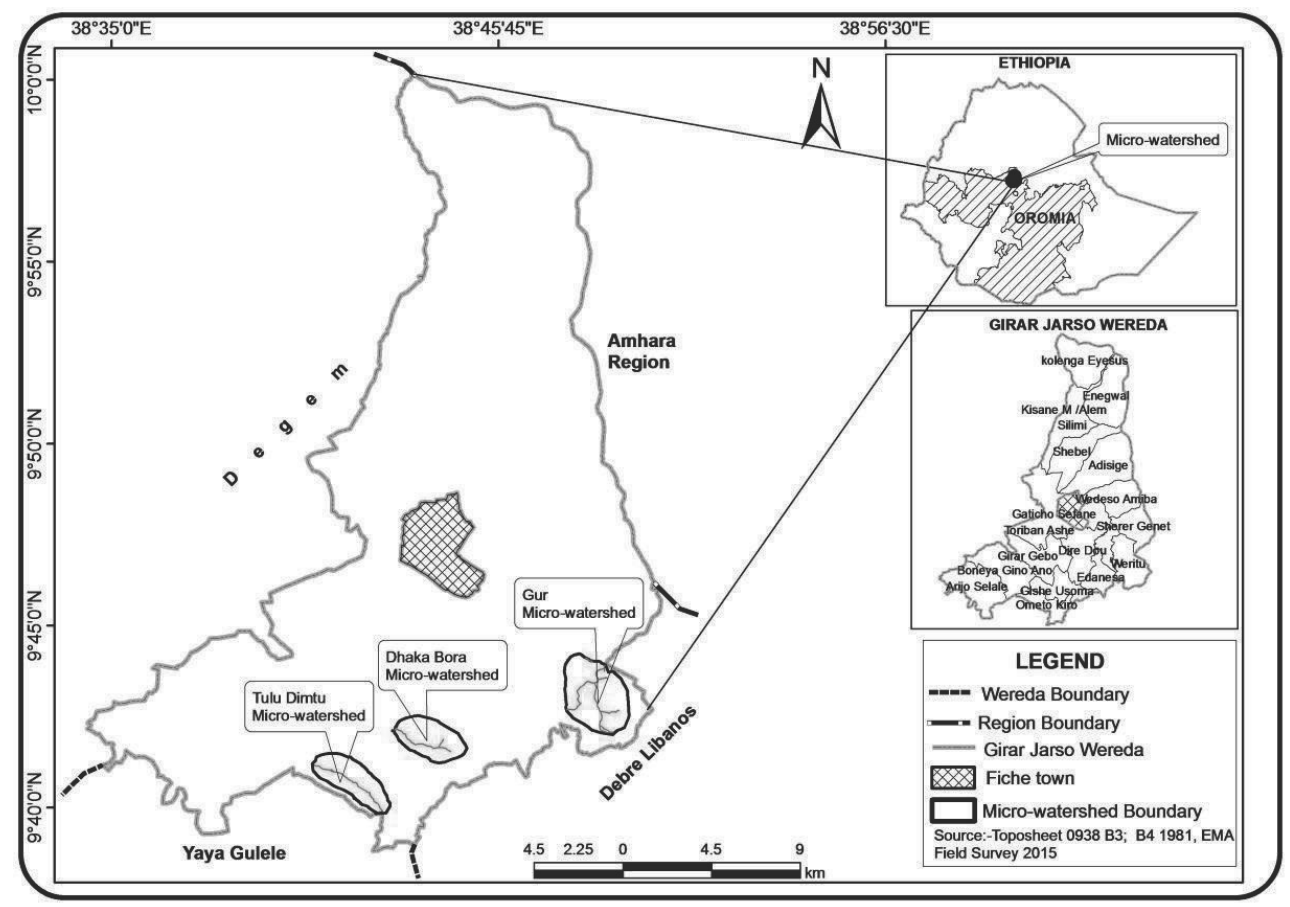

Figure 2.2 Map of Ethiopia, the Girar Jarso woreda and the three studied watersheds

\subsubsection{Data collection and analysis}

Data were collected through different data collection techniques, including field observations, household surveys and key informant interviews. Field observations were held in consultation with development agents working in the studied watersheds to obtain general information on the implemented stone bunds. Household surveys with the 80 farmers were carried out from May to June 2015 using structured and semi-structured questionnaires (see Appendix 1). Data related to farmers' perceived farmland characteristics, such as the farm size, erosion, soil fertility status, slope and location, were collected to help understand where the stone bunds were implemented. Data related to stone bund characteristics included maintenance of stone bunds, modifications made to make them fit to the farming system, and integration with soil fertility management measures. Application of chemical fertilizer, compost and manure are among the soil fertility management measures considered to measure integration made with the stone bunds. Data related to the characteristics of stone bunds were used to understand how stone bunds differ, and whether there is a difference between stone bunds implemented by SFs and NSFs. 
Furthermore, data were collected on the perceived effect of stone bunds on soil erosion, soil moisture and yield to compare both types of stone bunds. Definitions of the variables considered for this study are presented in Table 2.1. With regard to data analysis, descriptive statistics, including cross-tabulation of the percentage distribution, as well as the mean and standard deviations were used for analysis in Statistical Packages for Social Science (SPSS). Significance levels were tested at the $1 \%$ and $5 \%$ levels using a paired-sample t-test.

Table 2.1: Descriptions of variables used in this study

\begin{tabular}{|c|c|c|}
\hline Variables & Description & Values \\
\hline \multicolumn{3}{|c|}{ Perceived farmland characteristics } \\
\hline Farm plot size & Size of farm plots where the stone bunds are implemented & Hectare \\
\hline Soil erosion & Level of erosion before stone bunds implementation & 1=Severe, $2=$ Moderate, $3=$ Low \\
\hline Soil fertility & Fertility status where stone bunds are implemented & 1= Poor, $2=$ Medium, 3= Fertile \\
\hline Slope gradient & Slope gradient where stone bunds are implemented & 1= Steep, 2= Gentle, 3= Flat \\
\hline Distance & $\begin{array}{l}\text { Estimated walking distance of the plot to homestead of } \\
\text { the farmers }\end{array}$ & Minutes \\
\hline \multicolumn{3}{|c|}{ Stone bund characteristics } \\
\hline Maintenance & Whether the implemented stone bunds were maintained & $1=$ No, $2=$ Yes \\
\hline Modification & $\begin{array}{l}\text { Whether the implemented stone bunds were modified to } \\
\text { make them fit to the local conditions }\end{array}$ & $1=$ No, $2=$ Yes \\
\hline Fertilizer & $\begin{array}{l}\text { Whether chemical fertilizer was applied together with the } \\
\text { stone bunds }\end{array}$ & $1=$ No, $2=$ Yes \\
\hline Compost & $\begin{array}{l}\text { Whether compost was applied together with the stone } \\
\text { bunds }\end{array}$ & $1=$ No, $2=$ Yes \\
\hline Manure & $\begin{array}{l}\text { Whether manure was applied together with the stone } \\
\text { bunds }\end{array}$ & $1=$ No, $2=$ Yes \\
\hline \multicolumn{3}{|c|}{ Perceived Effects } \\
\hline Erosion & Effects on erosion after stone bunds were implemented & $\begin{array}{l}1=\text { Increased }, 2=\text { No-change }, \\
3=\text { Reduced }\end{array}$ \\
\hline Soil moisture & $\begin{array}{l}\text { Effects on soil moisture after the stone bunds were } \\
\text { implemented }\end{array}$ & $\begin{array}{l}1=\text { Reduced }, 2=\text { No-Change, } \\
3=\text { Increased }\end{array}$ \\
\hline $\begin{array}{l}\text { Soil } \\
\text { productivity }\end{array}$ & $\begin{array}{l}\text { Effects on soil productivity after the stone bunds were } \\
\text { implemented }\end{array}$ & $\begin{array}{l}1=\text { Reduced }, 2=\text { No-Change, } \\
3=\text { Increased }\end{array}$ \\
\hline Crop yield & Effects on yield after the stone bunds were implemented & $\begin{array}{l}1=\text { Reduced }, 2=\text { No-Change, } \\
3=\text { Increased }\end{array}$ \\
\hline $\begin{array}{l}\text { Yield } \\
\text { improvement }\end{array}$ & $\begin{array}{l}\text { Believed that yield improvement was only due to stone } \\
\text { bunds }\end{array}$ & $1=$ No, $2=$ Yes \\
\hline
\end{tabular}

\subsection{Results}

This section presents the findings of the study. In the first sub-section, farmers' perceived characteristics of the farmlands are presented. In the second sub-section, we compare the differences between stone bunds implemented by SF and those by NSF. In the third subsection, farmers' perceived effects of implemented stone bunds are presented. 


\subsubsection{Perceived farmland characteristics}

Figure 2.3 presents some clear perceived differences between SFs and NSFs. Firstly, the findings revealed that $90 \%$ of SFs implement stone bunds on farmlands at perceived moderate to severe erosion levels, compared to $67 \%$ of NSFs. In addition, $40 \%$ of SFs and only $10 \%$ of NSFs implements stone bunds on farmland with perceived poor soil fertility. Hence, a large majority (90\%) of NSFs and $60 \%$ of SFs implement stone bunds on their most fertile farmlands. Furthermore, more SFs (23\%) implement stone bunds on steeper farmlands, as compared to NSFs (15\%). A large majority of farmers (77\% of SFs and $85 \%$ of NSFs) implement stone bunds on slope gradients that are perceived as flat to moderate. Moreover, the mean farm plots sizes, where the stone bunds are implemented, are 0.58 hectare for SFs and 0.65 hectare for NSFs. Concerning locations of farmlands where stone bunds are implemented, the mean walking distances from home are about 13 minutes for SFs and about 32 minutes for NSFs.

\subsubsection{Stone bunds characteristics}

Figure 2.4 compares SFs and NSFs concerning the characteristics of their stone bunds. The results showed that about $91 \%$ of SFs maintain their stone bunds, compared to only $18 \%$ of the NSFs. Moreover, a great majority of SFs (83\%) confirmed that they modified their stone bunds during implementation to make them better fit to the local conditions, whereas only a small proportion of NSFs (13\%) made such modifications. Furthermore, a majority of SFs used higher numbers and more diverse soil fertility management measures integrated with their stone bunds, with $92 \%$ using compost (vs 32\% of NSFs), $83 \%$ using chemical fertilizer (vs $55 \%$ of NSFs) and $67 \%$ using manure (vs $13 \%$ of NSFs).

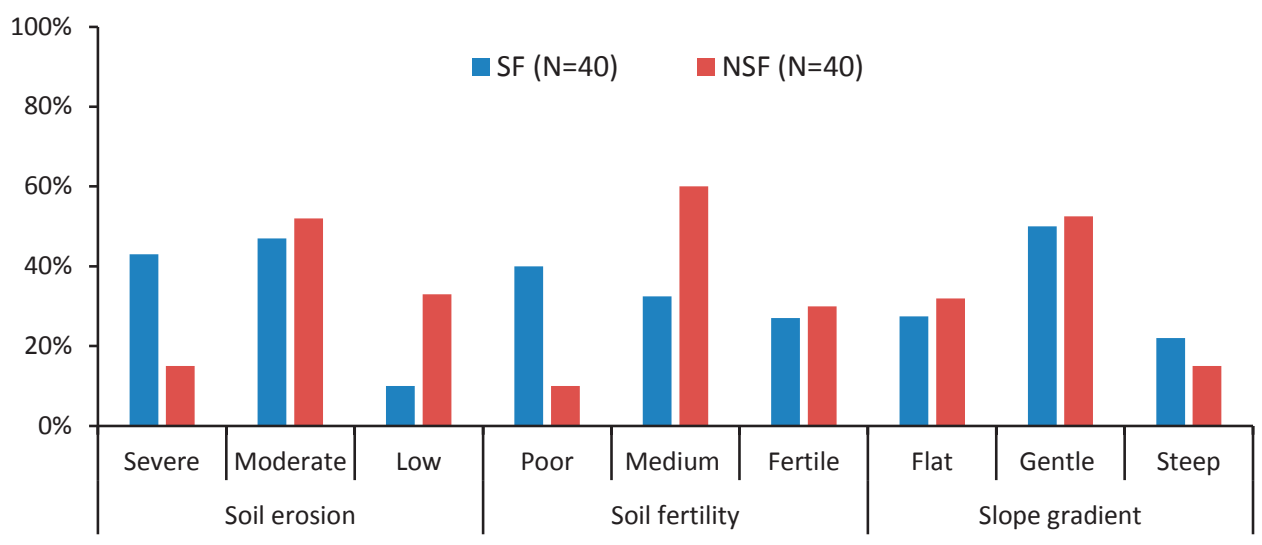

Figure 2.3 Perceived farmland characteristics in the Girar Jarso woreda, Central Ethiopian Highlands. Key: SF - spontaneous adopting farmers, NSF — non-spontaneous adopting farmers 


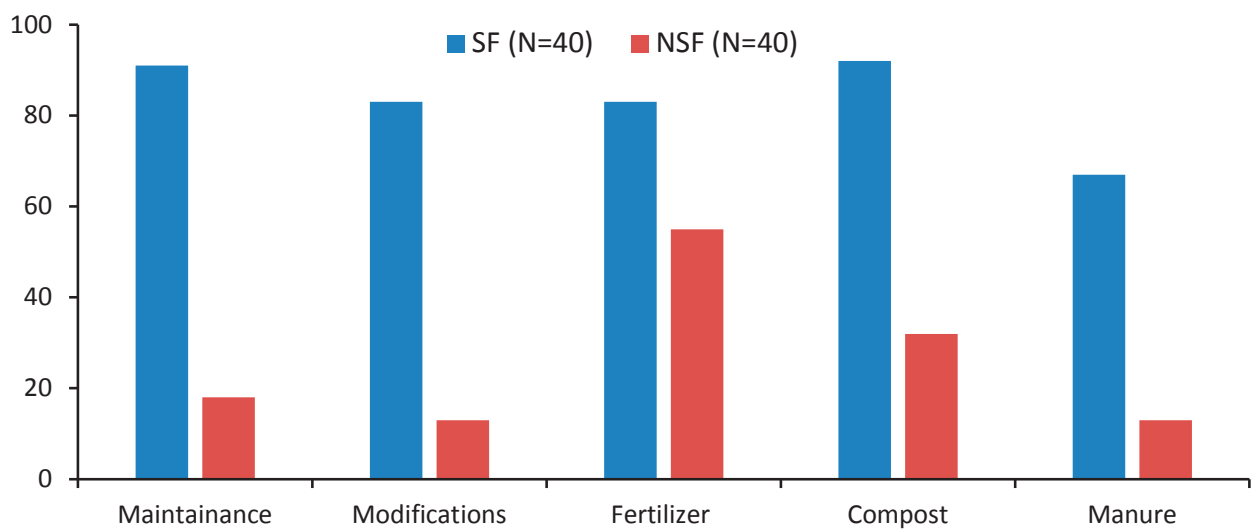

Figure 2.4 Perceived stone bunds characteristics in Girar Jarso woreda, Central Ethiopian Highlands. Key: SF - spontaneous adopting farmers, NSF — non-spontaneous adopting farmers

\subsubsection{Perceived effects of stone bunds}

With regard to the effect of stone bunds, Figure 2.5 shows how farmers perceive changes in erosion problems, productivity of the farmland and yield. About $88 \%$ of SFs perceive that soil erosion has decreased after constructing the stone bunds, while only $27 \%$ of NSFs perceive the same phenomenon. Moreover, $90 \%$ of SFs and $38 \%$ of NSFs observe that the soil productivity of their farmland has increased with stone bunds, while $93 \%$ of SFs and $61 \%$ of NSFs perceive increase in soil moisture of the farmlands. Furthermore, much more SFs than NSFs (70\% vs 23\%) perceive that the crop yield has increased after stone bunds implementation, although $79 \%$ of SFs and $44 \%$ of NSFs believe that this is not merely due to stone bunds, but also due to the integration with soil fertility management measures.

Overall, stone bunds are mainly spontaneously implemented on farmlands with a poor to medium soil fertility status, where erosion is perceived as moderate to severe, and these farmlands are located nearby the homestead of the farmer. This indicates that stone bunds are spontaneously implemented where they are most needed, and that stone bunds implemented by the mass mobilization campaign are often constructed on other farmlands. Besides, spontaneously implemented stone bunds are better maintained, more often modified to fit into the farming system, and more often integrated with diverse soil fertility management measures. As a result, compared to stone bunds implemented by the mass mobilization campaign, more beneficial effects are perceived from the spontaneously implemented stone bunds; not only in decreasing erosion problems on the farmlands, but also in enhancing soil productivity and crop yields. 


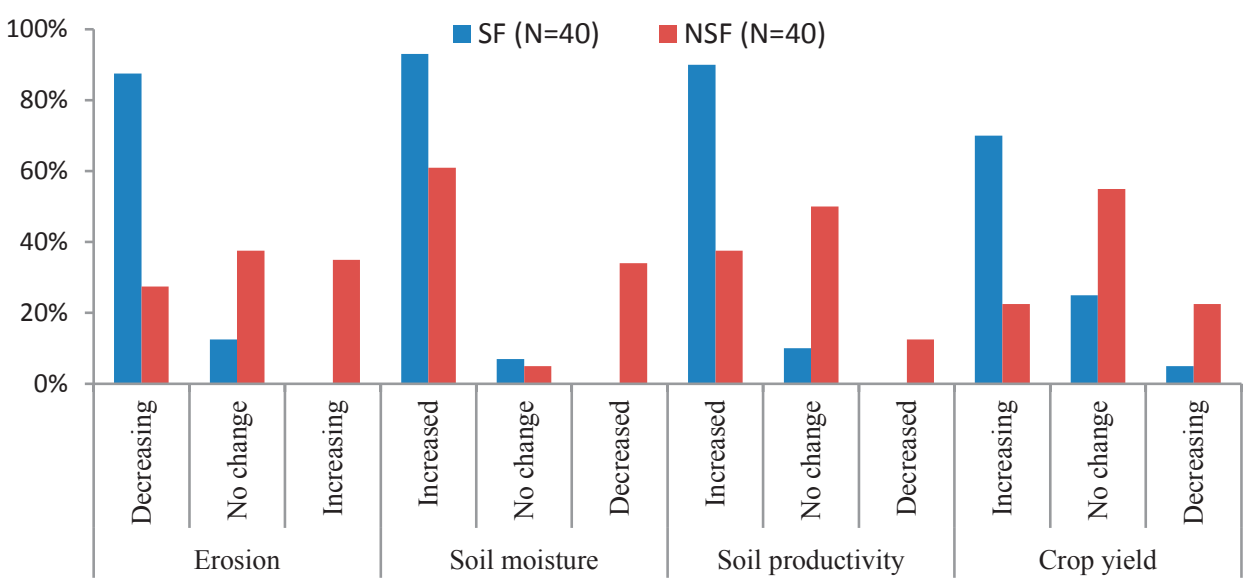

Figure 2.5 Perceived effects of stone bunds on the farmland in the Girar Jarso woreda, Central Ethiopian Highlands. Key: SF - spontaneous adopting farmers, NSF — non-spontaneous adopting farmers

\subsection{Discussion}

The aim of this study was to understand spontaneous spreading of stone bunds. Summarizing the results of this study, Table 2.2 shows that there are numerous significant differences between stone bunds implemented by SFs and NSFs. When looking at the farmland characteristics, the statistical analysis reveals that significant mean differences ( $p$ $<0.01$ ) exist concerning perceived soil fertility of the farmland, erosion levels and the locations of farmlands where stone bunds have been implemented. These three characteristics together are decisive in explaining where stone bunds are implemented by SFs. An explanation for this result is that farmers who use farmlands in areas that are more vulnerable to soil erosion, perceive erosion problems and loss of soil more easily (Abdela \& Derso, 2015; Teshome et al., 2016a). Particularly when visible signs (rills and gullies) appear on the farmlands, farmers perceive soil erosion as severe (Amsalu \& de Graaff, 2006) and hence decide to use erosion control measures (Shiferaw \& Holden, 1998; Aad Kessler, 2006). Moreover, farmlands closer to the homesteads can be better monitored and taken care of, enabling more frequent supervision of the implemented conservation measures (Bekele \& Drake, 2003). Consistently, Pender \& Gebremedhin (2008), Abebe \& Sewnet (2014) and Cholo et al. (2018) reported that farmers give more attention to farm plots closer to homestead areas than distant farm plots. This also enables farmers (farm owners) and/or other neighboring farmers to observe the effects of implemented stone bunds, suggesting that visible effects are crucial in terms of triggering spontaneous adoption and implementation of technologies. 
Table 2.2: Summary of main differences between stone bunds implemented by SFs and NSFs in the Girar Jarso woreda, Central Ethiopian Highlands. Values for characteristics and effects are shown in Table 2.1.

\begin{tabular}{llccccc}
\hline \multirow{2}{*}{ Variables } & & \multicolumn{2}{c}{ SF (N=40) } & \multicolumn{2}{c}{ NSF (N=40) } & \\
\cline { 2 - 5 } & & Mean & Std. Dev & Mean & Std. Dev & t-test \\
\hline \multirow{3}{*}{ Perceived farmland } & Farm plot size & 0.58 & 0.24 & 0.65 & 0.26 & 0.224 \\
characteristics & Soil erosion & 1.68 & 0.66 & 2.18 & 0.66 & $0.001^{* *}$ \\
& Soil fertility & 1.88 & 0.82 & 2.20 & 0.61 & $0.048^{*}$ \\
& Slope gradient & 2.05 & 0.71 & 2.18 & 0.68 & 0.424 \\
& Distance & 13.13 & 8.25 & 31.45 & 7.28 & $0.000^{* *}$ \\
Perceived stone bund & Maintenance & 1.95 & 0.22 & 1.18 & 0.39 & $0.000^{* *}$ \\
characteristics & Modification & 1.83 & 0.39 & 1.13 & 0.34 & $0.000^{* *}$ \\
& Fertilizer & 1.83 & 0.38 & 1.55 & 0.51 & $0.013^{*}$ \\
& Compost & 1.92 & 0.28 & 1.32 & 0.48 & $0.000^{* *}$ \\
& Manure & 1.67 & 0.48 & 1.13 & 0.34 & $0.000^{* *}$ \\
Perceived effects & Erosion & 2.88 & 0.34 & 1.93 & 0.80 & $0.000^{* *}$ \\
& Soil moisture & 2.93 & 0.27 & 2.21 & 0.96 & $0.000^{* *}$ \\
& Soil productivity & 2.80 & 0.61 & 1.88 & 0.94 & $0.000^{* *}$ \\
& Crop yield & 2.65 & 0.58 & 2.00 & 0.68 & $0.000^{* *}$ \\
& Yield improvement & 1.21 & 0.42 & 1.56 & 0.53 & 0.053 \\
\hline
\end{tabular}

Concerning the characteristics of the stone bunds, Table 2.2 shows that stone bunds implemented by SFs were significantly better maintained than those implemented by NSFs. Observations during fieldwork confirmed this: stone bunds implemented by NSFs were poorly maintained and some were even destroyed and broken during ploughing. These poorly maintained and damaged stone bunds can even be the cause of additional erosion problems (Amsalu \& de Graaff, 2006). However, the work of mass mobilization campaigns focuses more on constructing new structures rather than paying attention to maintaining the old or previously constructed structures (Wolka, 2014). Modifying stone bunds to make them fit to local conditions is another important variable included to understand the process of spontaneous spreading. Our analysis showed that spontaneously implemented stone bunds were significantly more often modified during construction to fit to the local conditions of the farming system than those implemented by the mass mobilization campaigns. Several characteristics of these stone bunds were modified, including the recommended spacing between bunds as well as the height and length of the stone bunds to fit the needs of the farming system. This was also observed in a study conducted in Hunde-Lafto area (Bekele \& Drake, 2003) and the Beressa watershed (Amsalu \& de Graaff, 2006), where farmers modified the original design of introduced technologies to fit the local conditions. Our findings support the diffusion of innovation literature (Rogers, 1983, 1995, 2002), which argues that technologies modified or changed by farmers during implementation spread better than other technologies hence facilitating the spontaneous spreading of stone bunds. 
Another important finding concerns the integration of stone bunds with other measures on the same field, as perceived by farmers. Integration means that soil management measures that are intended to conserve the soil, as well as to improve crop yields (such as fertilizer, compost and manure), are applied on the farmlands together with stone bunds. It was hypothesized that stone bunds implemented by SFs were better integrated with these soil fertility management measures and lead to higher yields, as compared to stone bunds implemented by NSFs. The analysis confirmed the stated hypothesis. With spontaneously implemented stone bunds, significantly more fertilizer, compost and manure are used in integration with the stone bunds. An explanation for this is the proximity of the stone bund plots implemented by SFs to their homesteads, because farmers are more likely to apply fertilizer, compost and manure on farmlands close to the homesteads (Pender \& Gebremedhin, 2008). Another explanation is that SFs are more dedicated and aware about the importance of integrating stone bunds with these soil fertility practices.

Moreover, the better integration of the stone bunds with fertilizer, compost and manure has its beneficial effects on erosion control, soil moisture, soil productivity and crop yield. The statistical analysis shows that significant differences between the perceived effect of stone bunds implemented by SFs and NSFs exist for all these factors $(p<0.01)$. Results showed that a large proportion of SFs perceive that erosion on the farmland has decreased, and that both soil productivity and crop yield have increased after stone bund implementation, and hence confirmed the hypothesis that stone bunds implemented by SFs lead to higher yields. These results may be explained by the fact that spontaneously implemented stone bunds are better maintained and integrated with more compost and manure. In line with this, Aad Kessler (2006) suggests that manure use together with erosion control measures, such as stone bunds, is a promising alternative for more productive farmlands and agricultural production.

A study conducted by Hurni (1993) describes that erosion adversely affects crop productivity by reducing availability of water to crop growth and soil nutrients. As a result, when soil erosion control measures, such as stone bunds, are combined with the use of compost and manure, they enhance soil moisture and improve availability of soil nutrients (Nyssen et al., 2007; Pender \& Gebremedhin, 2008). This is consistent with observations in this study, where a high number of SFs perceived that water availability on the farmland has increased after stone bunds were implemented. In addition, this will also result in higher crop yields, which, in this study, was significantly higher for SFs than for NSFs. This implies that the importance of 'relative advantage' (Rogers, 2002) holds true in our research suggesting that farmers' perceived relative advantage of stone bunds determines the process of spontaneous spreading. 
Most interestingly, the study found that many farmers (particularly SFs, but not significantly more than NSFs) believe that yield improvement was not due to the stone bunds only, but rather to the integration of these with soil fertility management measures. The analysis indicates that NSFs are also aware of the importance of integrating practices, but they perceive that they use less fertilizer, compost and manure. Because of this, NSFs do not experience higher crop yields. This finding is in line with a study conducted by Posthumus et al. (2001) in Burkina Faso, reporting that conservation measures are more profitable when integrated with soil fertility measures. Therefore, technologies that enhance profitability are crucial in stimulating farmer's adoption decision (Amsalu \& de Graaff, 2007), and hence are important to understand spontaneous spreading. In general, because the effect on yield is related to application of more fertilizer, compost and manure and they are constructed on erosion prone farmlands where the effect of stone bunds is more visible, spontaneously implemented stone bunds result in more short-term benefits than stone bunds implemented by the mass mobilization campaign. Therefore, in order to convince NSFs to also becoming SFs, the mass mobilization campaign must focus on constructing stone bunds where these are most needed, resulting in quick wins.

However, the study also found that the mass mobilization campaign is an important source of knowledge for farmers, and often motivates farmers to spontaneously implement stone bunds on their own farmlands (Danano, 2010). About $60 \%$ of the farmers acknowledge to have learned from the mass mobilization campaign and other projects (53\%). Nevertheless, most knowledge about stone bunds comes from neighboring farmers (93\%) and practical training (80\%). This implies that spontaneous spreading of stone bunds is particularly enhanced by farmer-to-farmer exchanges in the community, by education and by training. This was also observed in a study conducted in Keita valley (Karidjo et al., 2018), where farmers are inspired to adopt soil and water conservation practices by observing their neighboring practices and sharing their knowledge about the benefits of adoption. Our result is in line with the theory of diffusion of innovation discussed above, where Rogers (1995) argues that sources of information are important in learning and implementing an introduced technology. Therefore, this is an important requirement for the process of spontaneous spreading to take place.

\subsection{Conclusions and Recommendation}

The central aim of this study was to provide insights into how stone bunds have spontaneously spread in the Central Highlands of Ethiopia, thereby contributing to the understanding of the process of spontaneous spreading. A first conclusion drawn from this study is that stone bunds are spontaneously implemented where they are most needed: mainly on farmlands where farmers perceive severe erosion, poor soil fertility, steep slope 
gradient and located nearby the homestead area. This finding has important implications for the current mass mobilization campaigns, where farmers walk long distances to construct stone bunds on the selected farmlands. Essentially, long walking distances may discourage farmers to integrate stone bunds with soil fertility management measures, which is important to contribute to yield productivity and achieve household food security. Therefore, during the mass mobilization campaigns, stone bunds should be constructed based on farmers' opinion of where they are most needed and where the short-term (visible) effects can be achieved.

The result of this study further indicated that spontaneously implemented stone bunds affect soil erosion, soil moisture and soil productivity, and that they lead to higher yields compared to stone bunds implemented through mass mobilization. These findings provide important insights to policy makers and extension workers on how to control erosion problems and improve soil fertility, simultaneously. Putting more stone bunds on farmland is hardly useful unless they are integrated with soil fertility management measures, such as compost, manure and improved tillage practices to contribute to improve yields. As a final conclusion, we recommend that the mass mobilization campaign should use a more participatory and integrated approach, in which there is ample space for awareness raising and learning concerning the benefits of integrated farm management, and in which farmers themselves have a more leading role in the decision on where to construct stone bunds. Such a strategy will lead to more sustainable impact on soil fertility and food security than the current top-down intervention approach.

In general, this article addressed the process of spontaneous spreading of SLM in the Central Highlands of Ethiopia. The study found that spontaneously implemented stone bunds had different characteristics than the conventional way of spreading technologies, through mass mobilization campaigns. However, there is still an important issue to be addressed with respect to spontaneous spreading, namely to what extent SFs and NSFs are different. The next research challenge is to compare the characteristics and motivations of farmers who spontaneously implement stone bunds with those of farmers who do not perform spontaneous conduct on stone bunds. 
Understanding the spontaneous spreading of stone bunds in Ethiopia: Implications for sustainable land management 


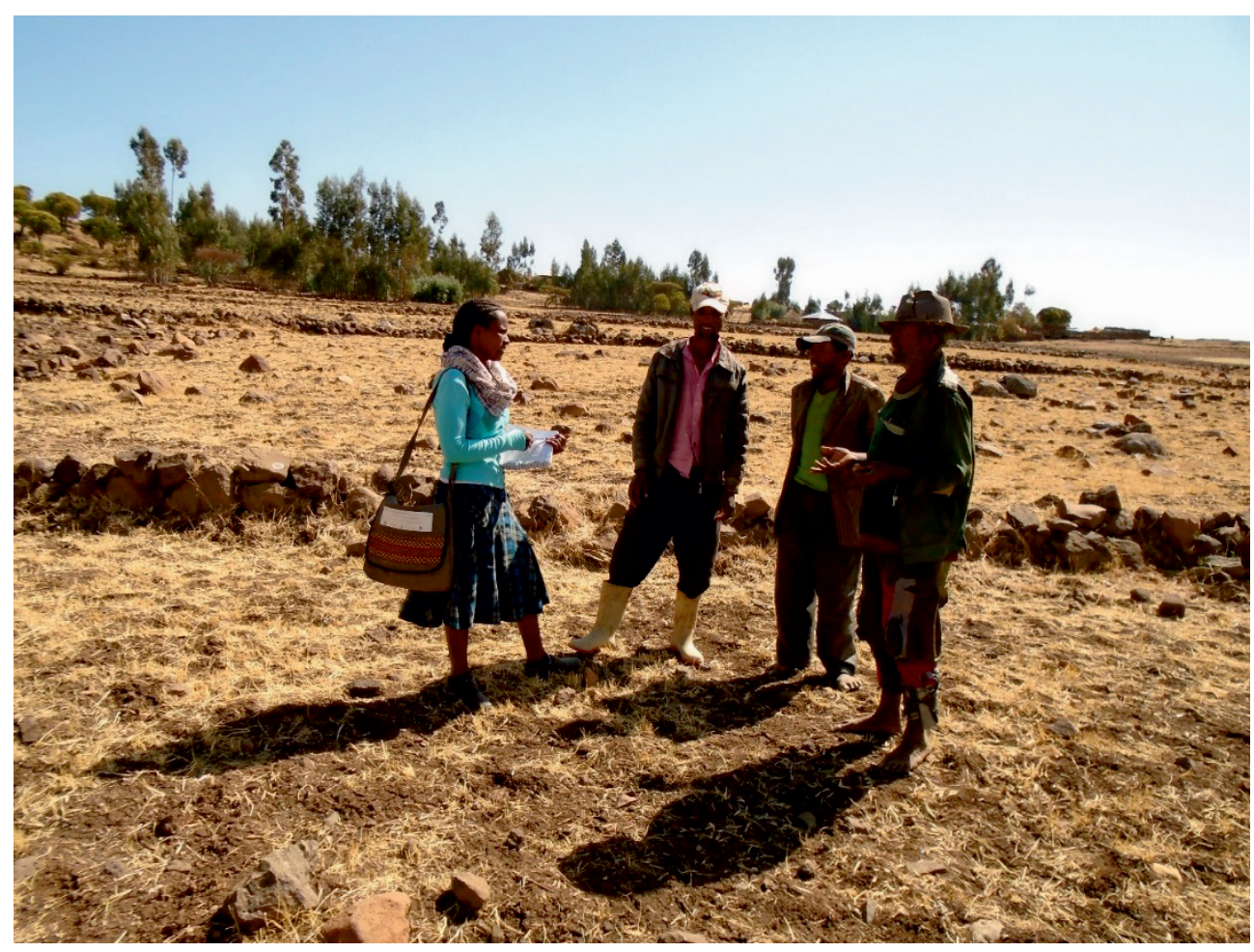




\section{How farmers' characteristics influence spontaneous spreading of stone bunds in the Highlands of Ethiopia: a case study in the Girar Jarso woreda}

This study aims to identify key differences between farmers who spontaneously implement stone bunds (i.e. farmers implementing stone bunds by their own initiative) and farmers who do not. Data were collected in the Girar Jarso woreda in the Central Highlands of Ethiopia, through a household survey with 80 farmers: 40 with spontaneously implemented stone bunds and 40 without. Independent samples t-test, principal component analysis and regression analysis were used to analyze the data. Results show that five key-factors explain differences between the two groups of farmers: 1) readiness to change, 2) available resources, 3) social capital, 4) type of family, and 5) commitment. These factors together explain 73\% of the variance in the dataset, and show that particularly characteristics related to the farmer's intrinsic motivation play a crucial role to spontaneously implement and integrate stone bunds into the farming system. Furthermore, results show that young farmers are most committed to soil conservation: they are often intrinsically motivated dynamic farmers who are ready to change their future and improve productivity and food security. The study suggests that government extension programs should therefore focus more on these young and dynamic farmers, and foster their readiness to change. This implies that extension workers and government officials should better understand the crucial role of farmers' intrinsic motivation when dealing with sustainable land management, and also reformulate extension strategies and messages. This is particularly important when developing scaling-up strategy that helps to sustainably increase agricultural production and achieve food security of small-holder farmers in Ethiopia.

Based on:

Abi, M., Kessler, A., Oosterveer, P. \& Tolossa, D. 2018. How farmers' characteristics influence spontaneous spreading of stone bunds in the highlands of Ethiopia: a case study in the Girar Jarso woreda. Environment, Development and Sustainability, https://doi.org/10.1007/s10668-018-0203-2. 


\subsection{Introduction}

Increasing agricultural productivity and food security, while sustaining the production potential of available natural resources, is a real challenge in Ethiopia. Subsistence agricultural production is the main economic activity for the majority of the population living in the country (Amsalu \& de Graaff, 2006). However, land degradation in the form of soil erosion and soil nutrient decline is severely threatening agricultural production in the densely populated Ethiopian Highlands (Sonneveld \& Keyzer, 2003; Amsalu et al., 2007; Adimassu \& Kessler, 2015). Soil erosion triggers loss of fertile top soil during heavy rainfall, especially on bare and unprotected farmlands, and results in a long-term decline and seasonal shortages in household food production (Gebremichael et al., 2005; Haileslassie et al., 2005). However, there is evidence that improved production and productivity in the Ethiopian Highlands is possible when sustainable land management (SLM) measures are applied to address soil erosion and soil loss (Kassie et al., 2010; Yimer, 2015).

Over the last three decades, the Ethiopian government has been promoting and implementing SLM measures in collaboration with a consortia of donors to address soil erosion and to achieve food security (Kassie et al., 2010). These SLM measures, especially the larger (infra-) structural ones, have been promoted and implemented mainly through project and government extension programs, based on community mass mobilization campaigns (Bewket, 2007; Wolka, 2014; Teshome et al., 2016a). Nevertheless, despite these considerable efforts made by the Ethiopian government to promote SLM, only a limited number of continued-users has been reported (Amsalu \& de Graaff, 2007; Shiferaw et al., 2009; Kassie et al., 2010). Also, spontaneous implementation of structural SLM measures (e.g. through farmer-to-farmer learning) was only sparsely found in Ethiopia (Shiferaw et al., 2009).

However, in a study conducted in the Central Highlands of Ethiopia, Abi et al. (2018b) found that some SLM measures, particularly stone bunds, were spontaneously implemented on some farmlands. Farmers doing this used their own family labor and knowledge, which was often obtained during their participation in the governmental mass mobilization campaigns. An interesting finding of this study was that such stone bunds were often constructed where they were most needed, for instance on erosion prone farmlands and close to the farmer's homestead where more frequent monitoring and supervision are possible. Furthermore, these spontaneously implemented stone bunds were often well integrated with other measures to achieve visible results within a short-term period of time. This enhanced integration of the stone bunds evidences that these farmers are experimenting with SLM measures to make them more effective in controlling erosion and improving productivity (Amede et al., 2006). Moreover, following Napier (1991), the fact that such farmers are 
interested and willing to spontaneously implement stone bunds and integrate them into their farming system, will also motivate them to continue using these practices.

This study investigates farmers' characteristics, particularly those factors that drive individual farmers to spontaneously implement stone bunds integrated with other measures in the Girar Jarso woreda. In this woreda, we previously conducted research on the characteristics of spontaneous stone bunds (Abi et al., 2018b), and analyzed the location of farmlands, stone bunds usages and their effects to contribute to understand where and why the stone bunds spread spontaneously. The present study aims to identify the characteristics of spontaneous farmers, by whom stone bunds spread spontaneously, compared to non-spontaneous farmers to fill the gap. Spontaneous farmers are farmers who adopt and implement stone bunds by their own initiative using their own family labor and knowledge, and knowledge obtained from somewhere else. Non-spontaneous farmers are farmers who have stone bunds on their farmland but these stone bunds were implemented through the mass mobilization campaign. The main research question is: what are the key-factors in household characteristics that explain why some farmers spontaneously implement stone bunds and other farmers do not? Furthermore, we hypothesize that spontaneous implementation of stone bunds is significantly related with at least one of these key-factors in household/farmer characteristics.

\subsection{Theoretical background}

In this study, we used theoretical insights about decision making processes to help direct the key-factors that drive individual farmers to spontaneously adopt and implement SLM practices. In our case, decision making is the mental process that leads to a choice of adoption or rejection of stone bunds (Rogers, 2002). In his theory of innovation diffusion, Rogers (1995) suggests five stages through which an individual passes during the innovation decision making process: (1) knowledge; (2) persuasion; (3) decision; (4) implementation; and (5) confirmation. An innovation is conceptualized as a new idea or practice (Meijer et al., 2015), and a new way of resolving problems (Napier, 1991); e.g. the use of stone bunds to reduce soil loss.

The decision to adopt and implement technologies such as stone bunds begins with the farmers' perception of erosion as a problem (Ervin \& Ervin, 1982; Mbaga-Semgalawe \& Folmer, 2000; de Graaff et al., 2008). These perceptions are shaped by personal, economic, physical and institutional characteristics of farmers (Ervin \& Ervin, 1982; Meijer et al., 2015). Similarly, Rogers (1983) suggested three characteristics of decision makers (farmers, in this case) that affect the innovation decision making process: 1) the socio-economic characteristics, 2 ) the personality characteristics and (3) the communication behavior. A 
wide range of factors therefore influence decisions, such as education, social status, wealth, motivation, behavior, social bonds, contact with change agents, exposure to information sources, etc. (Rogers, 1983).

Another theory relating to the decision making process is the theory of planned behavior (Ajzen, 1991). This theory explains that an individual behavior towards a technology is driven by the individual attitude, subjective norm and perceived behavioral control. According to Ajzen (1991), farmers tend to adopt a technology towards which they have a positive attitude, which on its turn is related to the farmers' perceived characteristics of a technology such as its relative advantage, compatibility and observability (Rogers, 1995). Besides, the value that farmers give to farming also affects their attitude towards a new technology. For instance, a farmer who positively values farming as a way of life may be more willing to conserve the soil by using new technologies (Willock et al., 1999). Furthermore, perceived usefulness of a technology, social capital and perceived ease of implementation influence farmers' intention to adopt and implement a technology (Werner et al., 2017; Zeweld et al., 2017).

A final theory used in this paper is the theory of self-determination (Deci \& Ryan, 1985; Ryan \& Deci, 2017). In this theory, two types of motivations are considered: intrinsic motivation and extrinsic motivation (Ryan \& Deci, 2000a;b)). The intrinsic motivation refers to doing an activity for the inherent satisfaction of the activity itself (internal self or self-determined), whereas extrinsic motivation refers to doing an activity driven by external coercions such as rewards, incentives or even punishments. The theory of self-determination further suggests that extrinsically motivated actions can become self-determined once individuals identify with the value of an activity and acknowledge the importance of a behavior; this is particularly important to willingly adopt the behavior (Ryan \& Deci, 2000b; Gagné \& Deci, 2005). Hence, this theory has also important implications for this study that focuses on spontaneous adoption of SLM technologies which were initially promoted through a project or government support.

\subsection{Methodology}

\subsubsection{Study area}

This study was undertaken in the Girar Jarso woreda in the Central Ethiopian Highlands. The woreda is found in the North Shewa zone of Oromia region at a distance of $112 \mathrm{~km}$ from Addis Ababa, the capital city of Ethiopia. The total area of the woreda is about $495 \mathrm{~km}^{2}$. Elevation ranges between 1300 and 3400 m.a.s.I. The woreda encompasses 17 rural kebele and has a total population of 80,000 people (CSA, 2013). Annual rainfall ranges between 
$800 \mathrm{~mm}$ and $1200 \mathrm{~mm}$ according to Fiche Station meteorological data. The main soil types found in the woreda are Vertisols (dominant soil types), Nitosols and Cambisols. Rain-fed mixed farming (crop production combined with livestock raising) is the main means of living for more than $90 \%$ of the population in the woreda. Farming in the woreda is characterized by low productivity due to severe erosion and poor soil fertility. Moreover, off-farm activities including petty trade and wage labor are important practices to supplement farmers' income in the woreda.

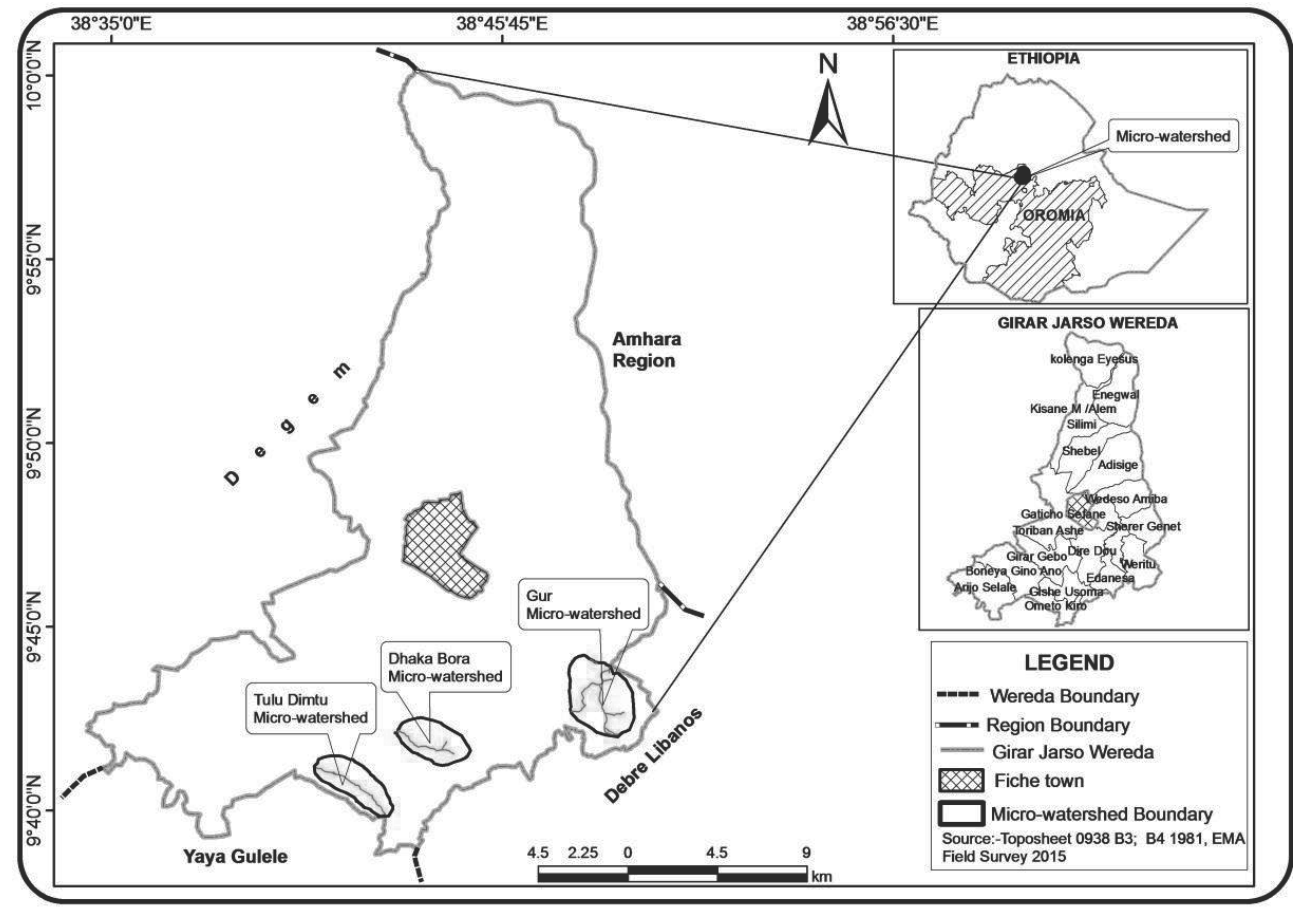

Figure 3.1 Map of Ethiopia, the Girar Jarso woreda and studied watersheds

\subsubsection{Method of data collection and sampling design}

Data for this research were obtained from a survey conducted in three watersheds in Girar Jarso woreda: Gur watershed, Dhaka-Bora watershed and Tulu-Dimtu watershed (Figure 3.1). The respective watersheds are 990 hectares, 570 hectares and 600 hectares in size. These watersheds were purposely selected, based on availability of stone bunds on the farmlands. Similarly, purposive sampling was used to select the study farmers. A household survey was conducted on 80 farmers to investigate the process of spontaneous spreading of stone bunds in these watersheds (see Abi et al., 2018b). Of these 80 farmers, 40 are Spontaneous Farmers (SF) and 40 are Non-Spontaneous Farmers (NSF). The distinction between SF and NSF was based on the way in which the stone bunds were implemented on 
the farmlands over a 5 year period (2010-2014). SF are farmers that have implemented stone bunds on their own initiative (i.e. intrinsic motivation), whereas NSF are farmers have only stone bunds that are implemented through mass mobilization campaigns (i.e. extrinsic motivation). The survey was carried out in November and December 2015 by using a structured questionnaire.

\subsubsection{Description of variables}

In the questionnaire, 32 possible factors that explain differences in farmers characteristics were included. These were obtained based on open interviews with farmers (see Appendix 2 ), and cover factors such as "source of motivation to implement stone bunds", "opinion concerning the implemented stone bunds", "ownership of stone bunds", "responsibility to maintain implemented stone bunds", "opinion about soil productivity and crop yields", and "perception on Integrated Farm Management (IFM)".

Table 3.1 presents a description of variables included in the study, which are related to the socio-cultural, economic and institutional characteristics of farmers. Among the variables included in the analysis, some of the more qualitative variables ("experience in IFM", "social relations", "motivation for stone bunds", "perception of stone bunds", "ownership of stone bunds", "drive to improve" and "empowerment") were measured using a 10 items for Likert-type scale. Farmers level of agreement or disagreement concerning the stated items were rated on a five point scale basis (ranging from $1=$ strongly disagree to $5=$ strongly agree). Later, these factors were computed by averaging responses across the items. Also, for ease of statistical analysis, we grouped the five point scale rating into a 3 point scale ( $1=$ Disagree, $2=$ Neutral/undecided and $3=$ Agree). The remaining - often more quantitative variables were measured based on the values as indicated in Table 3.1.

Table 3.1 Description of farmer/household characteristics

\begin{tabular}{|c|c|c|c|}
\hline No & Factors & Description & Values \\
\hline \multicolumn{4}{|c|}{ Socio-cultural characteristics } \\
\hline 1 & Age & Age of the household head & (\# of years) \\
\hline 2 & Education & Education level of the household head & $\begin{array}{l}(1=\text { Illiterate, } 2=\text { Basic } \\
\text { read \& write, } 3=\text { Literate })\end{array}$ \\
\hline 3 & Family size & Average number of family members in the household & (\# of persons) \\
\hline 4 & Family labor & Available family labor for farming activities & (\# of persons) \\
\hline 5 & Social position & $\begin{array}{l}\text { Current social responsibility of the farmer in the } \\
\text { community (e.g. development group leader, etc.) }\end{array}$ & $\begin{array}{l}\text { (1= No social position, } \\
2=\text { Have social position })\end{array}$ \\
\hline 6 & Wealth status & Wealth status in the community & $\begin{array}{l}(1=\text { Poor, } 2=\text { Inter- } \\
\text { mediate, } 3=\text { Better-off })\end{array}$ \\
\hline 7 & Knowledge about IFM & $\begin{array}{l}\text { Farmers are well informed about Integrated Farm } \\
\text { Management and soil management practices }\end{array}$ & $(1=$ No, $2=$ Yes $)$ \\
\hline
\end{tabular}


How farmers' characteristics influence spontaneous spreading of stone bunds in the Highlands of Ethiopia:

Table 3.1 Description of farmer/household characteristics

\begin{tabular}{|c|c|c|c|}
\hline No & Factors & Description & Values \\
\hline 8 & Experience in IFM & $\begin{array}{l}\text { Farmers are practicing Integrated Farm Management } \\
\text { on the farmland }\end{array}$ & $\begin{array}{l}\text { (1= Disagree, } 2=\text { Neutral, } \\
3=\text { Agree })\end{array}$ \\
\hline 9 & Planning & $\begin{array}{l}\text { Farmers have an annual farm planning (including } \\
\text { implementing / maintaining stone bunds) }\end{array}$ & $(1=$ No, $2=$ Yes $)$ \\
\hline 10 & $\begin{array}{l}\text { Field visit to check } \\
\text { erosion }\end{array}$ & $\begin{array}{l}\text { Number of farmland visits to recognize erosion } \\
\text { problem and loss of soil }\end{array}$ & $\begin{array}{l}(1=\text { Rarely, } 2= \\
\text { Sometimes, } 3=\text { Often })\end{array}$ \\
\hline 11 & Future prospects & $\begin{array}{l}\text { Future prospects on improving agricultural } \\
\text { productivity, food security and living condition }\end{array}$ & $\begin{array}{l}\text { (1= Negative, } 2=\text { Do not } \\
\text { know, } 3=\text { Positive) }\end{array}$ \\
\hline 12 & Social relations & $\begin{array}{l}\text { Farmers have good relations of trust with farmers, } \\
\text { extension workers and government officials }\end{array}$ & $\begin{array}{l}\text { (1= Disagree, } 2=\text { Neutral }, \\
3=\text { Agree })\end{array}$ \\
\hline 13 & $\begin{array}{l}\text { Perception of stone } \\
\text { bunds }\end{array}$ & $\begin{array}{l}\text { Farmers have a positive perception towards stone } \\
\text { bunds (their suitability, importance, profitability, and } \\
\text { effects on productivity) }\end{array}$ & $\begin{array}{l}(1=\text { Disagree, } 2=\text { Neutral }, \\
3=\text { Agree })\end{array}$ \\
\hline 14 & $\begin{array}{l}\text { Ownership of stone } \\
\text { bunds }\end{array}$ & $\begin{array}{l}\text { Farmers feel a responsibility to protect and maintain } \\
\text { stone bunds implemented on their farmland }\end{array}$ & $\begin{array}{l}\text { (1= Disagree, } 2=\text { Neutral, } \\
3=\text { Agree })\end{array}$ \\
\hline 15 & $\begin{array}{l}\text { Motivation for stone } \\
\text { bunds }\end{array}$ & $\begin{array}{l}\text { Farmers are motivated to implement stone bunds on } \\
\text { their farmland (work motivation) }\end{array}$ & $\begin{array}{l}(1=\text { Disagree, } 2=\text { Neutral }, \\
3=\text { Agree })\end{array}$ \\
\hline 16 & Drive to improve & $\begin{array}{l}\text { Farmers have interest to use improved technologies, } \\
\text { seek technical advice, and teach other farmers }\end{array}$ & $\begin{array}{l}(1=\text { Disagree }, 2=\text { Neutral }, \\
3=\text { Agree })\end{array}$ \\
\hline \multicolumn{4}{|c|}{ Economic characteristics } \\
\hline 17 & Farmland & Size of the cropland cultivated & (Hectare) \\
\hline 18 & Crop yield & Annual crop yield produced & (Quintal/year) \\
\hline 18 & $\begin{array}{l}\text { Income from crop } \\
\text { products }\end{array}$ & $\begin{array}{l}\text { Total amount of income obtained from sale of crop } \\
\text { products per year }\end{array}$ & (Birr/year) \\
\hline 20 & Farm oxen & Number of farm oxen owned & (Number) \\
\hline 21 & Livestock size & Livestock size owned & $(T L U *)$ \\
\hline 22 & Income from livestock & $\begin{array}{l}\text { Total amount of income obtained from sale of } \\
\text { livestock and products }\end{array}$ & (Birr/year) \\
\hline 23 & Income from off-farm & $\begin{array}{l}\text { Total amount of income obtained from off-farm } \\
\text { activities }\end{array}$ & (Birr/year) \\
\hline 24 & Tools owned & Number of farm tools owned & (Number) \\
\hline \multicolumn{4}{|c|}{ Institutional characteristics } \\
\hline 25 & Extension category & $\begin{array}{l}\text { Category or classification of the farmer in terms of } \\
\text { extension service uses }\end{array}$ & $\begin{array}{l}(1=\text { Non }- \text { model farmer } \\
2=\text { Model })\end{array}$ \\
\hline 26 & Extension contacts & Number of contacts with Development Agents (DA) & $\begin{array}{l}\text { (1= Rarely, } 2= \\
\text { Sometimes, } 3=\text { Often })\end{array}$ \\
\hline 27 & Participation & $\begin{array}{l}\text { Farmer's active participation in local community } \\
\text { organizations and SWC training programs }\end{array}$ & $\begin{array}{l}\text { (1= Low, } 2=\text { Medium, } \\
3=\text { High })\end{array}$ \\
\hline 28 & Empowerment & $\begin{array}{l}\text { Farmer feels to have the ability to make decision on } \\
\text { his/her own farmland during the campaign works }\end{array}$ & $\begin{array}{l}(1=\text { Disagree, } 2=\text { Neutral }, \\
3=\text { Agree })\end{array}$ \\
\hline 29 & Support/assistance & $\begin{array}{l}\text { Farmer obtained technical assistance and material } \\
\text { support to execute soil conservation practices }\end{array}$ & $(1=$ No, $2=$ Yes $)$ \\
\hline 30 & Land tenure security & Farmer feels secured to use and transfer farm plots & $\begin{array}{l}(1=\text { Not secured, } 2=\text { Feel } \\
\text { secured) }\end{array}$ \\
\hline 31 & Credit & Access to credit for soil management & $(1=$ No, $2=$ Yes $)$ \\
\hline 32 & Market & Access to local market to sell crop products produced & $(1=$ No, $2=$ Yes $)$ \\
\hline
\end{tabular}

*TLU= Tropical livestock unit 


\subsubsection{Data Analysis}

SPSS was used to process the collected data. First, an independent samples t-test was performed to test whether there is a statistical significant difference between SF and NSF in relation to the different farmer/household characteristics included in the study. Statistical significance was tested at $1 \%$ and $5 \%$ probability levels. Then, a Principal Component Analysis (PCA) was carried-out to reduce the 32 factors into a smaller set of components. PCA is a statistical data reduction technique that helps to reduce a data set consisting of a large number of interrelated variables into a smaller set of components (Abdi \& Williams, 2010; O'Rourke \& Hatcher, 2013). It is also used for transforming a set of related variables into a set of unrelated variables that account for decreasing proportions of the variation of the original observations (Everitt, 2004; Field, 2009).

A Varimax orthogonal rotation was used to obtain a rotated component matrix that facilitates the interpretation of the factors. In this rotated component matrix, factor loadings for each of the variables were obtained. Variables with factor loadings less than 0.40 were omitted to improve the clarity of factors in the new components, i.e. variables with factors loadings 0.4 and more were retained for analysis. Kaiser's criterion (the eigenvalue rule) was used to determine the number of factors retained. Based on this rule, factors with an eigenvalue of 1.0 and more were retained to run the final analysis. In addition, the eigenvalue helped to determine the amount of the total variance explained by that factor. Bartlett's test of sphericity was also used to determine whether the relations between the variables were large enough for PCA. Factor scores were generated by the PCA and new factors extracted which were denominated "farmer factors" according to the set of variables they encompassed.

Finally, a multiple linear regression analysis was applied to test the strength of the relationship between the spontaneous implementation (dependent variable) and the "farmer factors" (independent variables). Key-factors among the "farmer factors" are those that show a significant correlation at $1 \%$ and $5 \%$ probability level. In addition, following Field (2009) and Ashoori et al. (2016), beta values are used to determine the relative importance of these key-factors in explaining the spontaneous implementation of stone bunds. 


\subsection{Results and discussion}

\subsubsection{Farmer socio-cultural characteristics}

Descriptive statistics was used firstly to determine differences between Spontaneous Farmers (SF) and Non-Spontaneous Farmers (NSF) in relation to the socio-cultural characteristics included in the study. The mean comparison between the two groups of farmers showed a statistically significant difference in many factors at $1 \%$ probability level as well as some at $5 \%$ probability level. The socio-cultural results (Table 3.2 ) indicate that SF are generally younger farmers who have a better level of education and a more social responsibility in the community as compared to the NSF. The mean age was 43 years for SF and 55 years for NSF. However, in terms of wealth status, a majority of SF were intermediate, while the majority of NSF was better-off. Similarly, Lalani et al. (2016) found that poor farmers have highest intentions to use conservation agriculture. Similarly, SF have a smaller family size ( 5 persons) and relatively a lower available family labor for farming activities (4 persons) compared to the NSF.

Table 3.2 Socio-cultural characteristics of study farmers

\begin{tabular}{llccccc}
\hline No & Factors & \multicolumn{2}{c}{ SF $(\mathrm{N}=40)$} & \multicolumn{2}{c}{ NSF (N=40) } & T-test \\
& & Mean & St. Dev & Mean & St. Dev \\
\hline 1 & Age & 43.03 & 12.53 & 55.45 & 12.82 & $0.000^{* *}$ \\
2 & Family size & 5.33 & 2.35 & 8.25 & 1.78 & $0.000^{* *}$ \\
3 & Family labor & 3.53 & 1.69 & 5.50 & 1.63 & $0.000^{* *}$ \\
4 & Education & 2.10 & 0.84 & 1.4 & 0.59 & $0.000^{* *}$ \\
5 & Social position & 1.63 & 0.49 & 1.28 & 0.45 & $0.001^{* *}$ \\
6 & Wealth status & 2.03 & 0.83 & 2.73 & 0.51 & $0.000^{* *}$ \\
7 & Knowledge about IFM & 1.95 & 0.22 & 1.78 & 0.42 & $0.024^{*}$ \\
8 & Experience in IFM & 2.73 & 0.68 & 2.13 & 0.88 & $0.001^{* *}$ \\
9 & Field visits to check erosion & 2.60 & 0.55 & 2.23 & 0.62 & $0.005^{* *}$ \\
10 & Planning & 1.73 & 0.45 & 1.35 & 0.48 & $0.001^{* *}$ \\
11 & Future prospects & 2.73 & 0.45 & 2.03 & 0.58 & $0.000^{* *}$ \\
12 & Social relations & 2.68 & 0.57 & 2.05 & 0.88 & $0.000^{* *}$ \\
13 & Motivation for stone bunds & 2.60 & 0.78 & 1.68 & 0.79 & $0.000^{* *}$ \\
14 & Perception of stone bunds & 2.73 & 0.55 & 2.30 & 0.76 & $0.005^{* *}$ \\
15 & Ownership of stone bunds & 3.00 & 0.00 & 2.20 & 0.76 & $0.000^{* *}$ \\
16 & Drive to improve & 2.70 & 0.56 & 1.98 & 0.86 & $0.000^{* *}$ \\
\hline$* *$ p-value significant at 0.01, & $* p$-value significant at 0.05 & &
\end{tabular}

As shown in Table 3.2, the SF also visit their farmlands more frequently than the NSF. This enables SF to recognize erosion problems more easily and hence implement erosion control measures by their own initiative. Moreover, compared with the NSF, SF are farmers with better knowledge as well as experience in IFM. This was also observed in a previous study that showed that spontaneously implemented stone bunds were more integrated with compost and manure use to produce high yields and sufficient crop residues for livestock 
feeds (Abi et al., 2018b). Results also indicate that SF have a better farm planning and more positive future prospects to change and to make improvements in their household food security and living condition, and therefore have a longer planning horizon than the NSF. This result is in line with findings by Lapar \& Pandey (1999), Bekele \& Drake (2003) and Adimassu et al. (2012) that young farmers have more long-term visions and are more likely to invest in conservation measures.

Furthermore, compared to the NSF, SF are farmers who have a better drive to improve: who like to use improved technologies to improve production and protect productivity of their farmlands at the same time, and who teach other farmers about new technologies. Accordingly, SF had better relations of trust with neighboring farmers, extension workers and government officials. Regarding the motivation to implement stone bunds on the farmland, work motivation for stone bunds is higher among SF than among NSF (Table 3.2). Work motivation is directly related to the perception that farmers have on implemented stone bunds. Results also show that SF have a more positive perception of stone bunds than the NSF, which is of course due to the experienced positive effects of stone bunds on soil erosion, soil productivity and crop yields (Abi et al., 2018b). Not surprisingly, results also show that SF have a better sense of ownership and responsibility to protect and maintain implemented stone bunds than NSF.

\subsubsection{Farmer economic characteristics}

Table 3.3 presents the results of descriptive statistics when comparing SF and NSF in relation to the household's economic characteristics. Statistical test (t-test) shows that there are significant differences between SF and NSF in relation to farm size, crop yield, income from crop products and livestock size at $1 \%$ probability level, while in income from off-farm activities a statistical significant difference at $5 \%$ probability level was found.

As can be seen from Table 3.3, the mean size of cultivated farmland was 2.19 ha for SF and 3.35 ha for NSF. However, most surprisingly, SF produced on average 21.65 quintal of crop products per year, while NSF produced on average 46.38 quintal. This large difference in yield production is due to the size of farmland and type of crop products produced. Moreover, the mean income obtained from the sale of crop products was lower for the SF than for the NSF. The possible reason for this difference is the fact that SF used most of their produced crop products for their own consumption. According to the Central Statistical Agency (CSA) of Ethiopia, farmers utilize large amounts of their crop products for their own consumption leaving little for selling. CSA (2016) indicates that in general about $66 \%$ of cereal crop products produced are used for self-consumption and only about $17 \%$ for sale on the market. 
The number of farm oxen owned by the farmers in this study was more or less equal among the SF and the NSF. However, the total number of livestock they held, measured in TLU was 4.13 for SF and 5.88 for NSF. In addition, the SF obtained a smaller income from selling livestock and livestock products than the NSF. On the other hand, the SF obtained a higher income from off-farm activities than the NSF, which helps SF to compensate the limited income they obtain from selling crop and livestock products. A high income from off-farm activities also improves farmers economic status (Enki et al., 2001). Although not significant, the mean number of farm tools owned was 3.46 for SF and 2.67 for NSF.

Table 3.3 Economic characteristics of study farmers

\begin{tabular}{llrrrrl}
\hline \multirow{2}{*}{ No } & Factors & \multicolumn{2}{c}{ SF (N=40) } & \multicolumn{2}{c}{ NSF (N=40) } \\
\cline { 3 - 5 } & & Mean & St. Dev & Mean & \multicolumn{1}{c}{ St. Dev } & T-test \\
\hline 1 & Farm size & 2.19 & 1.11 & 3.35 & 0.94 & $0.000^{* *}$ \\
2 & Crop yield & 27.65 & 12.78 & 46.38 & 14.72 & $0.000^{* *}$ \\
3 & Income from crop products & 6097.50 & 2555.81 & 14047.5 & 4947.31 & $0.000^{* *}$ \\
4 & Farm oxen & 1.92 & 0.37 & 1.95 & 0.52 & 0.771 \\
5 & Livestock size & 4.13 & 1.62 & 5.88 & 1.38 & $0.000^{* *}$ \\
6 & Income from livestock & 2445 & 4305.52 & 3147.50 & 2763.64 & 0.388 \\
7 & Income from off-farm activities & 706.73 & 512.06 & 428.82 & 250.69 & $0.023^{*}$ \\
8 & Tools owned & 3.46 & 1.04 & 2.67 & 1.79 & 0.077 \\
\hline$* *$
\end{tabular}

** p-value significant at $0.01, \quad *$ p-value significant at 0.05

\subsubsection{Farmer institutional characteristics}

Table 3.4 compares the institutional characteristics of SF and NSF. Except for access to market, descriptive results show significant differences between the two groups of farmers in relation to all the institutional characteristics included in the analysis at $1 \%$ and $5 \%$ probability level (Table 3.4). Important, SF often are model farmers who have more frequent contact with extension workers than the NSF. Model farmers are farmers who are using more than $70 \%$ of the agricultural technologies provided through the extension services (FDRE, 2010; Tefera et al., 2016). Also, a majority of SF actively participate in local community organizations and SWC trainings and obtain more technical support from extension workers more than the NSF. Contrary to the NSF, the majority of SF had access to credit services. SF are however less secured to use and transfer their farmland than the NSF, given that SF are younger farmers and therefore rarely obtain their farmlands through formal land distribution.

Another important factor is farmers' decision-making ability (empowerment) on their own farmlands, especially during the campaign works. Empowerment infers that the decisionmaking process to manage and protect farmlands from erosion is decentralized to the farmer level (Van den Berg \& Jiggins, 2007). An implication is that farmers participate in the 
selection of SLM technologies suitable for their farmlands and decide where to implement them, even during the mass mobilization campaign. However, results show that only very few SF take decisions on their farmlands during the campaign works (Table 3.4). This is in line with findings by Snyder et al. (2014) that farmers decision making ability in relation to land management intervention is limited in Ethiopia.

Table 3.4 Institutional characteristics of study farmers

\begin{tabular}{clccccc}
\hline No & Factors & \multicolumn{2}{c}{ SF $(\mathrm{N}=40)$} & \multicolumn{2}{c}{ NSF $(\mathrm{N}=40)$} & \multicolumn{2}{c}{ T-test } \\
& & Mean & St. Dev & Mean & St. Dev \\
\hline 1 & Extension category & 1.63 & 0.49 & 1.28 & 0.45 & $0.001^{* *}$ \\
2 & Extension contacts & 2.20 & 0.91 & 1.30 & 0.72 & $0.000^{* *}$ \\
3 & Participation & 2.63 & 0.63 & 1.68 & 0.89 & $0.000^{* *}$ \\
4 & Support/assistance & 1.83 & 0.39 & 1.63 & 0.49 & $0.046^{*}$ \\
5 & Credit & 1.70 & 0.46 & 1.38 & 0.49 & $0.003^{* *}$ \\
6 & Land tenure security & 1.58 & 0.50 & 1.85 & 0.36 & $0.006^{* *}$ \\
7 & Market & 1.83 & 0.39 & 1.78 & 0.42 & 0.582 \\
8 & Empowerment & 1.13 & 0.34 & 1.00 & 0.00 & $0.023^{*}$ \\
\hline$* *$ p-value significant at 0.01, & $*$ p-value significant at 0.05 & & &
\end{tabular}

Generally, as can be seen from Table 3.2, 3.3 and 3.4, descriptive statistics showed a significant difference between the SF and NSF in many factors included in the analysis. Based on these factors, it is really difficult to identify the key-factors that explain differences in farmers characteristics. Therefore, in the next section, PCA is applied to reduce the number of factors into a smaller set of principal components to help identify those keyfactors.

\subsubsection{Key-differences between farmers: PCA}

PCA was performed on the 26 of the original 32 variables to identify key-differences between farmers who spontaneously implemented stone bunds and those that did not. Six variables were discarded due to factor loadings less than 0.4. The Kaiser-Meyer-Olkin (KMO) measure verified the goodness-of-fit of the variables for the analysis with a KMO equal to 0.843, which is 'great', according to Field (2009). Bartlett's test of sphericity (Chi-square = 1859.933, $\mathrm{df}=325$ and $\mathrm{p}$-value $=0.000$ ) indicated that relations between variables were sufficiently large for PCA. After PCA, five factors with eigenvalues higher than 1 were extracted. These factors explained about $73 \%$ of the variance in farmer's socio-cultural, economic and institutional characteristics (Table 3.5).

The first factor (factor 1) comprises seven socio-cultural factors: drive to improve, farm planning, perception of stone bunds, motivation for stone bunds, education level, social position and ownership of stone bunds. This factor is related to a farmer's personal characteristics and behavior (especially farmer's willingness and motivation to change and 
improve) but also to positive experiences with stone bunds. This first factor is denominated Readiness to change. The PCA indicates that readiness to change explains most of the variance in farmer's characteristics (41\%), which is much higher than the other factors.

Table 3.5 Rotated component matrix

\begin{tabular}{|c|c|c|c|c|c|}
\hline \multirow{2}{*}{ Farmer characteristics } & \multicolumn{5}{|l|}{ Farmer factors } \\
\hline & $\begin{array}{l}\text { Factor } 1 \text {, } \\
\text { Readiness to } \\
\text { change }\end{array}$ & $\begin{array}{l}\text { Factor 2, } \\
\text { Available } \\
\text { resources }\end{array}$ & $\begin{array}{l}\text { Factor 3, } \\
\text { Social capital }\end{array}$ & $\begin{array}{l}\text { Factor 4, } \\
\text { Type of } \\
\text { family }\end{array}$ & $\begin{array}{l}\text { Factor 5, } \\
\text { Commitment }\end{array}$ \\
\hline Drive to improve & 0.883 & & & & \\
\hline Farm planning & 0.847 & & & & \\
\hline Perception of stone bunds & 0.843 & & & & \\
\hline Motivation for stone bunds & 0.810 & & & & \\
\hline Education level & 0.723 & & & & \\
\hline Social position & 0.716 & & & & \\
\hline Ownership of stone bunds & 0.411 & & & & \\
\hline Crop yield produced & & 0.909 & & & \\
\hline Total Farm size & & 0.850 & & & \\
\hline Income from crop products & & 0.837 & & & \\
\hline Wealth status & & 0.767 & & & \\
\hline Livestock size & & 0.676 & & & \\
\hline Support and assistance & & & 0.844 & & \\
\hline Extension category & & & 0.752 & & \\
\hline Participation & & & 0.679 & & \\
\hline Credit services & & & 0.622 & & \\
\hline Social relations & & & 0.599 & & \\
\hline Experience in IFM & & & 0.593 & & \\
\hline Extension contacts & & & 0.579 & & \\
\hline Family Labor & & & & 0.779 & \\
\hline Land tenure security & & & & 0.755 & \\
\hline Age of $\mathrm{HH}$ & & & & 0.747 & \\
\hline Family size & & & & 0.731 & \\
\hline Field visits to check erosion & & & & & 0.830 \\
\hline Future prospects & & & & & 0.720 \\
\hline Knowledge about IFM & & & & & 0.430 \\
\hline Explained variance (\%) & 41.43 & 13.12 & 7.44 & 6.20 & 4.72 \\
\hline
\end{tabular}

Note: Only factor loadings over 0.40 are presented

Factor 2 comprises four economic factors (crop yield produced, farm size, income from crop products and size of livestock owned) and wealth status. These factors are directly related to household resource endowments and asset accumulation, and hence denominated Available resources. The third factor (factor 3) comprises five institutional factors (institutional support and assistance, use of extension services, participation in local organizations, use of credit services and number of contacts with extension workers), and two socio-cultural factors (social relations and experience in IFM). These factors relate to farmer's social networks and connectedness with other farmers and extension workers. Therefore, factor 3 is referred to as Social capital. 
Factor 4 comprises three socio-cultural factors (age of head of household, family size and available family labor) and one institutional factor (land tenure security). This fourth factor relates to the farmer's demographic condition and land tenure rights. This factor is therefore denominated Type of family. The final factor (factor 5) comprises three sociocultural factors: number of field visits to check erosion, future prospects and knowledge about IFM. This factor shows the commitment a farmer has to improve his/her living condition using his/her own knowledge and his/her connectedness with his/her farmlands. Therefore, this component is referred to as Commitment.

In order to identify one or more key-factors in household characteristics that explain why some farmers spontaneously implement stone bunds and others do not, a regression analysis was performed with the extracted scores (farmer-factors). Table 3.6 presents the results of the regression analysis for each factor. Spontaneous implementation of stone bunds is significantly related with all five farmer-factors included in regression analysis at $1 \%$ and $5 \%$ probability level. Thus, all these key-factors explain differences between the two group of farmers (SF vs NSF).

Results show that three key-factors (readiness to change, social capital and commitment) are positively related to spontaneous implementation of stone bunds, whereas the available resources and family type are negatively related. In terms of their relative importance, based on the results of beta values, available resources is the most important factor in explaining the spontaneous implementation of stone bunds followed by social capital, readiness to change and commitment (Table 3.6). Type of family has relatively low importance. Furthermore, the regression model predicts that $56 \%\left(R^{2}=0.561\right)$ of the variation in spontaneous implementation of stone bunds is explained by these five keyfactors.

The negative relation between the first key-factor (Available resources) and the spontaneous implementation of stone bunds implies that farmers with limited resources are more likely to spontaneously implement stone bunds. This is due to the fact that farmers with limited resource endowments and asset accumulation are more likely to invest in land management measures such as stone bunds in order to improve the productivity of their limited soil resources and to cover their food security condition (Adimassu et al., 2012; Nyanga et al., 2016). Consistently, the economic characteristics of the farmers in this study indicate that farmers who spontaneously implement stone bunds were farmers with relatively limited productive resources such as farmland, labor and livestock. These farmers are more enthusiastic to improve their agricultural production and productivity by conserving their soil using stone bunds and integrate them with more compost and manure (Abi et al., 2018b). Therefore, in order to convince farmers with higher available resources (farmland, livestock, labor, wealth, etc.) to spontaneously implement and integrate SLM 
How farmers' characteristics influence spontaneous spreading of stone bunds in the Highlands of Ethiopia:

practices into their farming system, the government extension program must pay more attention to awareness raising and learning from each other. In a previous study, we found that knowledge about stone bunds came from the neighboring farmers (Abi et al., 2018b), implying that the role of farmer-to-farmer learning in spontaneous adoption and implementation was important. Likewise, as the need to implement stone bunds is lower for the better-off farmers, awareness raising focused on sustainability issues and planning with a longer-term vision is essential for this group of farmers.

Table 3.6 Results of regression analysis of farmer factors with spontaneous implementation

\begin{tabular}{|c|c|c|c|c|c|}
\hline \multirow[b]{2}{*}{ Farmer factors } & \multicolumn{2}{|c|}{ Unstandardized coefficient } & \multirow{2}{*}{$\begin{array}{c}\text { Standardized } \\
\text { coefficient }\end{array}$} & \multirow[b]{2}{*}{$\mathrm{t}$} & \multirow[b]{2}{*}{ p-value } \\
\hline & $\beta$ & Std. Error & & & \\
\hline Readiness to change & 0.130 & 0.039 & 0.246 & 3.110 & $0.003 * *$ \\
\hline Available resources & -0.279 & 0.039 & -0.533 & -6.733 & $0.000 * *$ \\
\hline Social capital & 0.167 & 0.039 & 0.317 & 4.004 & $0.000 * *$ \\
\hline Type of family & -0.078 & 0.039 & -0.192 & -2.423 & $0.018^{*}$ \\
\hline Commitment & 0.116 & 0.039 & 0.231 & 2.911 & $0.005^{* *}$ \\
\hline
\end{tabular}

Model summary: $R=0.749 ; R^{2}=0.561 ;$ Adjusted $R^{2}=0.531 ;$ Std. Error of the estimate $=0.344$

** p-value significant at $0.01 ; \quad *$ p-value significant at 0.05

Social capital is the second most important key-factor that significantly and positively explains spontaneous implementation of stone bunds, suggesting that farmers who have a better social network and connectedness with other farmers and extension workers are more likely to implement stone bunds by their own initiative. This result is in line with findings by Adimassu et al. (2012), Nyanga et al. (2016) and Teshome et al. (2016b) that farmers with more social capital invest more in SLM practices. Interesting from this PCA is that support and assistance score high in the social capital factor. This is due to the fact that a majority of SF are model farmers and had better contact with extension workers. Model farmers have a greater chance to be involved in practical trainings, and often obtained more technical support from extension workers than other farmers. As a result, such farmers are better prepared and interested to implement new agricultural technologies including stone bunds on their farmlands. Adesina \& Zinnah (1993) indicated that better contact with extension workers affects the intensity of stone bunds use because this exposes farmers to available information. Particularly, a better contact with extension workers, active participation in extension program and strong social relation demonstrate how much SF benefitted from bridging social capital. This type of social capital provides a means for farmers to access a wider information network, technical support and resources (Leonard, 2004; Cramb, 2005; Sanginga et al., 2010). Similarly, farmers with more experience in IFM are more aware to spontaneously implement stone bunds integrated with more fertilizer, compost and manure using knowledge obtained from different sources. Simultaneously, for farmers who cannot afford to buy chemical fertilizer, access to credit service is important. 
This is the case of the SF with a lower wealth status, who actively seek for access to credit service to buy fertilizer.

The third most important key-factor that significantly and positively explains spontaneous implementation is readiness to change. In this key-factor, a majority of variables explaining the individual motivational characteristics of farmers who spontaneously implement stone bunds are included, such as drive to improve and motivation or willingness to use stone bunds. This implies that farmers who are willing and motivated to change and improve (dynamic farmers) are more likely to spontaneously implement stone bunds. This result is consistent with the findings by C. A. Kessler (2006) that dynamic farmers invest more in SWC practices. Following C. A. Kessler (2006), Quinn \& Burbach (2010), Kessler et al. (2016) and Ryan \& Deci (2017), farmers' willingness and interest can be considered as a sign of intrinsic motivation, suggesting that farmers who implement stone bunds by their own initiative are more intrinsically motivated farmers.

According to Napier (1991), when farmers are already intrinsically motivated to implement erosion control measures, such as stone bunds, they are also more willing to continue using it. Equally important is farmers' perception towards implemented stone bunds, particularly when trying to understand whether farmers are prepared to continue using them (de Graaff et al., 2008). Result of this study show a big difference between the two groups of farmers, with SF having a more positive perception towards implemented stone bunds on their land. This result is in line with findings in other parts of Ethiopia where a more positive perception towards implemented conservation measures has significant effects on its sustainable use (Shiferaw \& Holden, 1998; Amsalu \& de Graaff, 2007). Other important characteristics in the key-factor "Readiness to change" are farm planning, motivation for stone bunds and education. Results imply that farmers with a high education level have a better farm planning and motivation to make progress in their farming activities, suggesting the importance of educating farmers to enhance their capacity to plan their farming activities, also to become motivated to implement stone bunds on their farmlands.

Commitment is the fourth key-factor explaining differences in farmer characteristics. The positive relation between commitment and spontaneous implementation of stone bunds suggests that farmers who are more dedicated to improve their living conditions are more likely to spontaneously implement stone bunds. According to Ryan \& Deci (2017), commitment reflects intrinsic motivation, implying that farmers who are committed to improve their living conditions using stone bunds are intrinsically motivated farmers. Results of the PCA also show that the number of farm visits scores high in this key-factor, indicating that farmers who spontaneously implement stone bunds have higher connectedness with their farmland. Farm visiting is important to understand the severity of erosion problems on the farmlands (Amsalu \& de Graaff, 2006). For instance, rills or gullies 
formed due to erosion could be discovered through frequent farm visiting and hence enable farmers to perceive the extent of erosion problems on their farmlands (de Graaff et al., 2008). These perceived erosion problems drive farmers to become motivated to practice SLM technology on their own initiative (Prager \& Posthumus, 2010). Again, statistical results show that SF had better positive future prospects than the NSF. A possible explanation for the observed differences is the higher awareness about erosion effects on the future productivity of farmlands and better knowledge about IFM among SF compared with the NSF.

The fifth key-factor, explaining differences in farmers' characteristics, is the type of family. This key-factor has negative relation with spontaneous implementation of stone bunds. This implies that families which have high available family labor and secure land rights are more likely to implement stone bunds by themselves. Consistently, it is also reported in many studies (for instance, Bodnar \& De Graaff, 2003; Sietz \& Van Dijk, 2015) that when a farmer has a large number of economically active family members, they are more able to construct stone bunds on their farmland using their own family labor. However, our results do not support these findings; SF have lower family labor than the NSF. A possible explanation is that SF are young farmers with better education level, and hence better know-how to make use of available labor resources and their social capital. Land tenure security in this research has also a quite particular effect on the implementation of stone bunds. It is often argued that farmers' decisions to invest in SLM activities as well as their choice and implementation of practices are affected by tenure security (Gebremedhin \& Swinton, 2003; Teshome et al., 2016c). Likewise, Adimassu et al. (2016) considered land tenure security to be an incentive to continue land use management practices. However, results of this study do not support the previous findings. SF were less secure in their land tenure than NSF, but more likely to continue using implemented stone bunds. This may be explained by the more positive perception of stone bunds that SF have and their higher commitment to soil conservation.

Age of farmer is also an important factor in the "Type of family", implying that older farmers are less likely to spontaneously implement stone bunds on their farmlands. Statistical results show that SF were younger compared with NSF. Comparable to this study, MbagaSemgalawe \& Folmer (2000) found in Tanzania that old farmers are less interested in constructing labor intensive conservation technologies such as bench terraces and rock walls. Not only are young farmers more energetic and able to implement labor intensive technology by their own initiative, but Kassahun (2006) also disclosed that young farmers are more 'optimistic', therefore more willing or eager to use land management measures than other farmers. 


\subsection{Conclusions and recommendations}

The aim of this study was to identify key-differences in household characteristics between farmers who spontaneously implement stone bunds and farmers who did not in the Girar Jarso woreda. The results of PCA and regression analysis have identified five key-factors explaining differences in household characteristics. Most interesting result was that three key-factors (social capital, readiness to change and commitment) are positively related to the spontaneous implementation of stone bunds. This suggests the crucial role of social capital to foster individual farmer's readiness and commitment to spontaneously implement stone bunds on the farmlands. Among these key-factors, readiness to change and commitment indicate farmer's intrinsic motivation to implement and integrate stone bunds into the farming system. These two key-factors play a crucial role to foster farmers' intrinsic motivation to continue using stone bunds that are implemented on their farmlands. The analysis confirmed the hypothesis; even five key-factors are significantly related to the spontaneous implementation of stone bunds.

This research suggests that farmers who spontaneously adopted and implemented stone bunds on their farmlands are intrinsically motivated farmers who are ready to change, and improve their productivity and food security using available natural and social resources. This also seems to suggest that lack of available labor or farmland is not the major reason for farmers not to adopt the introduced SLM practices. Most important is the farmer's mindset and behavior: their readiness to change and concerns about effect that erosion has on the future productivity of their farmland. Our first conclusion is that when farmers are ready to change, they are able to implement labor intensive stone bunds by themselves; using their own family labor and seeking additional labor through their social networks. Hence, extension workers and government officials should better understand the crucial role of farmers' intrinsic motivation when dealing with SLM, and therefore reformulate their extension strategies and messages. A scaling-up strategy must focus on awareness raising, strengthening intrinsic motivation, ownership and integrated farming.

These findings provide two important recommendations to extension workers and government officials when aiming to foster SLM and when developing scaling-up strategy that helps to sustainably increase agricultural production and achieve food security of smallholder farmers in Ethiopia: (1) the need to create farmers' readiness to change, and (2) the need to focus more on farmers' intrinsic motivation. Both lead us to conclude that government extension programs aiming to foster SLM practices in Ethiopia should invest more in activities that focus on changing how farmers think and behave rather than on what farmers do. This will result in more sustainable impact of the extension program, including the mass mobilization campaign. 
How farmers' characteristics influence spontaneous spreading of stone bunds in the Highlands of Ethiopia: a case study in the Girar Jarso woreda 


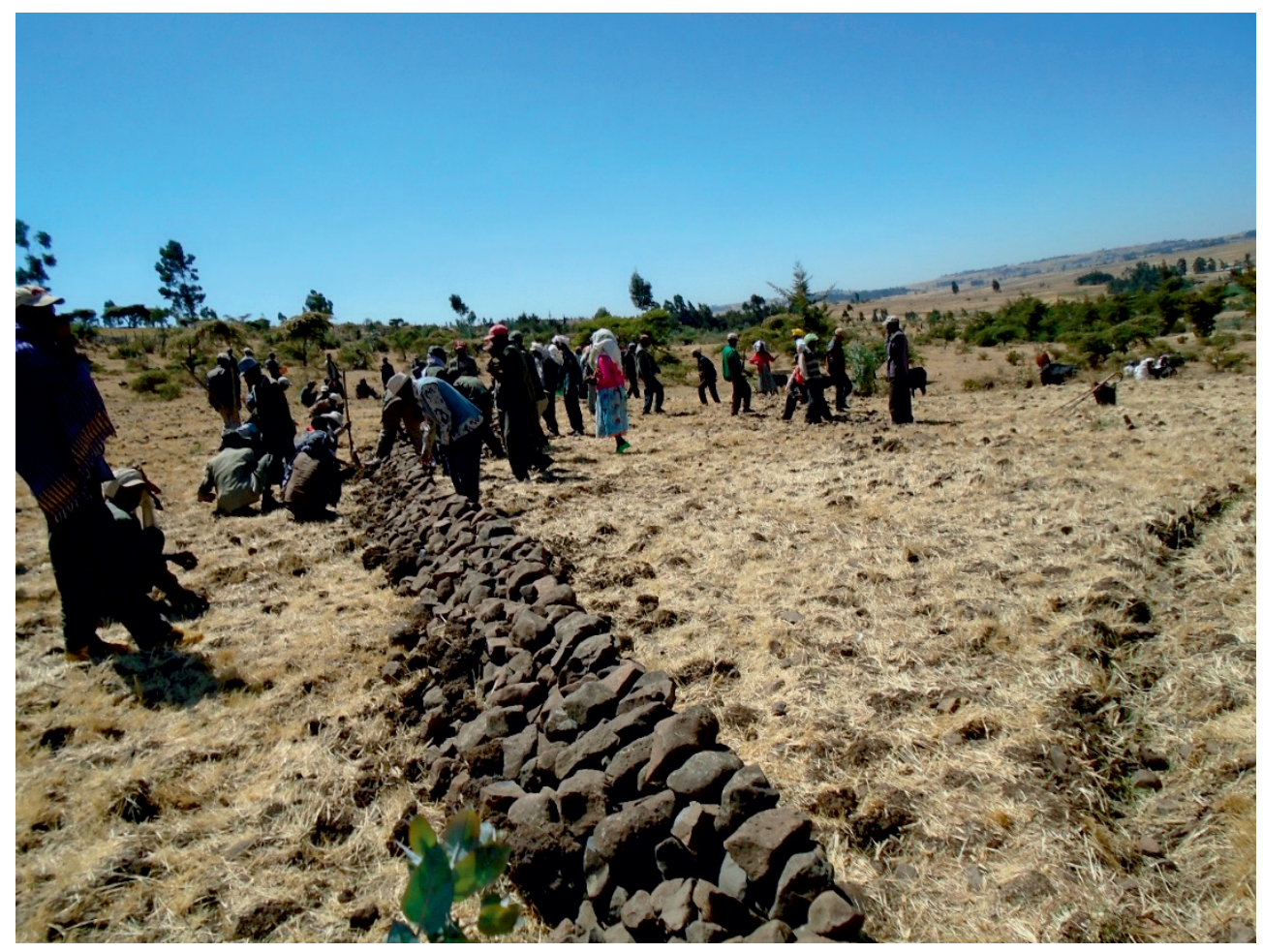




\section{Adapting the current mass mobilization approach in Ethiopia to enhance its impact on sustainable land management}

This paper analyses the effect of an adapted - more participatory and more integrated mass mobilization training approach on Ethiopian farmers' motivation to practice integrated farming and invest in Sustainable Land Management (SLM). It is based on the results of an experiment carried-out in the Sago-kara watershed in the Central highlands of Ethiopia, in which a group of 26 farmers received an adapted training at the start of the mass mobilization campaign in 2016, which aimed to strengthen farmers' knowledge and awareness about natural resource management, drought mitigation and integrated farm planning. One year later, both qualitative and quantitative data were collected through group discussions, field observations and household surveys. For the before-after comparison we used descriptive statistics to analyze the data; the with-without comparison (with a control group) differences were statistically tested at 1\% and 5\% probability levels. The results show that the adapted training approach enhanced awareness of farmers, created motivation for integrated farm management and fostered implementation of SLM practices in the field. Most interesting is that farmers who followed the training better plan for drought mitigation and are more aware of the possible effects of drought on their farming activities. The study concludes that the current mass mobilization approach in Ethiopia can have more impact on SLM if it would pay serious attention to: 1) creating awareness on the causes and effects of erosion and drought focusing on sustainability issues, 2) fostering farmers' intrinsic motivation to be good stewards of their land; 3) training in integrated farm planning, and 4) developing farm plans based on farmers' visions for resilient farming. In order to make agricultural extension in Ethiopia more effective, one has to start with capacity building of the rural extension staff in participatory training methods, followed by empowering and motivating farmers for SLM. This will not only lay a foundation for sustainable agriculture and more food security on the farm, but is also crucial for the scaling-up of resilient farming to watershed and landscape levels in Ethiopia.

Based on:

Abi, M., Kessler, A., Oosterveer, P. \& Tolossa, D. 2018. Adapting the current mass mobilization approach in Ethiopia to enhance its impact on sustainable land management: lessons from the Sago-Kara watershed. Environmental Management (under review) 


\subsection{Introduction}

Crucial for achieving sustainable agriculture is to improve farm resilience to production related risks (Milestad \& Darnhofer, 2003; Cavatassi et al., 2011). Sustainable Land Management (SLM) that contributes to increased production and improved resilience to external shocks (Kassie et al., 2010; Schwilch et al., 2014; Cordingley et al., 2015) has received greater attention in Ethiopia over the past decades (Snyder et al., 2014; Nedessa et al., 2015). In 2011, the government of Ethiopia initiated a Climate Resilient Green Economy (CRGE) strategy (Federal Democratic Republic of Ethiopia, FDRE, 2011) with focus on e.g. watershed management, crop management, soil nutrient management, irrigation development and diversification of livestock. However, despite these efforts, particularly smallholder farmers remain vulnerable to drought (Kassie et al., 2013; Mengistu et al., 2015) as evidenced by the recent 2015/2016 drought, which caused an estimated 10.2 million people in Ethiopia exposed to food insecurity and in need of food assistance (Catley et al., 2016; FAO, 2016).

SLM practices, covering physical soil conservation practices, soil fertility improvement, agro-forestry and forage development schemes, have been widely implemented in the highlands of Ethiopia over the past years (Kassie et al., 2010; Adimassu et al., 2016). These practices play an important role in improving agricultural productivity, increasing income and enhancing food security through reducing erosion, improving soil fertility and reducing the risk of drought (Schwilch et al., 2014; Cordingley et al., 2015; Mengistu et al., 2015). However, farmers' own investments in SLM practices remain quite limited, and SLM efforts have therefore only been partially successful (Adimassu et al., 2016). As a consequence, soil erosion and low soil fertility remain major problems that severely impede farmers' ability to improve agricultural productivity, their income and food security levels (Moges \& Taye, 2017). The community mass mobilization approach, which involves mobilizing and organizing all farmers in a watershed to work on SLM activities during the off-season (Danano, 2010), is the main strategy used by the Ethiopian government to implement and spread SLM practices (Nedessa et al., 2015). This approach stimulates implementation of SLM practices within a short period of time (Haregeweyn et al., 2015; Teshome et al., $2016 b)$, but sustainability of the implemented practices is often questioned (Weldemariam et al., 2013). Especially physical structures are often poorly adopted, hardly maintained and sometimes even removed by farmers (Kassie et al., 2010). Moreover, scaling-up of these practices over a larger area remains limited (Teshome et al., 2016b)

With these backdrops, one could question if the right strategy is currently being used. In this paper we argue that a more participatory and integrated approach could overcome several of these constraints, and lead to more sustainable impacts on agricultural productivity, income of farmers and food security, as well as foster wide-scale 
implementation (horizontal scaling-up) of SLM practices (Kessler et al., 2016). Firstly, a participatory approach is crucial in improving farmers' awareness of environmental problems, and also for developing more practical and promising solutions (Hoang Fagerström et al., 2003; Douthwaite et al., 2009). It also allows farmers, extension workers and researchers to interact and learn from each other (Defoer, 2002; Kraaijvanger \& Witteveen, 2018). Likewise, a participatory approach empowers farmers to take a leading role in the decision making process, which can also motivate them to adopt and implement new SLM practices on their farmlands (Nyagumbo et al., 2011; Abi et al., 2018a; Abi et al., 2018b), and to experiment and adapt those practices to the increasing climatic variability (Shiferaw et al., 2009). Secondly, an integrated approach is required for sustainable agriculture under changing climatic variability (Wall \& Smit, 2005; Feola et al., 2015; Mulema et al., 2017; Dar et al., 2018). Such an integrated approach improves the productive capacity of the soil (Rojas et al., 2016) and enables to achieve a more profitable and sustainable food crop production (Cook et al., 2009; Dar et al., 2018). In this case, integrating SLM practices into the broad farm management system (crop, livestock and soil management) is important, especially for small-holding farmers (Cook et al., 2009; Mengistu et al., 2015; Rojas et al., 2016).

This study provides insights in how to trigger both farmers' awareness and motivation to implement and integrate such SLM practices into their farming systems, and investigates this by means of assessing the effects of an adapted mass mobilization training approach in the Sago-kara watershed, Central highlands of Ethiopia. The central hypothesis of this study is that after providing trainings in the adapted approach, participating farmers are more aware of the benefits of integrated farming and therefore more motivated to practice integrated farm management in their fields, and will better plan how to invest in SLM practices to mitigate drought effects in the future. The rest of the paper is structured as follows. In the next section, we analyze the context of the current mass mobilization approach and how the adapted training approach was developed. This is followed by section describing the methodology of the study, the results, the discussion and finally in section six the conclusions and recommendations of the study.

\subsection{Context analysis of SLM in Ethiopia and the need for an adapted training approach}

\subsubsection{The current mass mobilization approach in Ethiopia}

Mobilizing farmers to work on soil conservation activities started in the early 1980s (Bekele \& Drake, 2003; Dejene, 2003). Previously, campaign works such as planting trees, terracing, 
constructing bunds and check dams were undertaken on communal lands using food-forwork payments (Bewket, 2007). However, this approach was criticized for a number of reasons: its top-down approach, a lack of a systematic intervention approach (e.g. watershed or micro-watershed level), limited consideration of variations in agro-ecological conditions, too much emphasis on technical options and coerced participation (Dejene, 2003; Bewket, 2007; Ludi et al., 2013a; Wolka, 2014). The focus of this study is the mass mobilization approach, which was launched in 2010 and aims to involve all able bodied farmers in the management of natural resources at a watershed level, without any payment (Danano, 2010).

In the current mass mobilization approach, SLM practices are implemented in all areas that require conservation measures, so on both communal and private farmlands. Mass mobilization supports the implementation of SLM practices over a large area (Haregeweyn et al., 2015; Teshome et al., 2016b), because it is undertaken during different mobilization rounds (Danano, 2010). Practices include hillside terraces, soil/stone bunds, check-dams, cut-off drains, waterways, planting trees, area enclosures and in-situ moisture conservation practices. Every other year, farmers receive training on the implementation of SLM practices (Leta et al., 2018). Similarly, they receive technical support and working tools during the campaign works (FDRE, 2010, 2016). The current approach is more systematic than previous approaches (it works at a watershed level), and gives more emphasis to farmer participation (Snyder et al., 2014). Each year, farmers contribute 30-45 days of free labor to implement SLM practices (Wolka, 2014).

However, despite of all these positive aspects, the current mass mobilization approach has a number of limitations. SLM practices are still implemented in a rather top-down manner, with limited active participation of farmers in the planning and implementation phases (Weldemariam et al., 2013; Snyder et al., 2014). Communities are mainly mobilized to make labor available for the implementation, but planning remains mostly centralized (Leta et al., 2018). In addition, little attention is given to making farmers more aware of erosion effects on future productivity. Hence, it does not really change farmers' mind-set nor does it motivate them to apply conservation measures on their own farmlands (Wolka, 2014). This was also observed in a recent study conducted in the Central highlands of Ethiopia by Abi et al. (2018a).

Moreover, SLM practices are still implemented without considering farmers indigenous knowledge and practices in the field (Snyder et al., 2014) nor farmers' needs and aspirations (Ludi et al., 2013b; Mulema et al., 2017). This lack of considering farmers' own interest and willingness when implementing SLM technologies (Abebe \& Sewnet, 2014; Moges \& Taye, 2017) often leads to lack of ownership and maintenance of SLM practices. Furthermore, the focus of the current mass mobilization is on constructing physical structures to arrest 
erosion, such as bunds, terraces, water harvesting and drainage structures (Dejene, 2003; Bewket, 2007; Wolka, 2014); only limited attention is given to other land management practices and to the integration of practices on the farm (Gete et al., 2006; Gebrehaweria et al., 2016). Finally, the approach generally works with strict targets that have to be achieved, and does not give sufficient attention to the future maintenance and sustainability of implemented practices (Ludi et al., 2013b; Snyder et al., 2014). Hence, several issues limit the effectiveness of the current mass mobilization approach, suggesting the need to move towards a more flexible and bottom-up approach (McDonald \& Brown, 2000).

In summary, the key-aspects missing in the current mass mobilization approach are: 1) its limited focus on raising awareness among farmers, 2) not paying attention to generating intrinsic motivation among farmers, 3 ) not considering integration of practices on the farm, and 4) not considering long-term planning (missing a focus on resilience). In the trainings that are provided to farmers during the mass mobilization campaigns these key aspects are not given attention. The main focus in the existing approach is on the technical aspects that are communicated to farmers (i.e. content of the training; Abate, 2014), rather than on the reasons behind the need for SLM and e.g. the importance of considering all components of farming (crop production, livestock production, soil management, etc.). Hence, the key challenge is how to foster farmers' awareness and motivation to implement SLM practices in their fields and integrate these in their annual farming plans to increase farm resilience and mitigate drought effects. This challenge is addressed in this paper, which describes and analyses the effects of an adapted training approach on a group of Ethiopian farmers, as compared to the current mass mobilization approach used by the Ethiopian extension service.

\subsubsection{Explaining the adapted training approach}

Considering the following four key-aspects that are currently missing in the mass mobilization approach, we developed an adapted training approach, which was more participatory and more integrated compared to the current mass mobilization campaign:

1. Awareness. Raising farmer's awareness about the effects of erosion and drought on soil fertility, and also about the benefits of implementing SLM practices on farmland is crucial to increase knowledge and readiness to change the future. In particular, raising farmer's awareness on the causes and effects of current problems is crucial to achieve a different future situation (Kessler et al., 2016), and also to change farmers' attitude and perception towards alternative farming activities that could reverse the current situation (Papadopoulos et al., 2015). 
2. Motivation. Once farmers are aware of the benefits of SLM practices, they will become more convinced that these practices actually work (to control erosion, improve yields and reduce drought risks), and hence be intrinsically motivated to implement them in their fields. When farmers are engaged in learning activities and experiment themselves how to, when and where to put their knowledge into practice, more sustainable results can be achieved (Chentanez et al., 2004; Deci \& Ryan, 2012). Hence, training should focus more on creating farmers' intrinsic motivation.

3. Integration. During training, farmers' current activities in the field should be considered, implying that trainings should be based on existing knowledge of the farming system. Particularly, training farmers while focusing on integrated farming is important, i.e. a farming system that integrates soil management practices with crop production, livestock production and off-farm income generation activities. Teaching and motivating farmers to develop their own solutions to problems (Blackstock et al., 2010) is crucial for integrating SLM practices into the farming system.

4. Planning. After training and learning about integrated farming, planning is crucial to empower farmers to set priorities and decide where and how to implement integrated farming practices (Van den Berg \& Jiggins, 2007). Being able to plan will make them more confident, i.e. in how to control erosion or how to respond to drought effects with their farming activities (Ward et al., 2007). When farmers are feeling confident, they take responsibility and will also plan to invest in SLM practices for the longerterm.

Table 4.1: Summary of the adapted training approach

\begin{tabular}{|c|c|c|c|}
\hline No. & Key aspects & Activities in the adapted training approach & Expected results \\
\hline 1 & Awareness & $\begin{array}{l}\text { Create awareness about natural resource } \\
\text { management, before actually planning and } \\
\text { implementing SLM practices with the mass } \\
\text { mobilization approach. }\end{array}$ & $\begin{array}{l}\text { Enhanced awareness about } \\
\text { current problems. }\end{array}$ \\
\hline 2 & Motivation & $\begin{array}{l}\text { Motivate farmers to learn and to believe that they can } \\
\text { solve their own problem by investing in SLM practices. }\end{array}$ & $\begin{array}{l}\text { Intrinsic motivation to invest in } \\
\text { SLM. }\end{array}$ \\
\hline 3 & Integration & $\begin{array}{l}\text { Train farmers in integrated farming and explain the } \\
\text { importance of integration on the farm. }\end{array}$ & $\begin{array}{l}\text { Integrated farming activities are } \\
\text { practiced on their fields. }\end{array}$ \\
\hline 4 & Planning & $\begin{array}{l}\text { Develop concrete farm plans based on farmers' } \\
\text { priority needs and capabilities to tackle identified } \\
\text { problems. }\end{array}$ & $\begin{array}{l}\text { Long-term plans with SLM } \\
\text { practices to mitigate erosion and } \\
\text { drought. }\end{array}$ \\
\hline
\end{tabular}

After developing the adapted training approach, during a two day validation training workshop with five local staff ( 2 Development Agents and 3 experts from the Girar Jarso woreda Agriculture Office), the following activities and expected results related to each of the key aspects were formulated and discussed (Table 4.1).

1. Create awareness: Awareness raising to selected farmers by the trained local staff, thereby emphasizing (a) the current and future problems of land degradation and 
drought on farming activities, and (b) the benefits of integrating SLM practices into the farm management. Aim of the training is to increase farmers' awareness, and create their readiness to change the future of their farming.

2. Motivate farmers: During awareness raising training, stimulate participatory learning between farmers, local staff and researchers, in order to make farmers more selfconfident to solve their own problems (Defoer, 2002; Van den Berg \& Jiggins, 2007). Farmers are given sufficient time to express their opinion on prevailing problems and solutions, and to better visualize the future of their farming system, aiming as such to foster their intrinsic motivation to implement and integrate SLM practices.

3. Train farmers in integrated farming: Training to enhance farmers' awareness of integrated farming and make them better understand the integration between their farming activities, which enables them to plan and practice it on their own fields. Topics of the training cover:

- Crop production: how to produce better yields by reducing erosion and using soil fertility improvement measures;

- Livestock production: how to produce more livestock products (e.g. milk), and byproducts (e.g. manure) by keeping healthy animals and collecting adequate fodder;

- Soil management: how to protect the soil and maintain its productive capacity to enhance crop production and forage production; and

- Off-farm income generating activities: how to generate income from various activities with good saving habits, allowing to further invest in soil management practices.

4. Develop farm plans: Farmers prepare an action plan based on their increased awareness of and insights in the benefits of integrated farming for the next year and coming production seasons. This plan considers existing problems and priority needs of the farm, and also covers integrated soil management practices such as stone bunds, compost, manure, improved tillage practices and agro-forestry. Making a plan contributes to developing a vision for resilient farming, and is closely related to drought and risk mitigation.

\subsection{Methodological design}

\subsubsection{Background of the study area}

The study was undertaken in the Sago-kara watershed, Central highlands of Ethiopia (Figure 4.1). The watershed covers about 355 hectare with about 340 households; and has a highly dissected, hilly and steep topography. Sago-kara watershed has a bimodal rainfall 
distribution, with the short rainy season (locally called arfasa) from March to May, and the long rainy season (locally called ganna) from June to September. The farming system is a mixed crop-livestock production system. The major crops produced are cereals, pulses, and some horticultural crops. The main livestock includes cattle, sheep, equine and poultry. However, soil erosion, low soil fertility, lack of vegetation cover, poor farm management practices and erratic rainfall have severely affected agricultural production in the Sago-kara watershed (CASCAPE, 2014; Tolossa et al., 2015). In order to tackle these problems, like elsewhere in the highlands of Ethiopia, SLM technologies have been introduced through the mass mobilization campaign. Despite widely implemented technologies such as bunds, terraces, soil moisture harvesting structures and tree planting, land degradation continues to be a serious problem to farmers living in the watershed.

Recognizing the degradation threats on agricultural production, the CASCAPE project ("Capacity building for scaling-up of evidence-based best practices in agricultural production in Ethiopia") initiated Integrated Micro-Watershed Management in the Sagokara watershed in the year 2013. CASCAPE focused on biological soil conservation measures such as planting trees, grasses and forages which were implemented to rehabilitate degraded lands, and improve vegetation cover and soil fertility.

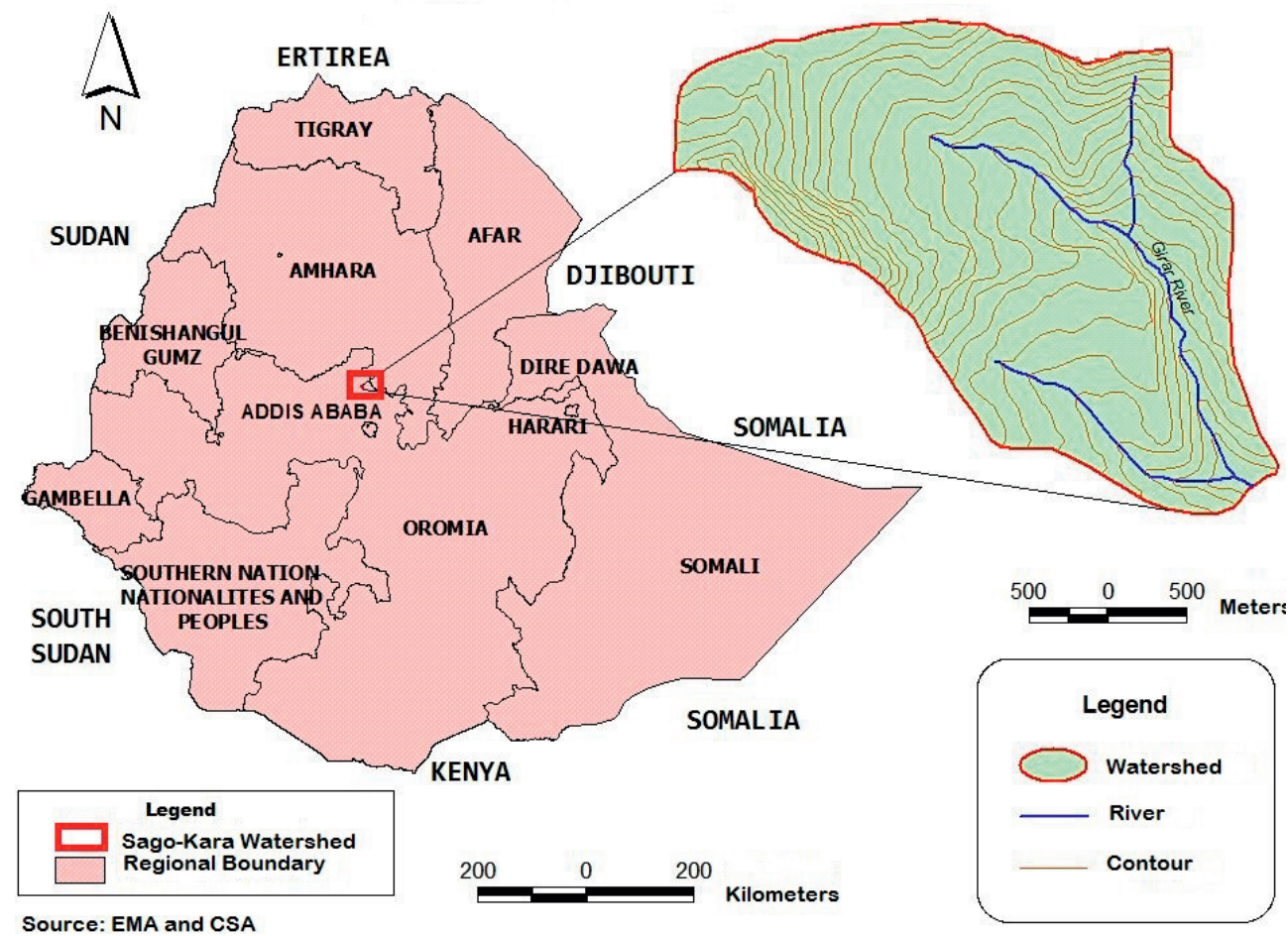

Figure 4.1 Location of the study watershed 


\subsubsection{Study design and Sampling technique}

This study was based on a controlled experimental design to analyze the effect of an adapted training approach. The Sago-kara watershed (hereafter called experimental watershed) was purposely chosen. The prevalence of severe soil degradation, its bi-modal nature of rainfall and the existing watershed management interventions (both government and project) were among the principal criteria to select the watershed. A purposive sampling technique was then used to select the farmers. Among 340 farmers living in the experimental watershed, a total of 52 farmers who had cultivated farmlands in the experimental watershed (i.e. nearby homestead areas) were selected. First, 26 farmers (hereafter called Experimental Farmers or EF) were randomly selected, and received a four days training in the field. The remaining 26 farmers, who did not receive the training, were considered as a Control Farmers (hereafter called CF). This implies that both groups of farmers were selected from the same watershed, and have similar environmental and socioeconomic conditions. The only difference is that EF received extra training during the experiment, whereas the CF were not.

\subsubsection{Method of data collection}

\section{Baseline data}

In 2015, before doing the training, we developed a baseline using group discussions with the $26 \mathrm{EF}$. The group discussions were held by using open ended questions (see Appendix 3), covering four main topics: 1) major environmental problems in the watershed, 2) existing farm management practices, 3) SLM practices implemented in the watershed, and 4) community participation in the current mass mobilization campaign. Through discussions, in depth information on awareness and knowledge of the EF on erosion problems and drought effects, their knowledge on integrated farming, their experience with SLM practices, level of farmers' participation in campaign works and their sense of ownership of SLM activities implemented on the farmlands were collected.

However, a baseline on individual characteristics and farmer' actual farming practices in the field were not collected. Given that such information is crucial to characterize farmers participating in the training, and to evaluate whether the EF and CF samples are comparable or not, we reconstructed a baseline data during the evaluation surveys (after training). Following Bamberger (2009) and Davis et al. (2012), we applied a recall technique to reconstruct baseline information. Farmers from both groups were asked to recall their social and economic situations in the year 2015, and whether they had implemented a range of soil management technologies on their farmlands or not. Since the adapted training was 
organized less than one year before, farmers had no difficulty of remembering this information.

Evaluating the effect of the adapted training

Nine months after organizing the adapted training we conducted a survey to evaluate the effects of the adapted training approach, by employing a "with-without" comparison: the EF were compared with the CF. The expected results of the training were evaluated using measurable indicators as specified in Table 4.2. For each indicator, we selected two variables to evaluate the expected results of the training. Evaluation data were collected using group discussions, field observations and household surveys. Group discussions with the EF were held using the same discussion topics as before the training. Field observations, in collaboration with local staff, were carried-out to observe EF activities in the field. Information generated through discussions and observations is used to qualitatively evaluate the performance of EF after the training.

Household surveys with the 52 farmers (both the EF and CF) were conducted to generate quantitative information. Surveys were conducted using a structured and semi-structured questionnaire. During the surveys, data related to farmers' opinions and perceptions on integrated farming and drought were collected to analyze the effect of the training intervention. Description of variables to evaluate the effect of training are also presented in Table 4.2. Among the variables included, some of the more qualitative variables ("awareness of IFM", "awareness of drought", "motivation for IFM", "motivation to tackle drought", "attitude towards IFM", "practice IFM" and "responsibility to control drought") were measured using a 5 to 10 items for Likert-type scale. Farmers responses were rated using a 3 point scales ( $1=$ No/Negative to $3=$ Yes/Positive). The "planning" variable was measured based on the values as indicated in Table 4.2. 


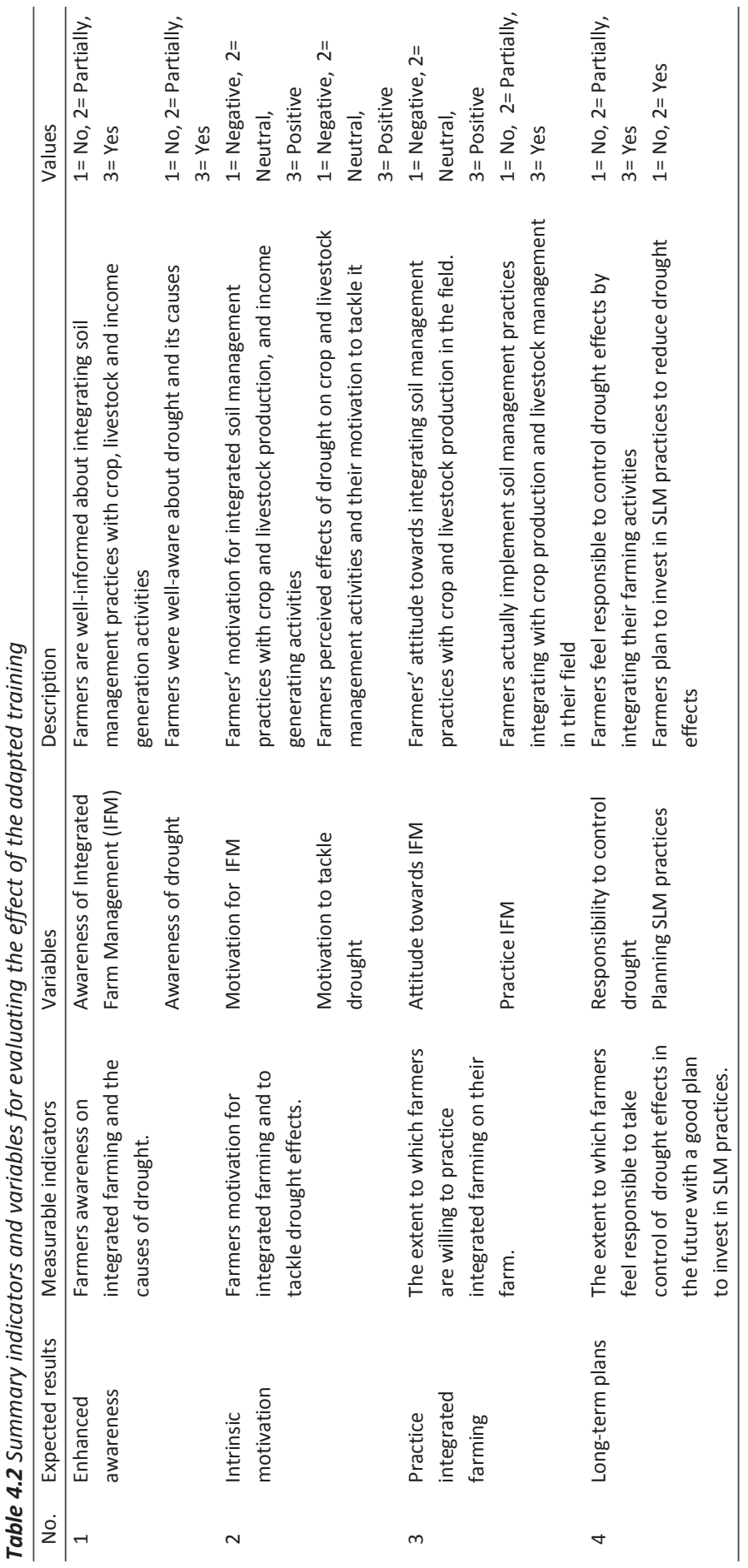




\subsubsection{Method of data analysis}

SPSS was used to process the collected data. Independent samples t-test and Pearson chisquare test were performed to compare and test the significance of the differences between the EF and CF. The significance level was tested at the $1 \%$ and $5 \%$ probability level. In the analysis, only comparable farmers from the total number of studied farmers (of both $\mathrm{EF}$ and $\mathrm{CF}$ ) were taken into account. These comparable farmers were selected based on their age. From a previous study, we learned that spontaneous farmers (i.e. farmers who adopt and implement stone bunds by their own initiative) were young farmers who have better planned their farming activities than the non-spontaneous farmers. This is because young farmers have often better education, and hence, can better plan to invest in their future even without an alternative training approach. Again, some scholars, for instance Bekele \& Drake (2003), Adimassu et al. (2012) and Moges \& Taye (2017) argue that older farmers are often discouraged to invest in conservation measures, and also often have shorter planning horizon than other farmers. Therefore, we categorized study farmers into three age groups: young farmers ( $\leq 35$ years), dulle-aged farmers (36 to 55 years) and older farmers ( $\geq 56$ years) (Tab4le3). For robustness of the training results and comparison purposes, we excluded responses of young farmers and older farmers from further analysis; including these two age categories would lead us to overestimate or underestimate the effect of the training. As shown in Table 4.3, about $77 \%$ of study farmers ( $20 \mathrm{EF}$ and $20 \mathrm{CF}$ ) were middle-aged farmers, and hence considered to analyze the training effects.

Table 4.3 Distribution of sample farmers by age groups

\begin{tabular}{lrrrrrrr}
\hline & \multicolumn{2}{c}{$\mathrm{EF}(\mathrm{N}=26)$} & \multicolumn{2}{c}{$\mathrm{CF}(\mathrm{N}=26)$} & \multicolumn{2}{c}{ Total (N=52) } \\
Age groups & $\mathrm{N}$ & $\%$ & $\mathrm{~N}$ & $\%$ & $\mathrm{~N}$ & $\%$ \\
\hline Young farmers ( $\leq 35$ years) & 5 & 19.2 & 2 & 7.7 & 7 & 13.5 \\
Middle-aged farmers (36 to 55 years) & 20 & 76.9 & 20 & 76.9 & 40 & 76.9 \\
Older farmers ( $\geq 5$ 6 years) & 1 & 3.8 & 4 & 15.4 & 5 & 9.6 \\
\hline
\end{tabular}

\subsection{Results}

\subsubsection{Baseline data}

Basic socio-economic characteristics of study farmers

Some basic characteristics of the studied farmers before the training are presented in Table 4.4. Results show that both groups of farmers are relatively similar in many of the characteristics included. However, compared to the CF, the EF were slightly younger and had a higher income from off-farm activities. This might be due to a small number of EF engaged in different income sources at the time of the survey. However, none of the variables showed statistically significant difference at $1 \%$ and $5 \%$ probability level between 
both groups of farmers. This implies that there is no significant difference between the two groups in terms of their basic characteristics, and the use of a with-without comparison approach in evaluating the effect of the adapted training approach is justified.

Table 4.4 Basic socio-economic characteristics of farmers in 2015

\begin{tabular}{llrrrrr}
\hline & & \multicolumn{2}{c}{$E F(N=20)$} & \multicolumn{3}{c}{ CF (N=20) } \\
No Variables & Values & Mean & Std. Dev & Mean & Std. Dev & t-test \\
\hline Age & \# of years & 43.90 & 6.75 & 47.60 & 5.43 & 0.064 \\
Available family labor & \# of persons & 3.40 & 1.43 & 4.20 & 1.82 & 0.131 \\
Attend formal education & 1= No, 2= Yes & 1.35 & 0.49 & 1.10 & 0.31 & 0.061 \\
Farming experience & \# of years & 23.95 & 8.56 & 26.85 & 5.26 & 0.205 \\
Farmland size & Hectare & 2.10 & 0.81 & 2.40 & 0.73 & 0.225 \\
Farm oxen & \# of ox & 1.80 & 0.52 & 1.70 & 0.87 & 0.661 \\
Crop yield produced & Quintal/year & 18.93 & 9.73 & 22.83 & 9.06 & 0.197 \\
Livestock size & TLU & 5.06 & 1.06 & 5.78 & 1.50 & 0.085 \\
Income from livestock products & Birr/year & 7590 & 2706.16 & 7412 & 3011.32 & 0.845 \\
Income from off-farm activities & Birr/year & 5425 & 2914.27 & 2980 & 1418.45 & 0.098 \\
\hline
\end{tabular}

\section{Soil management practices}

Table 4.5 compares soil management practices of the EF and CF during the 2015 production year. The statistical results show that there was no significant difference in use of soil management practices between the EF and the CF at $1 \%$ and $5 \%$ probability level before the adapted training was given. The results further show that in general, before the training, the application of these soil management technologies was quite limited among all farmers in the area. Especially the use of vegetative measures such as planting trees and grasses on farmlands was very low, which is probably related to the problem of free grazing in the area.

Table 4.5 Soil management practices used by farmers in 2015

\begin{tabular}{|c|c|c|c|c|c|}
\hline \multirow{2}{*}{$\begin{array}{l}\text { Soil management practices applied } \\
\text { (only 'Yes' responses) }\end{array}$} & \multicolumn{2}{|c|}{$E F(N=20)$} & \multicolumn{2}{|c|}{$C F(N=20)$} & \multirow{2}{*}{$\begin{array}{l}\text { Chi-square } \\
\text { test }\end{array}$} \\
\hline & $\mathrm{N}$ & $\%$ & $\mathrm{~N}$ & $\%$ & \\
\hline \multicolumn{6}{|l|}{ Chemical fertilizer } \\
\hline DAP (Di-Ammonium Phosphate) & 12 & 60 & 13 & 65 & 0.744 \\
\hline UREA (Ammonium Nitrate) & 16 & 80 & 14 & 70 & 0.465 \\
\hline \multicolumn{6}{|l|}{ Natural fertilizer } \\
\hline Compost & 13 & 65 & 8 & 40 & 0.113 \\
\hline Manure & 10 & 50 & 6 & 30 & 0.197 \\
\hline \multicolumn{6}{|l|}{ Agronomic measures } \\
\hline Crop rotation & 20 & 100 & 20 & 100 & - \\
\hline Contour ploughing & 17 & 85 & 18 & 90 & 0.633 \\
\hline Minimum cultivation & 11 & 55 & 7 & 35 & 0.204 \\
\hline \multicolumn{6}{|l|}{ Structural measures } \\
\hline Stone bunds & 9 & 45 & 7 & 35 & 0.519 \\
\hline Soil bunds & 8 & 40 & 11 & 55 & 0.342 \\
\hline \multicolumn{6}{|l|}{ Vegetative measures } \\
\hline Plant trees & 9 & 45 & 8 & 40 & 0.749 \\
\hline Plant grasses & 3 & 15 & 0 & - & 0.072 \\
\hline
\end{tabular}




\subsubsection{Results of the experiment: with-without comparison approach}

In this sub-section, the results of the experiment (the effect of the adapted training approach) are presented comparing the EF with the CF. Our focus in this study is on the results of key-aspects that together explain the intrinsic characteristics of farmers and their integrated farm management in the field. The results show that the adapted training approach has had significant effects on EF as compared to the CF, at $1 \%$ and $5 \%$ probability level for almost all indicators considered (see Table 4.6).

Table 4.6 Effects of training on EF as compared to CF

\begin{tabular}{|c|c|c|c|c|c|c|}
\hline \multirow[b]{2}{*}{ Key-aspect } & \multirow[b]{2}{*}{ Variables $=$ Effect of training } & \multicolumn{2}{|c|}{$E F(N=20)$} & \multicolumn{2}{|c|}{$C F(N=20)$} & \multirow[t]{2}{*}{ t-test } \\
\hline & & Mean & Std. Dev & Mean & Std. Dev & \\
\hline \multirow[t]{2}{*}{ Awareness } & Awareness of IFM & 2.39 & 0.50 & 1.86 & 0.38 & $0.019^{*}$ \\
\hline & Awareness of drought & 2.90 & 0.31 & 3.00 & 0.00 & 0.163 \\
\hline \multirow[t]{2}{*}{ Motivation } & Motivation for IFM & 2.60 & 0.82 & 1.55 & 0.83 & $0.000 * *$ \\
\hline & Motivation to tackle drought & 2.50 & 0.89 & 2.60 & 0.82 & 0.714 \\
\hline \multirow[t]{2}{*}{ Integration } & Attitude towards IFM & 2.65 & 0.49 & 1.95 & 0.89 & $0.004 * *$ \\
\hline & Practice IFM & 2.08 & 1.04 & 1.00 & 0.00 & $0.014^{*}$ \\
\hline \multirow[t]{2}{*}{ Planning } & Responsibility to control drought & 2.70 & 0.57 & 2.20 & 0.77 & $0.025^{*}$ \\
\hline & Planning SLM practices & 1.55 & 0.51 & 1.15 & 0.37 & $0.007 * *$ \\
\hline
\end{tabular}

**p-value significant at $1 \%$ probability level; ${ }^{*}$ p-value significant at $5 \%$ probability level

Table 4.6 shows that the training generated significant differences between the EF and CF concerning six out of the eight variables. Smallest effects are observed in the key-aspect of awareness, where only on "awareness of IFM" the EF score significantly better (2.39) compared to the CF (1.86). Consistently, EF are also significantly more motivated for IFM (2.60) as compared to the CF (1.55). For both awareness and motivation concerning drought, no significant differences were measured between both groups of farmers. This is due to the fact that the incidence of drought in Ethiopia has become a common phenomenon (Gebrehiwot et al., 2011; Viste et al., 2013), and hence, farmers can easily perceive the effect of drought on crop and livestock production, and can be motivated to tackle it.

Concerning the key-aspect on "Integration", a significant difference is found between EF and CF in terms of their attitude towards IFM (2.65 vs 1.85) and how they actually practice integrated farming in their fields (located nearby their homestead) using knowledge obtained from the training (2.08 for EF vs 1.00 for the CF). Hence, although farmers were already practicing mixed farming methods, the integration of soil management technologies (fertilizer, bunds, terraces, etc.) on their fields has significantly improved after having followed the adapted training approach. Finally, concerning "planning", the results show significant differences between the two groups of farmers in taking responsibility and how they plan to control drought effects (2.70 for EF vs 2.20 for CF). Similarly, and most 
interesting, the majority of EF (1.55) has a better future plan for their farming activities by implementing various SLM practices compared to the CF (1.15).

\subsubsection{Reflections on the learning experiment: Focus group discussions}

During group discussions held after the training, a majority of EF evaluated that the training was very good and that it gave them insights in how to visualize the future of their farming. A majority of EF (more than 70\%) believed that they have now well understood the benefits of integrating SLM practices into their farm management system, suggesting a change in mind-set. It was also clear during the group discussions that EF were more motivated to produce more quality crops by controlling their soil from erosion and using more soil fertility improvement technologies such as fertilizer, manure and compost. Furthermore, most EF had concrete plans to produce more livestock products such as milk and manure; and were motivated to protect their soil and maintain its productive capacity to increase crop production and forage production. For instance, seven of the EF (35\%) reported that they already started practicing IFM on their fields after the training. They applied fertilizer, compost and livestock manure integrated with stone/soil bunds to enhance soil productivity and yields. It was also confirmed through field observations that their existing stone bunds were better maintained. Furthermore, a large majority of EF (more than $85 \%$ ) believed that IFM is important to mitigate the effects of drought on farming activities. As a result, they became more confident in controlling erosion and mitigating drought effects on farming activities by investing in SLM practices. For the future, EF (about 55\%) planned to implement various SLM practices on their farmlands in a more integrated way: to control soil erosion, to enhance productivity and to produce more crop yields and forages for their livestock, and eventually to mitigate the effects of drought risks on their farming activities.

\subsection{Discussion}

\subsubsection{Integrated Farm Management (IFM)}

This study was designed to provide insights into farmers awareness and motivation to implement and integrate SLM practices into their farm management system, by means of an adapted mass mobilization training approach. As mentioned in the context analysis, the current mass mobilization training approach is not able to change farmers' mindset and to motivate them to apply and integrate soil conservation technologies on their own initiative on their farmlands. It was clear from the baseline data that only a small number of studied farmers actually applied structural and vegetative measures, as compared to agronomic 
measures and fertilizer use. Moreover, most of these practices were applied separately, hence not together or in an integrated way on their fields. However, an isolated implementation of these practices will not provide sustainable impacts, implying that the integration of practices is crucial (Cook et al., 2009; Kessler et al., 2016). The general information obtained through group discussions showed that EF awareness and motivation to integrate SLM practices into their farm management system improved significantly after the adapted training. Similarly, the results from the with-without comparison showed that the adapted training approach has brought significant effects on EF $(p<0.05)$, compared to CF.

This has important implications for the current mass mobilization training approach where the message communicated rarely reflects the interests of farmers (Leta et al., 2018). The awareness raising training as currently provided every other year in the mass mobilization approach (Teshome et al., 2016b; Leta et al., 2018) is not able to motivate farmers to implement SLM practices on their own initiative (Mulema et al., 2017). Involving farmers in analyzing their current situation, such as drought, soil erosion and declining productivity, is crucial to enhance their awareness and their intrinsic motivation (Hoang Fagerström et al., 2003; Smithers \& Furman, 2003; Kessler et al., 2016). In our case, intrinsic motivation was measured by the farmers' motivation for IFM. This intrinsic motivation leads to a positive attitude towards IFM and helped EF to actually practice integrated farming on their fields. This finding is consistent with Blackstock et al. (2010) who reported that providing wellreasoned and logical messages during awareness raising training is crucial in persuading farmers to adopt certain practices. Likewise, Papadopoulos et al. (2015) show that training has the ability to change farmers' attitude towards alternative forms of farming activities, such as IFM. Similar findings are also reported by Duveskog et al. (2011) in rural Kenya and by Luther et al. (2018) in Indonesia, where participation in farmer field school trainings improved knowledge of participants, and enabled them to practice more effective agricultural practices on their fields. Farmer field school is an intensive training approach introduced to transfer knowledge to farmers and assist them to learn in an informal setting within their own environment (Feder et al., 2004; Guo et al., 2015). At the beginning of this study, we hypothesized that after an adapted training, participating farmers would be more aware of the benefits of IFM and therefore more motivated to practice integrated farming in their fields. We can confirm this hypothesis; EF were more motivated to practice IFM in their fields.

\subsubsection{Drought}

Despite the fact that both the EF and CF have a quite similar awareness and perception of drought, the training has brought significant changes in terms of taking responsibility to 
control drought with their own future plan $(p<0.05)$. We found that the EF's responsibility to control the effects of drought has improved. A possible explanation is that EF were involved in action planning, and hence feel empowered to make decision themselves to solve their own problems. Involvement of farmers in action planning and learning improves their ability to take full control over the decision-making process (Kraaijvanger \& Witteveen, 2018). Certainly, participatory learning processes strengthen farmers' confidence in their own solutions (Hagmann \& Chuma, 2002; Van den Berg \& Jiggins, 2007; Ward et al., 2007) and increase their ability to choose among options and develop solutions that are appropriate for their specific ecological and socio-economic circumstances (Bewket, 2007; Douthwaite et al., 2009). Enhancing farmers self-confidence is important for sustainable development (Kessler et al., 2016), because, self-confident (self-reliant) farmers can become effective partners in development intervention (Ward et al., 2007). This implies that enhancing farmers awareness about drought and its causes, and involving them in the decision making process to take control of their own future with a good future plan, are crucial for realizing sustainable impact with the mass mobilization approach.

Another interesting finding was that EF plan to invest in SLM practices in the future aiming to mitigate the drought effects on farming activities. A possible explanation is that EF were more ready to change the future of their farm and more aware of the possible effects of drought on their farming activities, and hence more motivated to invest in SLM practices. Similarly, even though all farmers are aware of the effects of drought on their farming activities, CF did not develop plans to mitigate the future effects of drought. This illustrates the importance of raising farmers' awareness by focusing on sustainability issues and planning with a long-term vision, also during the mass mobilization training. Again, feeling able to change and control drought (empowerment) are crucial issues here. Kassie et al. (2013) indicate that participatory learning through climate school fields can improve farmers' understanding of climate variability and motivate them to change their farming activities. Similarly, Milestad \& Darnhofer (2003) indicated that learning increases the ability of a farmer to respond to change and integrate their experience in an appropriate manner. The ability of farmers to invest in SLM practices in the face of climate change is an important factor in their resilience and the sustainability of soil management interventions (Douthwaite et al., 2009; Mengistu et al., 2015; Leta et al., 2018). Investments in SLM practices improve soil moisture, reduce soil loss, reduce risk of production failures, and increase production and diversification of income sources (Schwilch et al., 2014). The results also confirmed the stated hypothesis. After an adapted training, participating farmers plan to invest more in SLM practices to mitigate drought effects in the future as compared to the CF. 


\subsection{Conclusions and recommendations}

This study investigated the effect of an adapted - more participatory and more integrated - training approach to the current mass mobilization approach with farmers living in the Sago-kara watershed, central highlands of Ethiopia. It was based on the results of an experiment, in which a group of 26 farmers received an extra training at the start of the mass mobilization campaign in 2016, to strengthen their knowledge and awareness about natural resource management, drought mitigation and integrated farm planning. Though validated in a limited area, and with a limited number of farmers, the adapted training approach shows promising results. The adapted training approach enhanced awareness of farmers, created intrinsic motivation, fostered implementation of SLM practices in the field and built responsibility in controlling erosion and reducing drought. Most interesting was that farmers who followed the training were better able to plan for drought mitigation and were more aware of the possible effects of drought on their farming activities. These results indicate the potential contribution of a more integrated and more participatory approach to the current mass mobilization approach, especially regarding the scaling-up of SLM practices and the generation of more sustainable impact.

We therefore conclude that the current mass mobilization approach in Ethiopia can significantly enhance its impact on SLM and will be more sustainable, if it would pay serious attention to four key-aspects: 1) creating awareness on the causes and effects of erosion and drought focusing on sustainability issues, 2) fostering farmers' intrinsic motivation to be good stewards of their land; 3) training in integrated farm planning, and 4) developing farm plans by farmers themselves that are based on a vision for resilient farming. Crucial for this is to make the current agricultural extension in Ethiopia more effective, by starting with capacity building of the rural extension staff in participatory training methods, and by empowering and motivating farmers for SLM. This will not only lay a foundation for sustainable agriculture and more food security on the farm, but is also crucial for the scalingup of resilient farming at watershed and landscape levels. Our recommendations for increasing the sustainable impact of the mass mobilization training approach in Ethiopia is that extension workers and government officials should: (1) train farmers in small groups to make the training more effective in terms of creating awareness and intrinsic motivation among farmers, and (2) empower them to take responsibility of controlling their own future by developing concrete farm plans.

Overall, this research addressed the effect of an adapted training strategy at the farmhousehold in the Central Highlands of Ethiopia. The study found that a more integrated and participatory training strategy is crucial to intrinsically motivate farmers to practice integrated farming and invest in SLM practices to mitigate drought effects. However, unless it is implemented at a wider geographical areas, only implementation of the adapted 
training approach at the farm-household level will not lead to the desired sustainable impact. On the other hand, although the adapted training resulted in promising results, the cost of intensive training may hamper its implementation over large areas, and the use of farmer-to-farmer knowledge spreading is therefore crucial (Feder et al., 2004; Van den Berg \& Jiggins, 2007). The next research challenge is therefore to analyze the enabling environment for scaling-up SLM in the Central Highlands of Ethiopia, and how it can support an approach as presented and discussed in this paper. 


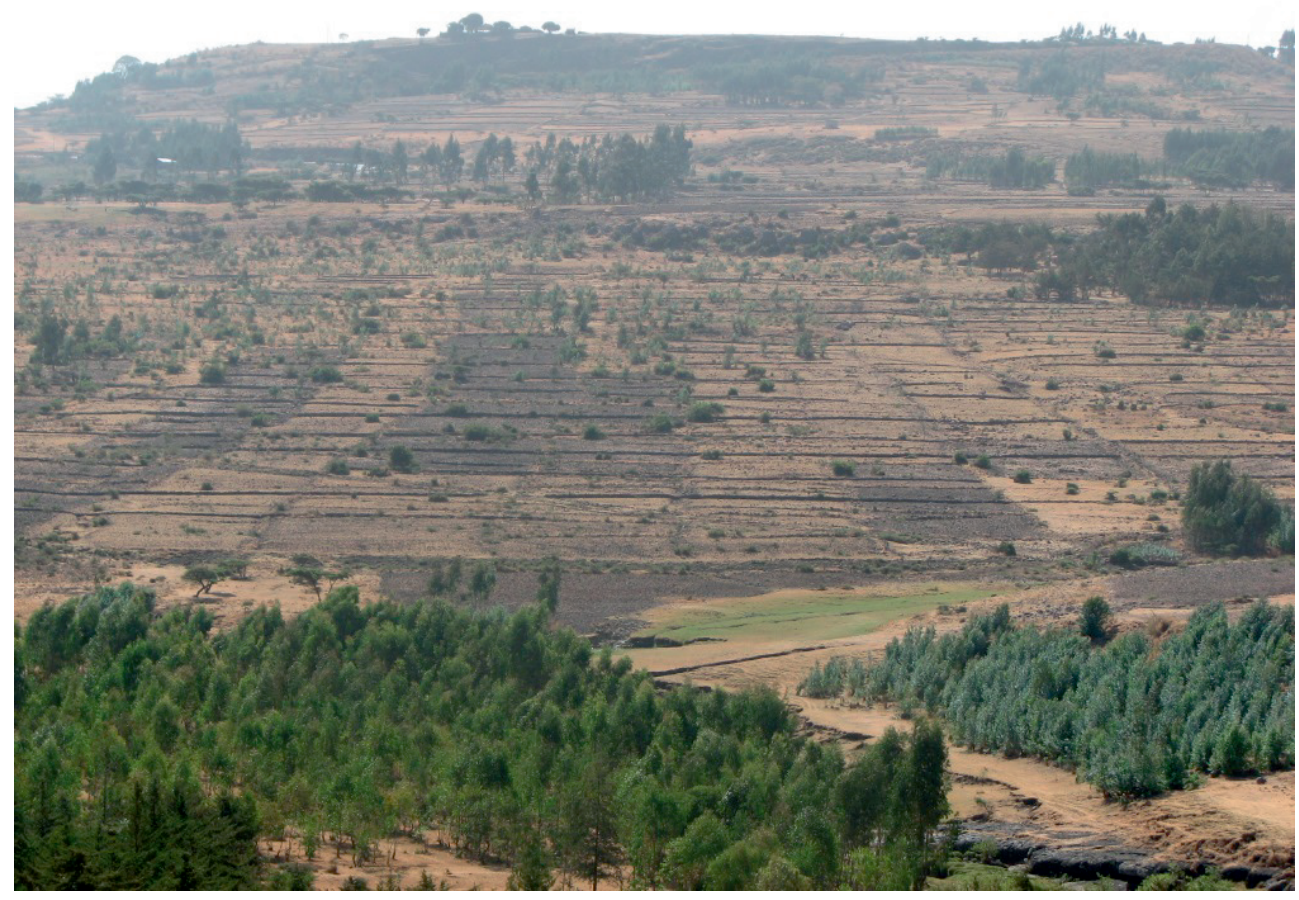




\section{Towards an enabling policy and institutional environment for scaling-up sustainable land management in the central highlands of Ethiopia}

An effective policy and institutional environment is a necessary condition for scaling-up Sustainable Land Management (SLM). This study assesses the national, regional and local level institutions influencing scaling-up SLM practices in the central highlands of Ethiopia, as perceived by key stakeholders. The qualitative data are generated through interviews with key informants and a review of relevant policy documents. The results indicate that the main perceived limitations hindering the scaling-up of SLM relate to the processes of policy formulation and implementation, the limited institutional capacity, and the lack of institutional collaboration. The findings suggest that in order to speed-up this scaling-up process, the government and other development actors should pay due attention and invest more in three core elements of the present policy and institutional environment. First, the process of policy formulation and implementation needs to be more supportive, participatory and applying a bottom-up approach. Second, the capacity of institutions requires strengthening through awareness raising, skills training and learning, as well by providing logistic facilities and adequate equipment. Third, it is important to actively foster partnerships and consolidate institutional collaboration through mainstreaming SLM in all concerned sectoral offices as well as using existing social networks and relations at community level. Finally, the government needs to rely more on voluntary policy instruments such as training, mutual learning, information exchange and creating intrinsic motivation, rather than emphasizing command and control instruments such as regulations and bylaws. When voluntary instruments are better integrated in the existing mass mobilization approach, and the coordination and collaboration across different institutional levels and sectors improved, SLM in the central highlands of Ethiopia can effectively contribute to improved soil quality and food security.

Based on:

Abi, M., Kessler, A., Oosterveer, P. \& Tolossa, D. Towards an enabling policy and institutional environment for scaling-up sustainable land management in the central highlands of Ethiopia. (submitted) 


\subsection{Introduction}

Over the last decades, Sustainable Land Management (SLM) through improved soil and water conservation has been a key strategy to increase agricultural production and achieve food security in Ethiopia (MoARD, 2010; Snyder et al., 2014; Yirga et al., 2014). In the successive Growth and Transformation Plans of Ethiopia (GTP I: covering 2010 - 2015, and GTP II: covering 2016 - 2020), SLM practices have received special attention and are expected to be implemented through community mass mobilization campaigns (FDRE, 2010, 2016; Teshome et al., 2016b; Leta et al., 2018). Mass mobilization is a strategy pursued to mobilize all farmers living in a particular watershed with the purpose of implementing SLM activities (Danano, 2010). Although aimed at scaling-up SLM practices (Nedessa et al., 2015), the mass mobilization approach has only partially achieved this objective and brought limited benefits to farmers (Ludi et al., 2013a; Wolancho, 2015). Nevertheless, scaling-up of SLM practices to achieve more benefits to farmers remains a major challenge.

Previous studies have shown that several political and institutional factors limit the effectiveness of the mass mobilization approach for this purpose. For instance, Gete et al. (2006) indicate important constraints such as a lack of awareness among policymakers about the extent and impacts of land degradation, limited availability and poor sharing of information on SLM, and institutional instability. Similarly, Yirga et al. (2014) and Nedessa et al. (2015) indicate that poor collaboration and coordination among key stakeholders, a top-down approach in planning and implementation and a limited capacity among implementing staff hinder scaling-up SLM practices. Other factors mentioned are a lack of enforcement of laws and policies, of empowering farmers to solve their own problems, and of regular follow-up and monitoring. Furthermore, inadequate attention given to locally available knowledge and social networks, and weak linkages between stakeholders in spreading SLM technology, are mentioned as well (Ludi et al., 2013a; Mulema et al., 2017; Ariti et al., 2018; Nigussie et al., 2018). Finally, the absence of an adequate enabling policy and institutional environment to shape farmers' actions, either individually or collectively, and to increase their capacity to invest in SLM practices is hindering the effective implementation and scaling-up of SLM in Ethiopia (Adimassu et al., 2016).

Given the importance of creating such an enabling environment (Franzel et al., 2004; Tukahirwa et al., 2013b; Kessler et al., 2016), this study aims to further our knowledge on the limitations at institutional and policy level in Ethiopia. The study starts by analyzing the existing institutional and policy environment with respect to the implementation of SLM in the central highlands of Ethiopia and then reviews in what way this environment would need to change to facilitate scaling-up SLM using the mass mobilization approach. Hereby we distinguish between three institutional levels (local, regional and national level), in order 
to help understand where to start when aiming for more sustainable and large-scale impact. The main research question is therefore: "what changes are required in the policy and institutional environment of Ethiopia to enable the scaling-up of SLM practices using the mass mobilization approach?". To answer this question, we provide in the next section an overview of the current policies and institutional arrangements relevant for SLM, followed by an introduction to and explanation of the theoretical and conceptual frameworks applied in this study in section three. The methodology of this study is explained in section four and the findings in section five. The paper concludes with section six in which we formulate conclusions and recommendations.

\subsection{Main policies and institutional arrangements for SLM in Ethiopia}

The Government of Ethiopia has developed a wide range of policies, strategies, legal frameworks and proclamations to address environmental problems relevant for the promotion and implementation of SLM practices in recent years. Table 5.1 shows the major policies, strategies, proclamations and legal frameworks important for SLM. In order to put these policies and strategies into practice, different institutions have been established at the national, regional and local level (Getenet \& Tefera, 2017). The institutional arrangements and organizational structures for the implementation of SLM are created in line with the decentralization and regionalization policy of the Ethiopian government (Haregeweyn et al., 2012; MoA, 2014). To this end, a multi-sectoral institutional arrangement has been established at national, regional and local levels leading to support the scaling-up of SLM through the mass mobilization approach (Danano, 2010; Haregeweyn et al., 2012; Wolancho, 2015; Teshome et al., 2016b).

National institutions include government organizations working at the federal level. These institutions are responsible for formulating the policies and strategies related to land management, strengthening the capacity of the regional and local level institutions, developing extension strategies, providing financial support to strengthen the capacity of the regional and local level institutions, planning SLM activities, and facilitating monitoring and evaluation of implemented practices at the national level (MoA, 2014). The Ministry of Agriculture and Natural Resources plays a leading role in the coordination of SLM activities at national level (MoARD, 2010; Haregeweyn et al., 2012; Adego et al., 2018). Regional level institutions (in our case in the Oromia region) support the mass mobilization through building the capacity of local level institutions, providing material and financial support, facilitating the technical and practical training manuals, planning SLM at the regional level and facilitating the monitoring and evaluation of the local level implementation of SLM (MoA, 2014). The regional Bureaus of Agriculture and Natural Resources are responsible for the coordination of SLM activities. 
Local institutions include organizations working at the woreda (similar to district, an official administrative unit) and kebele (similar to ward, the lowest official administrative unit) level (Haregeweyn et al., 2012; Wolancho, 2015; Getenet \& Tefera, 2017). These institutions support scaling-up SLM practices through selecting watersheds, mobilizing the community resources (labor), organizing farmers in groups, providing training, technical support and working materials, assisting in planning and implementing SLM practices, and monitoring activities at the watershed level (MoA, 2014). At this administrative level, the woreda Agriculture and Natural Resource Offices are responsible for coordinating and organizing the planning and implementation of SLM (Haregeweyn et al., 2012). The farmers' development groups (comprising 20 to 30 members) are key actors at local level. Through these farmers' development groups, farmers are working together to achieve better results and foster the scaling-up of SLM (Tukahirwa et al., 2013b; Yirga et al., 2014). Through the creation of 'one-to-five' groups (groups of five farmers living and working in the same area with one farmer leading the group) (Teshome et al., 2016b; Nigussie et al., 2018), these farmers' development groups are crucial in transferring the knowledge on SLM practices among farmers (Danano, 2010; Snyder et al., 2014; Adego et al., 2018).

Table 5.1 Policies, strategies, proclamations and frameworks related to SLM in Ethiopia

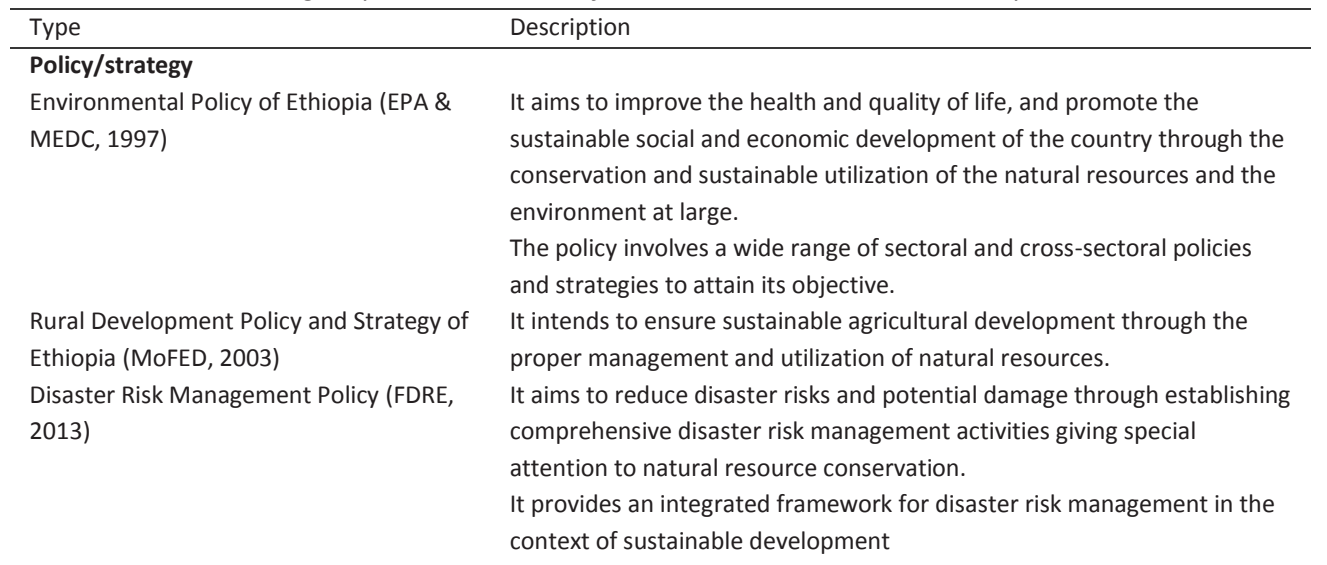

\section{Proclamation}

The Federal Rural Land Administration and Use Proclamation (FDRE, 2005)

\section{Framework}

The Ethiopian Strategic Investment Framework for SLM (MoARD, 2010)

It places the responsibility and obligation to maintain the productivity of the land on the community.

The proclamation 465/2005 states that "A land user will not have the right to use the land if he fails to apply conservation measures on the land or lets the land to degrade and loose its productivity"

It aims to improve the livelihood and economic well-being of the country's populations by scaling-up SLM practices with proven potential to restore, sustain and enhance the productivity of agricultural lands. It guides the prioritization, planning and implementation of current and future investments in SLM. 


\subsection{Theoretical and conceptual frameworks}

\subsubsection{Theoretical framework}

Institutions are "the rules of the game in a society, or more formally, humanly formulated constructs that shape the social and individual interactions and behavior" (North, 1990). Similarly, Ostrom (1992) defines institutions as the set of rules actually used (the working rules or rules in use) by a group of individuals to organize actions that produce sustainable outcomes affecting those individuals and others. Working rules are those rules actually used, monitored and enforced when individuals make their own or collective choices (Ostrom, 1992). Such rules can be formal (e.g. laws, policies and regulations) and informal (e.g. behavioral norms) (Imperial, 1999). Hence, both formal and informal institutions exist and both play an important role in shaping the management of natural resources and in providing the norms and values that support policy decisions and management practices related to SLM (Hillman \& Howitt, 2008; Pahl-Wostl, 2009). Analyzing formal and informal institutions is important when trying to understand why everyday social activities are organized in a particular way, because paying attention only to formal institutions fails to comprehend daily reality. Policies are important, but it is critical as well to analyze how they are implemented in practice. In this study, we analyze the policies and institutions relevant for the planning, implementation and scaling-up of SLM, in order to determine by what formal rules (laws, policies, regulations) and informal rules (behavioral, social and cultural norms) they are guided.

To be effective in contributing to the scaling-up of SLM, institutions need to have the required capacity. Institutional capacity refers to the effectiveness and efficiency of formal institutions in implementing their goals (Pahl-Wostl, 2009). The institutional capacity for scaling-up SLM relates to knowledge of staff on SLM in terms of effective practices and costs and benefits, and to the human and material resources available for implementing the assigned tasks (Hillman \& Howitt, 2008). Next, as explained, different institutions are involved in organizing and implementing SLM practices and therefore collaboration between them is vital. In institutional theory, institutional collaboration (i.e. understanding the collaborative relationships between and among different institutions and with their environment (Wood \& Gray, 1991)) involves institutionalizing some form of structure and organizing shared and individualized responsibilities among the different institutions involved (Wood \& Gray, 1991; Phillips et al., 2000). Institutional collaboration is crucial for successful implementation and scaling-up of SLM (Kessler, 2008) because it facilitates mobilizing resources such as labor, materials, finances and information, and advances their effective implementation (Adimassu et al., 2013). In the case of SLM, institutional collaboration entails the harmonization between multiple activities that could not be achieved when each institution would work independently (Adimassu et al., 2013). 
However, collaboration between different formal institutions is difficult without the sharing of information and responsibility and without mutual trust (North, 1990; Wood \& Gray, 1991; Kessler, 2008). Involving the relevant institutions in policy formulation and in its implementation is therefore crucial.

Selecting the correct policy instruments during the process of policy formulation and implementation is also critical (Roseland, 2000; Borrás \& Edquist, 2013). Such a selection should be based on the effectiveness of the policy instrument, its monitoring and enforcement capacity, as well as its dissemination effect and conformity with other policies and political preferences (Shiferaw \& Holden, 2000). A wide variety of possible policy instruments is available and can be categorized as regulatory, economic and voluntary instruments (Roseland, 2000; Shiferaw \& Holden, 2000; Pregernig, 2001; Cocklin et al., 2007). Regulatory policy tools are generally government-initiated legal instruments (e.g. laws, regulations and bylaws) and use a command-and-control approach, which means that they prescribe a particular behavior and use legal instruments (fines, etc.) to secure their implementation ('sticks'). Economic policy instruments make use of monetary incentives, such as subsidies and tax reductions to encourage a particular behavior ('carrots'). Voluntary instruments (also called informative policy instruments) involve training, exchange of information and persuasion ('sermons') (Pregernig, 2001; Cocklin et al., 2007; Borrás \& Edquist, 2013). Over time, many countries have witnessed a shift in the use of these different categories away from regulatory (command-and-control) towards the use of economic and voluntary instruments. In this study, we use this differentiation in policy instruments to assess whether the same trend is also occurring in Ethiopia with respect to the scaling-up of SLM. It may be expected that the use of economic and voluntary instruments in this policy and institutional environment offer better opportunities to engage farmers actively in this process.

\subsubsection{Conceptual framework}

Figure 5.1 presents the conceptual framework that underpins this study. The framework is developed to identify the characteristics of the policy and institutional environment in Ethiopia with respect to the process of horizontal and vertical scaling-up of SLM. An enabling environment involves a combination of interrelated political, institutional, financial, economic and environmental conditions (Akhtar-Schuster et al., 2011; Amjad et al., 2015). In the context of this study, an enabling environment consists of the political and institutional conditions that encourage more farmers to invest in SLM practices and speedup their spreading over a wider geographical area. 


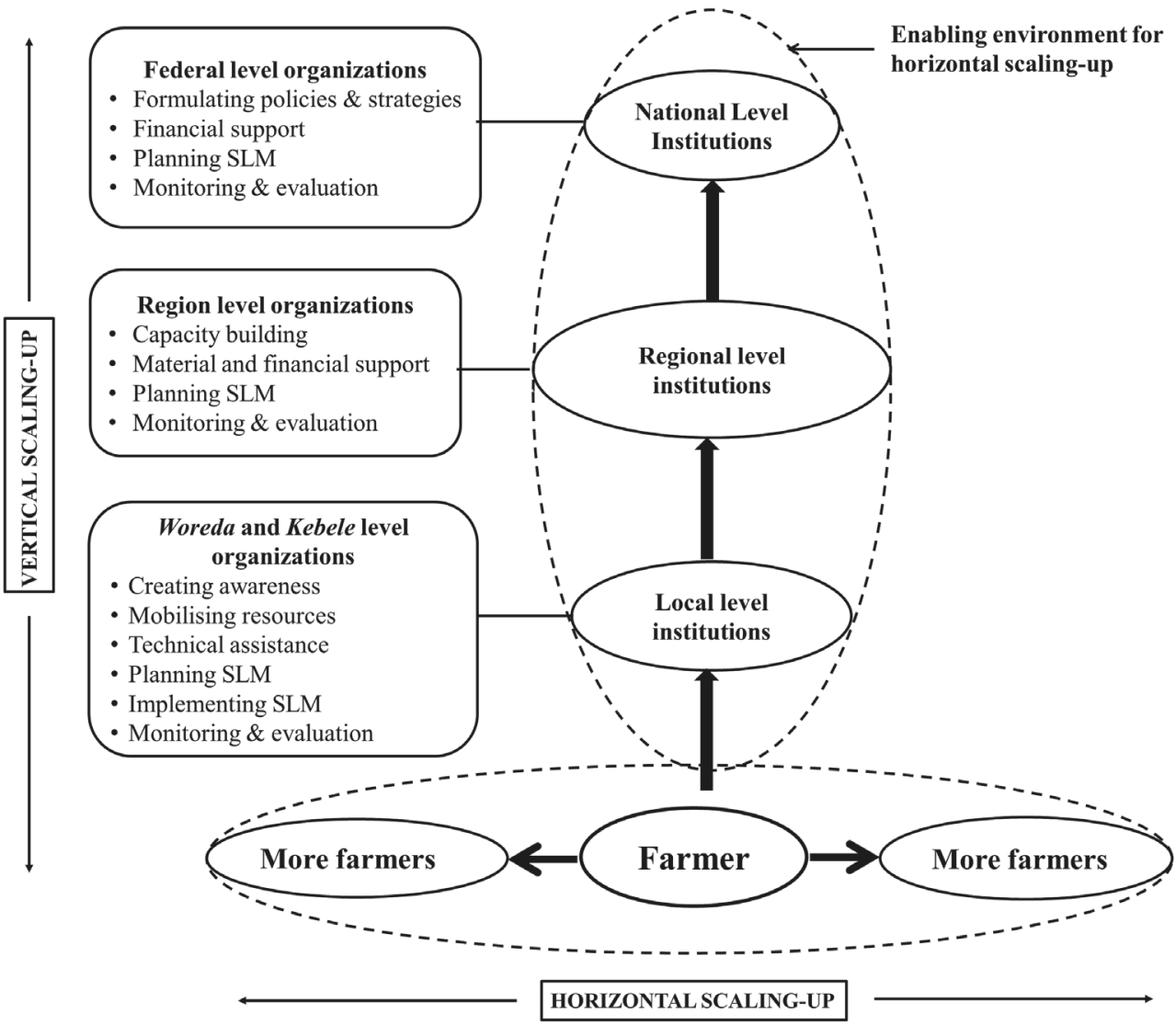

Figure 5.1 Conceptual framework of the enabling environment for the horizontal and vertical scaling-up of SLM considering three institutional levels in Ethiopia (adapted from IIRR (2000) and (Gündel et al., 2001)).

In Ethiopia, scaling-up of SLM practices to reach large number of farmers is undertaken through 1) the mass mobilization approach, and 2) regular extension services (Nedessa et al., 2015). In this paper, we focus on the first strategy. Vertical and horizontal scaling-up are used because both are important. Horizontal scaling-up involves the geographical spreading of SLM practices to reach large numbers of farmers, whereas vertical scaling-up involves the coordination between different institutional levels and policy departments to establish a coherent and conducive environment (IIRR, 2000; Gündel et al., 2001; Franzel et al., 2004). In this study, the enabling environment is differentiated into three institutional levels (local, regional and national level) to help understand the role and responsibilities of the institutional hierarchy for the horizontal spreading of SLM practices. As shown in Figure 5.1, national level institutions are responsible for formulating policies and strategies for SLM, providing financial support, planning the national SLM strategy, and for monitoring and evaluating SLM activities implemented at the local level. Regional level institutions are 
responsible for building the capacity of local institutions, providing material and financial support, and for planning, monitoring and evaluating SLM. Local level institutions are responsible for creating awareness, mobilizing resources, providing technical assistance, planning SLM at the local level, and for implementing, monitoring and evaluating SLM.

\subsection{Methodology}

\subsubsection{Study context}

This study builds on previous research in the Sago-kara watershed, central highlands of Ethiopia (Abi et al., 2018a). The watershed is located in Torban-Ashe kebele of Girar Jarso woreda, and covers about 355 hectare with about 340 households and has a highly dissected and hilly topography. The primary economic activity of the farmers in the watershed is mixed agriculture consisting of crop and livestock production. This agricultural production is mainly rain fed, and severely affected by soil erosion, low soil fertility, lack of vegetation cover and poor farm management practices (Tolossa et al., 2015). In order to tackle these problems, like elsewhere in the highlands of Ethiopia, SLM technologies such as bunds, terraces, soil moisture harvesting structures and tree planting have been implemented through the mass mobilization approach. Despite the implementation of these technologies, land degradation persists and continues to be a serious problem in the watershed undermining the production capacity of farmers.

\subsubsection{Methods of data collection}

Interviews with policy makers and implementers at the three institutional levels were carried out to assess the policy and institutional environment for scaling-up SLM through the mass mobilization approach. We selected 30 key informants ( 5 from national level institutions, 8 from regional level institutions, and 17 from local level institutions). Table 5.2 presents an overview of the interviewed informants and the institution they represented. These interviewees were selected on the basis of their position in the institutions at the time of the interview. Representatives from the higher-level institutions (national and regional) were selected based on their experience with SLM. Interviews were carried out between April and May 2017 using an open-ended interview method to allow for in-depth engagement with their particular professional capacity. Our questions focused on three core issues: (1) institutional capacity, (2) institutional collaboration, and (3) the process of policy formulation and implementation (see Appendix 4). Based on these three core issues, 
all informants were asked to identify, in their perspective, the most important limitations for national, regional and local institutions for scaling-up SLM.

\subsubsection{Methods of data analysis}

Qualitative content analysis was used to analyze the data from the interviews and document reviews. This method is considered most appropriate to analyze qualitative data for institutional analysis (Alexiadou, 2001; Mwangi \& Bettencourt, 2017; Nigussie et al., 2018).

Table 5.2 Description of key informants from different institutional level

\begin{tabular}{|c|c|c|}
\hline Level & Description & Sample size \\
\hline \multirow[t]{5}{*}{ National } & Representative from Ministry of Agriculture and Natural resource & 1 \\
\hline & Representative from Ministry of Finance and Economic Development & 1 \\
\hline & Representative from Ministry of Livestock and Fishery & 1 \\
\hline & Representative from Federal Rural Land Administration and Utilization & 1 \\
\hline & Representative from the National Sustainable Land Management program & 1 \\
\hline \multirow[t]{7}{*}{ Regional } & Representative from Oromia Bureau of Finance and Economic Development & 1 \\
\hline & Representative from Oromia Bureau of Agriculture and Natural Resource & 1 \\
\hline & Representative from Oromia Bureau of Livestock and Fishery & 1 \\
\hline & Representative from Oromia Bureau of Rural Land Administration and Utilization & 1 \\
\hline & Experts from Oromia Bureau of Agriculture and Natural Resource & 2 \\
\hline & Experts from Oromia Bureau of Livestock and Fishery & 1 \\
\hline & Coordinator of the Oromia region Sustainable Land Management program & 1 \\
\hline \multirow[t]{12}{*}{ Local } & Official from Girar Jarso woreda Administration & 1 \\
\hline & Official from Girar Jarso woreda Finance and Economic Development Office & 1 \\
\hline & Official from Girar Jarso woreda Agriculture and Natural Resource Office & 1 \\
\hline & Official from Girar Jarso woreda Livestock and Fishery Office & 1 \\
\hline & Official from Girar Jarso woreda Land Use and Administration Office & 1 \\
\hline & Experts from Girar Jarso woreda Agriculture and Natural Resource Office & 2 \\
\hline & Expert from Girar Jarso woreda Livestock and Fishery Office & 1 \\
\hline & Expert from Girar Jarso woreda Land Use and Administration Office & 1 \\
\hline & Torban-Ashe kebele Administrator & 1 \\
\hline & Development Agents from Torban-Ashe kebele & 3 \\
\hline & Representative from Sago-Kara watershed management committee & 1 \\
\hline & Representatives from farmers development groups in the Sago-Kara watershed & 3 \\
\hline \multicolumn{2}{|c|}{ Total sample size } & 30 \\
\hline
\end{tabular}

\subsection{Results and discussion}

This section is divided into two subsections. The first subsection explains the most important limitations at the three institutional levels for scaling-up SLM through the mass mobilization approach, as perceived by the key informants. The second subsection discusses 
the policy and institutional changes required to speed-up the scaling-up process and to make the mass mobilization approach more effective.

\subsubsection{Limitations for scaling-up SLM practices}

\section{National level}

\section{a) Limited knowledge on SLM among decision-makers}

This study found a lack of knowledge on SLM practices among decision-makers at the national level institutions. From the five informants interviewed at this level, only two responded correctly when asked to explain SLM and its benefits. Most informants relate SLM with a particular type of soil conservation measures such as bunds and planting trees, mainly useful to reduce soil erosion. However, SLM is broader and includes multiple technologies suitable for the improvement or maintenance of the productive capacity of agricultural land (Hurni, 2000; Dumanski \& Peiretti, 2013), such as soil conservation, soil fertility management, conservation agriculture and irrigation development (Dumanski \& Peiretti, 2013). Besides, the Ministry of Agriculture has documented SLM technologies and approaches (both recently introduced and traditional) applied in Ethiopia (Danano, 2010) that are accessible also for decision-makers involved in SLM decision-making. However, most interviewees were not aware of this, which limits their ability to make informed decisions with respect to scaling-up SLM practices. From this result, we conclude that the emphasis put on the implementation of physical soil conservation measures through the mass mobilization approach is due to the limited knowledge on SLM among decisionmakers.

\section{b) Poor coordination and integration between and among sectors in scaling-up SLM}

The government of Ethiopia has established a multi-sectoral institutional arrangement to coordinate and implement SLM activities through mass mobilization (Wolancho, 2015; Teshome et al., 2016b). However, the interview results show that the coordination and integration between the different sectors (e.g. agriculture, livestock, finance and land administration) with respect to SLM is not very effective. This poor coordination and integration seems to be due to each sector following a 'disciplinary' approach, whereas, the implementation and scaling-up of SLM requires a more interdisciplinary and integrated approach (Gete et al., 2006). Snyder et al. (2014) and Getenet \& Tefera (2017) also report that coordination between the government agencies for natural resource management in Ethiopia does not exist. This makes it difficult to integrate different sources of knowledge and exchange information on scaling-up of SLM practices. Likewise, the lack of coordination hinders the sharing of responsibilities, which in turn, causes duplication of efforts and 
conflicting approaches when implementing and scaling-up SLM practices (Nedessa et al., 2015).

c) Use of a top-down policy formulation and implementation approach by decision-makers Despite policy documents claiming that the current natural resource conservation strategy in Ethiopia follows a bottom-up approach, in practice the process of policy formulation and implementation for SLM is still primarily top-down (Cullen et al., 2014; Ariti et al., 2018). This was recognized by the key informants at national level involved in this study, given that a majority of them identified the use of a top-down approach to policy formulation and implementation as a limitation for the national level institutions to engage in scaling-up SLM practices. They also recognized that such top-down approaches hindered achieving more sustainable impacts in enhancing food security and improving natural resource management. This result is in line with Bewket (2007), Snyder et al. (2014), Mulema et al. (2017) and Moges \& Taye (2017) who report that soil and water conservation planning and implementation policies in Ethiopia follow a conventional top-down approach.

\section{Regional level}

\section{a) Poor communication and learning between local farmers and professionals}

Regular communication between key stakeholders and common learning activities are important in sharing knowledge and building capacity to effectively implement and scaleup SLM (Gündel et al., 2001; Franzel et al., 2004; Carter \& Currie-Alder, 2006). However, the majority of our key informants at the regional level confirmed that communication was poor and that learning between farmers and professionals was lacking. Poor communication limits the flow of information and learning between the regional and local level institutions. Consistently, Gete et al. (2006) indicate that the lack of a suitable forum in Ethiopia to share information and communication hinders the scaling-up process.

\section{b) Use of a top-down planning and monitoring approach of SLM}

Similar to the national level, interview results show that a top-down planning and monitoring approach to technical assistance is common also at the regional level. The Oromia Bureau of Agriculture facilitates the development of training materials and manuals before the commencement of the mass mobilization. Skills training provided to officials and extension workers and farmers at the local level relies on these materials and manuals (Leta et al., 2018). Similarly, plans for scaling-up SLM practices are developed at the regional level, based on the records of previous year's achievements (from the woreda reports). For instance, kebele DAs explained, "We prepare our kebele plan every other year. But, we implement what is already planned at the Oromia Bureau of Agriculture and Natural Resource". This indicates that the process of planning SLM activities still follows a top-down approach, without involving farmers and considering the reality at the local level. 
Local level

a) Limited capacity of extension workers and officials to transfer knowledge on SLM

Despite the increased commitment by the Ethiopian government to build the capacity of extension workers and officials to support natural resource conservation activities (Getenet \& Tefera, 2017; Leta et al., 2018), the majority of our informants observed that the capacity of extension workers and officials to transfer knowledge about planning and implementing SLM practices to farmers is still limited. For instance, a key informant from the kebele administration noted, "Though training on soil and water conservation is given every other year, increasing knowledge of farmers on how to plan and implement SLM practices on their own fields is lacking". This is because the limited capacity in terms of skills, workforce, budget, equipment and facilities makes it difficult to provide adequate support (e.g. technical advice), and transfer knowledge on available SLM technologies to farmers. Knowledge on SLM implies more than an understanding of SLM practices alone, and also involves how to implement such practices and what (related to the benefits for farmers) these can achieve when implemented in the field (Meijer et al., 2015).

\section{b) Staff turnover}

Staff turnover, the replacement of trained and professional staff working on SLM activities by new staff (Adimassu et al., 2013), is high at the local level. The majority of our informants responded that this was an important limitation for local level institutions with respect to the scaling-up of SLM practices. High staff turnover results in a shortage of qualified staff (with the necessary scientific and technical knowledge and familiar with the local context), which in turn limits the transfer of knowledge on SLM practices and the regular supervision and monitoring of implemented practices. Likewise, high staff turnover undermines the coordination and facilitation of the scaling-up process at the local level.

\section{c) Limited use of existing social networks in the scaling-up process}

The majority of our informants identified that the use of existing networks such as farmer groups and community-based organizations when aiming for scaling-up SLM is limited. Explaining how the existing social networks were not well involved in this process, a key informant from a local institution responded, "although development groups were formed to share experiences about their farming practices, learn from each other and take collective action in soil conservation activities, they rather serve to fine farmers and resolve conflicts that arise in the community". However, social networks may be very effective in improving the flow of information (e.g. about new technologies and their benefits) in a community (Wossena et al., 2013). According to Tukahirwa et al. (2013a), social networks at the local level are crucial to share information between farmers and transfer knowledge on SLM practices. This was also observed in a previous study in the Girar Jarso woreda (Abi et al., 
2018c), where we found that farmers who spontaneously implement stone bunds on their farmlands learn this mainly from their neighboring farmers (through their social networks).

d) Lack of considering farmers' knowledge and priority needs when planning SLM practices The results show that farmers' indigenous knowledge and their priorities are generally not considered during the planning phase of SLM activities. A possible explanation is that a topdown SLM planning and implementation approach still persists at the local institutional level as well, and that farmers are not involved in the decision-making process. When clarifying how the current planning method of scaling-up SLM overlooked farmers, a farmer group representative explained, "Every other year, farmers are mobilized to contribute labor to construct bunds and plant trees in the already identified watershed, but they rarely participate in the selection of the watershed and technologies implemented". A limited participation of farmers in planning SLM practices affects their sense of ownership of the implemented technologies (Ludi et al., 2013a; Ariti et al., 2018). The lack of farmers' involvement in the planning of SLM activities has important implications for the maintenance of implemented SLM technologies in the field. In a recent study conducted in the central highlands of Ethiopia, Abi et al. (2018c) reported that stone bunds implemented through mass mobilization were not well-maintained, and that some of them were broken or even destroyed.

Despite the perceived limitations with respect to scaling-up SLM practices through the mass mobilization approach as presented above, there are different opportunities for more effective implementation and scaling-up in the central highlands of Ethiopia. First, the existence of environmental policies and strategies in the country is a key opportunity to improve policy formulation and implementation on SLM. The national environmental policy promotes the active participation of all concerned stakeholders during the planning, implementation and monitoring stages of SLM practices (EPA \& MEDC, 1997). Second, the national strategic planning framework offers an opportunity for scaling-up (MoARD, 2010). The framework sets out a strategy for scaling-up SLM practices, guides the prioritization, planning and implementation of current and future investments in SLM, and advocates for coordination of efforts and harmonization of approaches. Third, the existing structure of public institutions offers the opportunity to foster institutional collaboration for scaling-up. For instance, the organizational set-up of the Ministry of Agriculture and Natural Resources, from the federal to local level, has the potential of implementing and scaling-up SLM in different parts of the country (Gete et al., 2006; MoA, 2014). Fourth, SLM steering committees and technical committees at all institutional levels are an opportunity for networking and building institutional collaboration over larger areas. It brings together different stakeholders and actors to exchange knowledge, increase flows of information and expertise, and mobilize resources and capacity for scaling-up SLM practices (Cullen et al., 2014; Yirga et al., 2014). Fifth and finally, the experiences from our previous study in the 
Sago-Kara watershed (Abi et al., 2018a) provide an opportunity for scaling-up SLM through a more effective and integrated mass mobilization approach in Ethiopia. With rather small changes, such as an adapted training at the start of a mass mobilization campaign in a watershed, farmers' knowledge and awareness about natural resource management can be quickly enhanced. The key issue here is to pay more specific attention to awareness creation, the generation of intrinsic motivation of farmers to invest in SLM and to build capacities to foster implementation of SLM practices in the field. Similar experiences e.g. from central Zimbabwe (Nyagumbo et al., 2011) show that a participatory approach empowers farmers and enhances their willingness to invest in SLM. Empowering farmers improves knowledge exchange, competitiveness and self-confidence. Similar findings are reported by Kessler et al. (2016) in Burundi, where an integrated approach resulted in significant impacts in scaling-up sustainable agricultural practices, particularly through integrated soil fertility management. In such an integrated approach, learning, vision building, integrated farm planning and scaling-up of intrinsic motivation and capacity to invest in SLM practices are transferred (Kessler et al., 2016).

In conclusion, the potential for scaling-up and effective implementation of SLM practices through mass mobilization is present in Ethiopia. However, exploiting these opportunities requires certain effective changes in the policy and institutional environments, as discussed in the following sub-section.

\subsubsection{Changes required at the policy and institutional level: building an enabling environment}

\section{Policies}

On the basis of the results presented in subsection 5.5.1, we can suggest that the process of planning, implementing and monitoring of scaling-up SLM practices should be more participatory and bottom-up. A key informant from the local level institution also suggested this: "participation of farmers in mass mobilization should not only be limited to labor contribution for implementation of soil conservation activities: Farmers need to plan and monitor these activities together with DAs and experts". This implies that it is not enough that farmers only participate in the implementation of SLM activities during mass mobilization, but that involving them also in the planning and monitoring processes is required. This is crucial for effective implementation of SLM practices, and developing a sense of ownership of the implemented practices (Millar \& Connell, 2010). Consistently, Bewket (2007), Cullen et al. (2014) and Adego et al. (2018) suggest the need for a participatory and bottom-up approach in the planning and implementation of SLM practices in Ethiopia. In such an approach, the planning process starts with the identification of existing problems and selecting appropriate technologies together with farmers (Ariti et al., 
2018). This empowers farmers to take a leading role in the scaling-up and decision-making process (Hellin \& Schrader, 2003; Abi et al., 2018b). Furthermore, supportive policies and regulations are required to ensure large-scale planning, implementation and monitoring of SLM practices during the mass mobilization approach.

Policy support may contribute through providing agricultural extension services (e.g. training, inputs and credit services) and building infrastructure (e.g. roads, electricity and communication services) to create an enabling institutional environment (Kuyvenhoven, 2004). Agricultural extension services are the major sources of information for scaling-up SLM in the field (Nedessa et al., 2015). It helps to improve farmers' motivation to engage in these activities (Wossena et al., 2013), and to increase their capacity to invest in them (Adimassu et al., 2016). Consistently, Abi et al. (2018b) report that farmers who obtained adequate support from extension workers spontaneously implement and integrate SLM practices on their farmlands. Building a good material infrastructure is important to strengthen social integration and networks and to facilitate communication between farmers, officials and professionals (Binswanger \& Aiyar, 2003; Kuyvenhoven, 2004). An informant from the woreda administration noted, "Constructing weather-roads and connecting all kebeles will enable extension workers and officials to transport working materials or equipment to all working sites during campaign works, and to undertake frequent monitoring and supervision of implemented activities".

Implementing existing bylaws (regulations) is required to improve the institutional environment. Bylaws serve to prevent and manage conflicts within the community (Sanginga et al., 2010), and to protect implemented SLM practices (Teshome et al., 2016b). They also facilitate addressing specific problems at the community level (Sanginga et al., 2010), and motivate community members to participate and work together in the formulation and implementation of SLM practices (Yirga et al., 2014; Leta et al., 2018). This implies that using a mix of voluntary instruments (learning, skills training, information exchange, etc.) next to the wise use of regulatory instruments (legislation and bylaws) is crucial to speed-up the scaling-up of SLM practices in Ethiopia. Mutual learning, skills training and information exchange are effective policy instruments for motivating large numbers of farmers to participate in the implementation and scaling-up of SLM practices (Pinto-Correia et al., 2006; Greiner \& Gregg, 2011; Ashoori et al., 2017). Still, legislation and bylaws remain important to protect and manage implemented SLM practices in the field (Teshome et al., 2016b). 


\section{Institutions}

With respect to institutions, the main suggestions to address the limitations identified in section 5.5.1 include building capacity and strengthening collaboration and networking.

\section{a) Building capacity}

Scaling-up SLM practices requires adequate institutional and human capacities, as well as learning through skills training, communication and sharing of experiences (Noordin et al., 2001; Franzel et al., 2004; Tukahirwa et al., 2013b). So, strengthening institutional capacity at all levels is important (Millar \& Connell, 2010; Amjad et al., 2015; Thomas et al., 2018). This starts by creating awareness about the importance of SLM (e.g. on agricultural production and food security) through learning and education. Increasing awareness of the causes and effects of the current problems (e.g. land degradation and climatic variability) and the benefits of implementing SLM practices to tackle these problems is crucial (Kessler, 2008; Abi et al., 2018a). Besides, sharing knowledge and information among concerned stakeholders is necessary to make effective decisions (Franzel et al., 2004; Carter \& CurrieAlder, 2006; Mulema et al., 2017).

Building the capacity of extension workers and government officials with respect to communication, collaboration and learning is important (Carter \& Currie-Alder, 2006; Tukahirwa et al., 2013b). At the local level, this was seen as the main limitation for scalingup SLM practices. To address this limitation, institutional capacity building activities focusing on improving the professional (skills and knowledge of the existing staff) and operational capacity (staff, budget and equipment) are required (Imperial, 1999). These activities improve the capacity of extension workers to plan, implement and monitor SLM activities (Mulema et al., 2017) and improve the knowledge on SLM among farmers (e.g. how to effectively implement them in their own fields), and change their attitude to have them genuinely participating in the SLM planning and implementation process (Ludi et al., 2013a). Therefore, the regional government should build the capacity of extension workers and government officials at the local level, through providing skills training, offering technical advice and support and allocating adequate budget and logistic services.

\section{b) Strengthening collaboration and networking}

Scaling-up SLM requires collaboration between stakeholders at all institutional levels and across different institutional sectors, including decision-makers, professionals, officials, extension workers and farmers (Dumanski \& Peiretti, 2013; Thomas et al., 2018). Hence, mainstreaming SLM activities is important to avoid duplication of efforts and promote synergy (Nedessa et al., 2015). Gete et al. (2006) also report that intra-(interdisciplinary) integration is required for scaling-up SLM. In a previous study, we found that the collaboration between the Agriculture Office and the Livestock Office at the local level of 
the Girar Jarso woreda is very important to provide training in integrated farm management (Abi et al., 2018a).

At community level, making use of the available community-based organizations and strengthening social networking are promising avenues for speeding-up the scaling-up process. Existing community-based organizations such as iddir (institutions for funeral purposes), mahiber (religious institutions to celebrate specific saints) and debo (labor sharing or exchange mechanisms among farmers to perform different farming activities) can form a reliable base for implementing rural development activities and organizing agricultural extension (Leta et al., 2018). These organizations play a vital role in empowering community members to become their own agents of change (Noordin et al., 2001) and in promoting collaboration, sharing information, facilitating training and mobilizing resources (material, finance and labor) for SLM activities (Getenet \& Tefera, 2017). Collaboration at community level is particularly important for collective decision-making during campaigns (Kessler, 2008). Therefore, a wide social network of information and technical support (Adimassu et al., 2012) involving these organizations seems useful.

\subsection{Conclusions and recommendations}

This study analyzed the policy and institutional limitations at national, regional and local level for scaling-up SLM practices through mass mobilization in the central highlands of Ethiopia as perceived by representatives from these levels. Three core issues were perceived as the main institutional limitations: the processes of policy formulation and implementation, the available institutional capacity and the lack of institutional collaboration. This study also identified opportunities for scaling-up SLM in Ethiopia and found that changes in the present institutional and policy environment of Ethiopia are urgently required to exploit potential opportunities and overcome perceived limitations. The study concluded that a much more bottom-up approach, building institutional capacities and strengthening synergies and partnerships between the local, regional and national levels are needed for the horizontal and vertical scaling-up of SLM practices in Ethiopia.

Finally, we recommend that the government of Ethiopia should address three core elements of the present institutional and policy environment. First, transform the process of policy formulation and implementation and make it more participatory and bottom-up. Second, build the capacity of institutions through awareness raising and learning, as well as by providing logistic facilities and equipment. Third, strengthen the institutional collaboration through mainstreaming SLM in all sectoral offices and using existing social networks and relations. However, taking over these three recommendations without 
applying the right policy instruments would not lead to a wide-scale spreading of SLM practices. Therefore, we recommend that the government of Ethiopia puts less emphasis on using command and control instruments - although these remain necessary when used wisely - and rely more on voluntary instruments such as training, mutual learning, information exchange and creating intrinsic motivation. Implementing these recommendations and integrating them into the existing mass mobilization approach would enhance the impact of the latter and would let SLM to actually contribute to improved soil quality and food security in the central highlands of Ethiopia. 


\section{Synthesis}

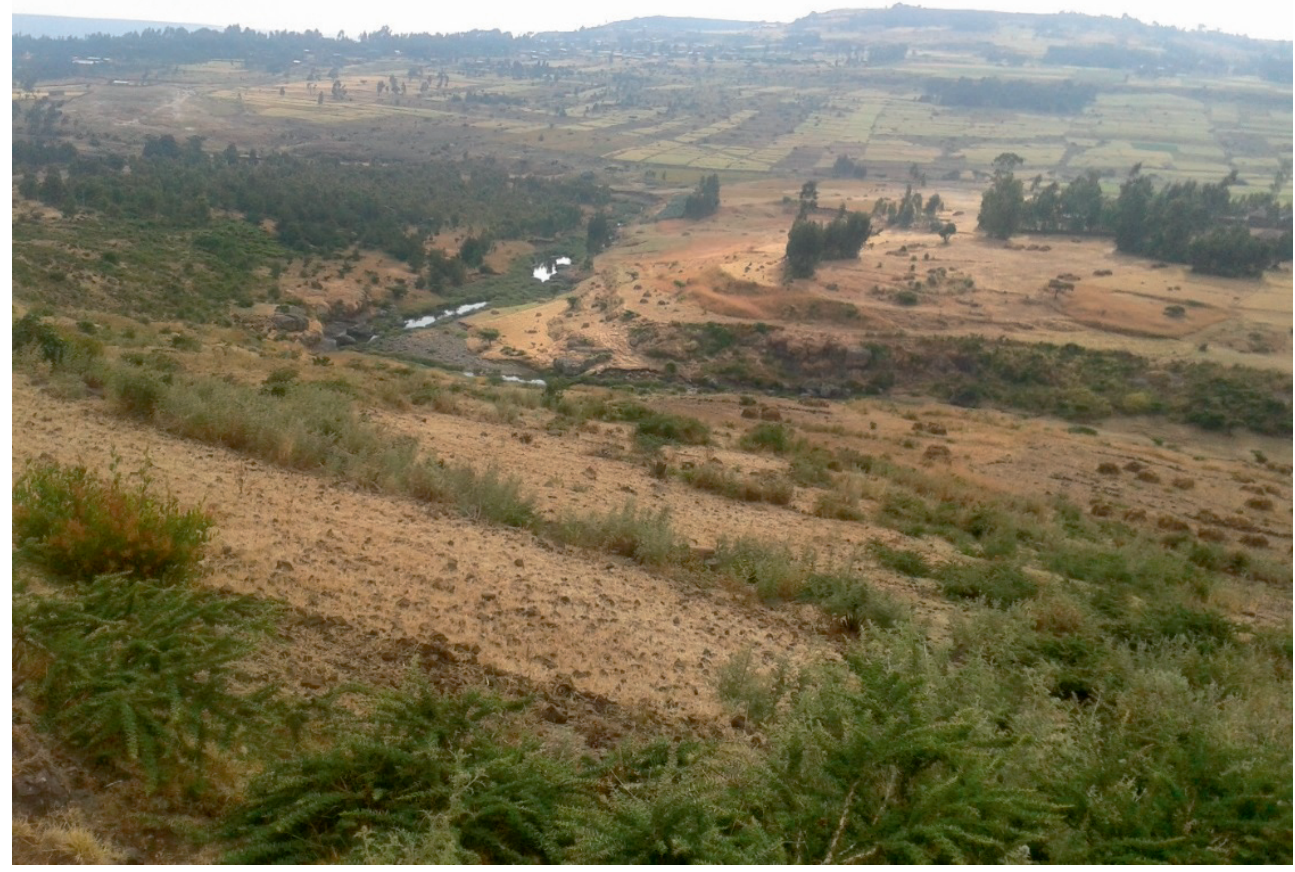




\subsection{Problem, objective and research questions}

In the central highlands of Ethiopia, land degradation and climatic variability remain critical challenges to food security. Severe land degradation in the form of soil erosion and soil fertility decline has threatened the agricultural production potential of the farmland in many parts of the country (Sonneveld \& Keyzer, 2003; Tamene \& Vlek, 2008; Adimassu et al., 2012; Adimassu et al., 2016). Similarly, recurrent drought due to climatic variability further affects crop production and food security (Kassie et al., 2013; Mengistu et al., 2015). Nevertheless, smallholder farmers in the central highlands of Ethiopia need to produce more food to meet the needs of the country's growing population. In order to increase agricultural productivity in Ethiopia and reverse the problem of land degradation, Sustainable Land Management (SLM) is urgently required.

Various strategies promoting SLM have been introduced by the government of Ethiopia and development partners to combat land degradation and improve resilience to climate variability over the past decades (Kato et al., 2011; Adimassu et al., 2013; Kassie et al., 2013; Haregeweyn et al., 2016; Teshome et al., 2016c). However, wide-scale adoption of SLM practices by farmers remains limited (Kassie et al., 2010; Adimassu et al., 2016; Teshome et al., 2016b). At the same time, we observe that some farmers spontaneously adopt and implement the introduced SLM practices on their farmlands. Such spontaneous adopting farmers often modify the practices during the implementation to make them fit their specific farming system (Bekele \& Drake, 2003; Amsalu \& de Graaff, 2006; Teshome et al., 2016a). This phenomenon is interesting because it illustrates a more bottom-up development of SLM practices that could inform SLM strategies more generally. However, limited research has been done to understand the spontaneous spreading of SLM practices, i.e. adoption and implementation of SLM practices by farmers on their own initiative. The main objective of this study was therefore to analyze the spontaneous adoption and scalingup of SLM in the central highlands of Ethiopia. The research posed the following specific research questions:

i. How have stone bunds spontaneously spread in the Girar Jarso woreda, and what are their characteristics?

ii. What are the key-factors in household characteristics that explain why some farmers spontaneously implement stone bunds and other farmers do not?

iii. How to trigger Ethiopian farmers' motivation and awareness to practice integrated farming in their fields, and to invest in SLM practices in the future?

iv. What changes are required in the policy and institutional environment of Ethiopia to enable the scaling-up of SLM practices through a more integrated mass mobilization approach? 
These research questions have been addressed on the basis of empirical research in the Girar Jarso woreda in the central highlands of Ethiopia as well as among relevant (regional and national) policy institutions in the country. The results of these studies have been presented in the previous chapters of this thesis and the structure connecting the different chapters is presented in Figure 6.1.

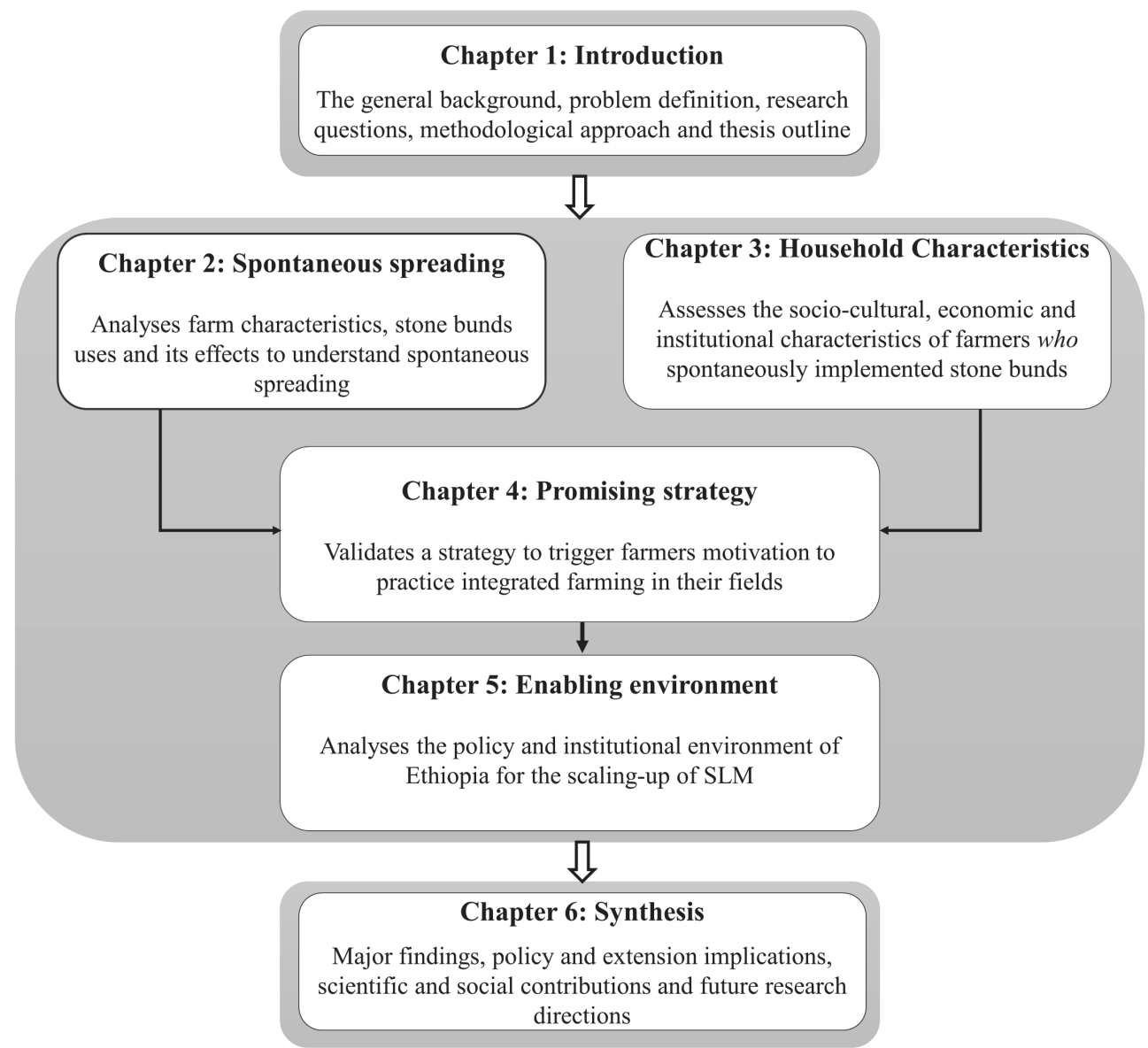

Figure 6.1 Synopsis of the analysis of spontaneous adoption and scaling-up of SLM practices

In the following section 6.2, the results of the previous four empirical chapters are synthesized and discussed in order to address the above research questions. Next, section 6.3 reflects on the core issues from the research findings; section 6.4 presents the implications of this study for policy-making and extension strategies; section 6.5 points out the contribution of the research to science more generally; and section 6.6 presents the limitations of the study and recommendations for future research. The final section 6.7 presents the general conclusions. 


\subsection{Main findings of the research}

i. How have stone bunds spontaneously spread in the Girar Jarso woreda, and what are their characteristics? (Chapter 2)

The first research question gave attention to the stone bunds that were spontaneously constructed by farmers in the Girar Jarso woreda. We found that location of farm plots, soil erosion severity and soil fertility status are decisive factors in explaining how the stone bunds have spontaneously spread. The findings show that stone bunds were spontaneously implemented particularly on farmlands located nearby homesteads where farmers perceived severe erosion and poor soil fertility. Furthermore, such spontaneously implemented stone bunds were better maintained, more often modified during the implementation process to make them fit to local conditions, and wellintegrated with other land management measures (such as use of fertilizer, compost and manure). Our findings are consistent with previous studies from Ethiopia that show that farmers give more attention (also apply more fertilizer, compost and manure) to farm plots closer to their homestead when deciding to implement soil conservation measures (Bekele \& Drake, 2003; Pender \& Gebremedhin, 2008; Abebe \& Sewnet, 2014; Hishe et al., 2018). In our case, the benefits of implementing stone bunds on farmlands closer to homesteads were twofold: 1) frequent monitoring and supervision of broken or damaged stone bunds allowing maintenance when needed; and 2) integration of additional soil fertility management measures (e.g. compost and manure) with the implemented stone bunds. Integration of different SLM practices is crucial to enhance soil moisture, improve availability of soil nutrients (Nyssen et al., 2007; Pender \& Gebremedhin, 2008) and increase crop production (Vancampenhout et al., 2006). Similar results were reported in Burkina Faso by Zougmoré et al. (2010), where soil and water conservation measures combined with compost increased soil moisture and reduced loss of fertile soil.

ii. What are the key-factors in household characteristics that explain why some farmers spontaneously implement stone bunds and other farmers do not? (Chapter 3)

The second research question attempted to investigate key-differences in household characteristics between farmers who spontaneously implemented stone bunds and farmers who did not. Five key household characteristics explaining this difference were identified on the basis of the Principal Component Analysis. These are readiness to change, available resources, social capital, type of family and commitment. The first factor, readiness to change, refers to the observation that farmers who spontaneously implemented stone bunds were more dynamic and motivated to change and improve. Farmers with a more positive perception of stone bunds, better farm planning and a higher motivation to make progress in farming activities were more eager to spontaneously implement stone bunds. Similar results were also reported in Bolivia by 
Kessler (2006a), where progressive farmers invested more in SLM practices. Contrary to previous findings (e.g. Amsalu \& de Graaff, 2007; Tiwari et al., 2008; Teshome et al., 2016a), our findings revealed that especially farmers with relatively limited available resources such as farmland, labor and livestock spontaneously implemented stone bunds. This second factor indicates that to improve their livelihood and food security, the urgency to invest in their farmland is higher for such farmers, which drives them to spontaneously implement stone bunds. Consistently, Nyanga et al. (2016) reported that farmers with a better drive to improve their future invest more in SLM practices. Similarly, our study revealed a third factor, social capital, which points out that farmers who had a stronger social network and better connectedness with other farmers and extension workers implemented more stone bunds by their own initiative. Such networks are crucial to improve farmers' awareness of and attitude towards the potential of improved technologies, thereby influencing their decision to implement SLM practices (Wossena et al., 2013). Consistent with the findings of previous studies from Ethiopia (e.g. Bekele \& Drake, 2003; Adimassu et al., 2012; Miheretu \& Yimer, 2017), our findings reported that educated young farmers who were more willing, energetic and optimistic were among the farmers who spontaneously implemented labor intensive SLM technology by their own initiative. This fourth factor, type of family, suggests that lack of available labor is not the major reason for farmers not to adopt SLM practices. In contrast to earlier findings (Bodnár \& De Graaff, 2003; Sietz \& Van Dijk, 2015), we find that young farmers with limited family labor spontaneously implement stone bunds relying on their social networks. Our study further revealed a fifth factor, commitment, which points at the farmers' concern about the future and the environment, which particularly motivates young farmers - who generally have better education and access to information - to implement conservation practices (Papadopoulos et al., 2015).

iii. How to trigger Ethiopian farmers' motivation and awareness to practice integrated farming in their fields, and to invest in SLM practices in the future? (Chapter 4)

The aim of the third research question was to evaluate the effects of an adapted, more participatory and more integrated, training approach on Ethiopian farmers' motivation to practice integrated farming and invest in SLM. The study was based on a one-year field experiment carried out in 2016 in the Sago-Kara watershed where a group of farmers - next to the usual mass mobilization campaign - received an adapted training which aimed to strengthen their knowledge and awareness about natural resource management, drought mitigation and integrated farm planning. Results of the experiment showed that the current mass mobilization strategy in Ethiopia can significantly enhance its impacts on SLM and will have more sustainable effects, if it would pay serious attention to four key-aspects: 1) creating awareness on the causes and effects of erosion and drought focusing on sustainability issues; 2 ) fostering farmers 
intrinsic motivation to be good stewards of their land; 3) training in integrated farm planning; and 4) developing farm plans by farmers themselves that are based on a vision for resilient farming. Similar results were also found in other studies. For instance, Duveskog et al. (2011) found that participation in farmer field schools improved farmers' awareness, and enabled them to practice more effective agricultural practices in the field. Likewise, Kilpatrick (2000) found that training increased farmers' abilities and willingness to make changes in their farm management practices. Hence, in order to make mass mobilization more sustainable, more focus on awareness raising and training is crucial, as it will empower farmers and trigger their motivation to invest in SLM.

iv What changes are required in the policy and institutional environment of Ethiopia to enable the scaling-up of SLM practices through a more integrated mass mobilization approach? (Chapter 5)

The fourth research question explored the policy and institutional environment that is relevant for the process of scaling-up SLM in the central highlands of Ethiopia. The limitations for institutions at the national, regional and local level to scaling-up SLM, as perceived by our key informants, relate to policy formulation and implementation, institutional capacity and collaboration. Regarding policy formulation and implementation, the main limiting factors were the use of top-down approaches for planning, implementation and monitoring, combined with a lack of considering farmers' knowledge and their priority needs. Concerning the institutional capacity, we observed limited knowledge on SLM among decision-makers at national level, as well as a limited capacity among extension workers and officials to transfer knowledge to the lower institutional levels. With respect to the institutional collaboration, several important limitations were perceived: poor coordination and integration between and among the different government sectors responsible for SLM, poor communication and little social learning between local farmers, professionals and officials, and a limited use of existing social networks and local institutions. The study concluded that changes at policy and institutional level are urgently required to speed-up the scaling-up of SLM practices, together with building the capacity and collaboration within and between institutions. Our results are consistent with the findings of recent studies conducted in Ethiopia (Snyder et al., 2014; Moges \& Taye, 2017; Mulema et al., 2017; Ariti et al., 2018), which report that soil and water conservation planning and implementation policies in Ethiopia follow a top-down approach. In such top-down approaches, farmers are not involved in the decision-making process, and their knowledge and priorities are not considered (Ludi et al., 2013a; Adego et al., 2018). The limited institutional collaboration and integration for natural resource management in Ethiopia (Mulema et al., 2017) hinders exchange of knowledge on SLM and scaling-up between the three institutional levels. 


\subsection{Towards a more participatory and integrated approach for SLM in Ethiopia}

This sub-section reflects on some key issues drawn from the research findings. First, we discuss the combination of spontaneous implementation of SLM with organized mass mobilization campaigns. Next, we reflect on the significance of SLM when embedded in a broader, more integrated, food security strategy. Finally, we address the challenge of enhancing soil fertility beyond the individual farm level, hence how to better enable scalingup to landscape level

The findings from Chapter 2 show that stone bunds implemented by means of mass mobilization were less well-maintained and less well-integrated with other soil fertility management measures as compared to spontaneously constructed stone bunds. As a result, these farmers experience fewer positive effects with respect to soil erosion, soil moisture and crop yields. The results also show that spontaneously adopting farmers are farmers who actively participated in government extension programs (including the mass mobilization campaigns) and frequently contacted extension workers (Chapter 3). Therefore, promoting participatory approaches is crucial to foster farmers' spontaneity and have them interact and learn from each other by sharing their experiences (Defoer, 2002; Kraaijvanger et al., 2016). Participatory approaches empower farmers to make decisions themselves and enable them to invest in the SLM practices that they think can solve their priority problems (e.g. loss of soil fertility) (Chapter 4). In the literature, we also find a widespread consensus that a more integrated and participatory approach for SLM could lead to more sustainable impact (Thackway et al., 2005; Haregeweyn et al., 2012; Biswas et al., 2017). This implies that the mass mobilization strategy as promoted by the Ethiopian authorities must change and be combined with a strategy that triggers the spontaneous adoption of SLM practices by individual farmers.

This leads to the question: how can farmers' spontaneity be combined with an organized governmental campaign? From our research we suggest that such a combination is possible by paying more attention to learning and training in the mass mobilization strategy. Strengthening the participatory character of the learning and training activities (e.g. through farmer-to-farmer extension methods) would increase farmers' knowledge and enhance their intrinsic motivation. Being integrated in an organized campaign such as the mass mobilization would be highly beneficial, because more farmers can become involved and the knowledge may spread faster. Moreover, participation in mass mobilization campaigns triggers the building of social capital and the mobilization of resources such as labor and working materials (Prager \& Creaney, 2017). Finally, as we found in Chapter 3 , spontaneously adopting farmers learned a lot during the mass mobilization campaigns 
about the implementation of stone bunds. Hence, the current mass mobilization strategy is not wrong, but it must be improved and made more effective (spreading SLM faster), as such generating more sustainable impact.

In Ethiopia, where a large majority of the population faces problems to sustain agricultural productivity and food security, integrated soil fertility management is critically important. However, SLM in Ethiopia still focuses on certain selected technologies and material infrastructures (Bewket, 2007; Abebe \& Sewnet, 2014; Wolka, 2014). The question is: in what way can this focus be shifted towards the promotion of more integrated soil fertility management strategies? What is needed to make such a shift? From the results of this study, more positive effects of improved physical infrastructures are observed when these are integrated with other soil fertility management measures such as the application of manure and compost (Chapter 2). Likewise, the field experiment in the Sago-Kara watershed (Chapter 4) underlines that such a shift towards a more integrated soil fertility management strategy is needed and also feasible. Farmers are generally receptive to learn and improve their farming methods, as they have to struggle to maintain their crop production levels, and climatic shocks such as droughts are a yearly threat to their food security. More focused training on integrated farm management motivates farmers to focus on the issue of integrated soil fertility management, enhances their farm resilience and promotes a more sustainable agricultural production (Papadopoulos et al., 2015; Kessler et al., 2016; Rojas et al., 2016; Rose et al., 2018). This can be very well combined with the mass mobilization approach, which already provides the organizational framework to tackle land degradation and food security. However, a shift is needed from short-term objectives (focused on production increase and stopping erosion) to long-term objectives that aim at restoring soil quality and at applying sound crop rotations with diversified and mixed cropping system. Promoting technologies and (more agro-ecological) soil management activities in an integrated manner contributes not only to increased food production, but also to a more diversified production and higher incomes, which in turn lead to improved food security. However, as these impacts require long term application of SLM practices with the right strategy, it is essential to ensure government commitment for longer time periods; hence, a change in mind-set towards a vision of sustainability is not only required among farmers, but also within governmental institutions at different levels.

This relates to the scaling-up issues addressed in this study. Although we focused on farmbased SLM practices, land degradation problems go beyond the individual farm-scale level and should be dealt with at a larger scale (landscape or watershed-approaches). This leads to the question: how can the farm-based improvements spontaneously implemented by individual farmers fit into a watershed or landscape-level approach? In Chapter 4 - in the experiment - we showed that more focus on learning and on achieving soil productivity, has the potential to address land degradation at a larger scale; but it needs an adequate 
enabling institutional environment to motivate farmers to implement SLM practices also at a watershed level and beyond (Adimassu et al., 2016; Kessler et al., 2016). Strong political leadership that promotes promising strategic directions is required to deal with large-scale land degradation; unfortunately such leadership with the right vision and understanding of SLM issues is currently not present in Ethiopia. In particular, government support (leadership) that builds strong systems at all institutional levels (national to local) is crucial to lead to more sustainable impacts of integrated approaches for SLM at a landscape level (Milder et al., 2014). Hence, urgent action at all institutional levels is required to genuinely tackle land degradation and increase food security.

\subsection{Policy and extension implications}

The empirical results from Chapter 2, 3 and 4 provide practical evidence and material supporting policy recommendations for the horizontal scaling-up of SLM practices, which is currently mostly undertaken through the mass mobilization approach in Ethiopia. The scaling-up process is about learning and integrating SLM practices that work better or that better fit the farming system (Wigboldus et al., 2016). Learning in a scaling-up process is not only related to knowing the best way to address a problem, but also towards having confidence in finding the best way to do so (Sturdy et al., 2008). From the results of this research, we observed that when farmers learn from each other (through their social networks) and spontaneously implement stone bunds, they better maintain and integrate them in their farming activities. Findings from other studies in Kenya (Amudavi et al., 2009; Kiptot \& Franzel, 2015), Tanzania (Nyanga et al., 2016) and Zimbabwe (Gwandu et al., 2014) also show that farmer-to-farmer learning is the most effective extension method to trigger adoption and facilitate the spreading of improved technologies. Therefore, also in Ethiopia, an extension strategy is needed that supports farmer-to-farmer learning.

In addition, the results from this research support the idea that location-specific factors determine farmers' decisions to implement SLM practices (Bekele \& Drake, 2003; Adimassu et al., 2012; Moges \& Taye, 2017). As was observed in Chapters 2 and 3, farm and farmer specific factors influence the spontaneous implementation of SLM practices. This has important implications for the current mass mobilization approach that does not address those specific contexts, and therefore has limited effect on the large-scale implementation of SLM practices by farmers and on farmers' fields (Moges \& Taye, 2017). This implies that government officials and extension workers should not only focus on mobilizing - and utilizing - farmers to implement SLM practices, but also on raising farmers' awareness on environmental problems and facilitating them to find and implement location-specific solutions. 
Results from Chapter 2 and 3 further indicate that when farmers are intrinsically motivated they are able to implement SLM practices by themselves, without needing to wait for external support or incentives. The pertinent issue for extension workers and decisionmakers is to provide the right information about SLM, to create awareness among farmers about the effects of erosion on the future productivity of farmlands, and to discuss the benefits of implementing SLM practices (Chapter 4; Papadopoulos et al., 2015). This is important in order to increase the problem-solving and decision-making abilities of farmers (Defoer, 2002; Van den Berg \& Jiggins, 2007). Indeed, awareness raising does not simply mean informing farmers about the effects of erosion and the benefits of SLM. Rather, it is about changing mind-sets of farmers by creating concerns about the effects of erosion on their current and future production, by creating intrinsic motivation, and by building confidence that the problem can be solved and that the future can be better through longterm planning (Kessler et al., 2016). As such, farmers will become what they are meant to be: good stewards of the land and its natural resources, able to produce our food in a sustainable way!

\subsection{Contribution to science and society}

The results of this research have also important contributions to science. During the past years, much more knowledge about the adoption of introduced SLM practices in the central highlands of Ethiopia has become available (for instance, Bekele \& Drake, 2003; Tadesse \& Belay, 2004; Amsalu \& de Graaff, 2007; Teklewold et al., 2013; Teshome et al., 2016a; Miheretu \& Yimer, 2017). The main topic of this research, the spontaneous spreading of SLM practices, is however a marginally touched upon issue in this previous work. Results from Chapter 2 provide important insights into how SLM practices (in our case, stone bunds) have spontaneously spread, which adds knowledge to the theory of diffusion. The empirical findings from Chapter 3 provide further insights into the farmers' decision-making process with respect to implementing SLM practices. Previous studies show that farmers' characteristics and perceived benefits of soil conservation play a crucial role in the decisionmaking process on whether or not to adopt SLM practices (Bekele \& Drake, 2003; Amsalu \& de Graaff, 2007; Anley et al., 2007; Meijer et al., 2015). As observed in Chapter 3, we found that particular farmers' characteristics (i.e. readiness to change, social capital and commitment) explain their decision to spontaneously implement stone bunds.

Methodologically, the use of a snowball sampling approach to identify spontaneous adopting farmers (Chapter 2 and 3 ) proved effective, and is among the innovative research methods applied in this thesis. The snowball sample selection approach is useful for studying individual farmers decision-making processes, and knowledge and technology spreading within a specific group of people or communities (German et al., 2006; Kumar, 
2011). Another innovative method applied in this thesis is the use of a participatory learning approach in the field experiment (Chapter 4). This method integrates local farmers' knowledge and scientific knowledge when adapting a training approach at the grass root level. The use of a participatory learning approach is an important tool to better understand farmers and their practices in the field (Sturdy et al., 2008; de Souza et al., 2012; Kraaijvanger \& Witteveen, 2018b). It provides an opportunity to understand how knowledge, experience and learning is exchanged among farmers, and ultimately contributes to foster a better-grounded bottom-up decision-making approach (Raymond et al., 2010; Bautista et al., 2017).

This study also provides an important contribution to society in enhancing insights about SLM and in achieving food security. The activities of farmers with respect to the stone bunds in their fields, the modifications made to fit their farming systems and the integration made with soil fertility management measures show the intimate relation between SLM and food security (Chapter 2). As also indicated by McDonald \& Brown (2000), adaptation of SLM technologies to specific farm management systems is an important component of SLM. This is crucial to contribute to solve problems such as low soil fertility and crop yields (Nyssen et al., 2007; Pender \& Gebremedhin, 2008). In our research, we observed that spontaneously adopting farmers are experimenting with SLM measures to make them more effective in controlling erosion and improving productivity (Chapter 2 ). The results imply that intrinsic motivation is key and that once farmers are motivated and see that SLM practices actually work in their fields, they will adopt them. Likewise, it is key to further promote the integration of erosion control technologies with soil fertility improvement measures; together these will increase crop yields (Branca et al., 2013) and improve household food security (Cordingley et al., 2015; Rojas et al., 2016).

\subsection{Limitations of the study and recommendations for future research}

During the research, we were confronted with several limitations. First, the sample size (study areas as well as studied farmers) was rather small and may limit the representativeness of the findings, making it difficult to generalize or extrapolate them to a larger population. Second, the methods applied may limit the robustness of the results of this study, as we primarily relied on farmers' opinions and perceptions. For instance, we did not measure the actual erosion on the farmlands, but relied on farmers' perception of erosion (Chapter 2 ) and on how farmers perceived the implemented practices in terms of declining erosion. Third, for obvious limitations of time, our field experiment focused on measuring the immediate effects of training, most notably, awareness, intrinsic motivation, 
integrated farming and planning SLM practices (Chapter 4). Consequently, measuring the long-term impact, which Van den Berg \& Jiggins (2007) and Sterk et al. (2013) call 'developmental impact', was not done. Therefore, the following recommendations are suggested for future research.

1) Evaluate the socio-economic impact of spontaneous spreading of SLM practices through farmer-to-farmer learning compared with the mass mobilization campaign. This is important to justify policy recommendations to support a more farmer-tofarmer oriented extension approach.

2) Understand the drivers of farmers' intrinsic motivation, particularly factors that drive individual farmers to implement SLM technologies integrated into their farming system. This is necessary to provide insights in the decisive factors of a scaling-up strategy to foster SLM in Ethiopia.

3) Evaluate the long-term impact of the adapted training approach on resilient farming, food production and livelihoods, considering the influence of individual (specific) household factors. This information is important for Ethiopian extension services to better select target groups with whom to achieve more sustainable impacts.

4) Investigate whether farmers who participated in the training transferred knowledge on integrated farm management to their neighboring farmers or not. Such information is important to better understand whether the adapted training was useful to encourage mutual learning or not.

\subsection{Overall conclusions}

This thesis provided detailed insights on the process of spontaneous spreading of SLM practices in the Girar Jarso woreda, central highlands of Ethiopia. These insights showed the geographical spreading (horizontal scaling-up) of SLM practices in the study area. The research also investigated an alternative training approach aimed at triggering farmers' intrinsic motivation and awareness. Finally, the thesis analyzed the institutional environment needed to speed-up the scaling-up of SLM practices in the highlands of Ethiopia. The following general conclusions can be drawn from the findings of the study.

1) In order to sustainably enhance the productive capacity of smallholder farmers and increase their food security, it is necessary to focus on enhancing farmers' intrinsic motivation to improve their livelihood, by means of training and education in SLM activities. Our study revealed that farmers who are more motivated and dynamic to improve their future are the ones that spontaneously implement stone bunds and experience higher crop yields. 
2) When smallholder farmers participate in planning SLM practices, they will feel more ownership of the practices, become more motivated and willing to participate in conservation activities, learn more about the SLM practices and how to maintain these, and will start implementing SLM practices also in different situations (based on the needs of their farm plots). More focus on training as well as on participatory planning and learning in the mass mobilization strategy is therefore crucial to ensure effective implementation of SLM in Ethiopia.

3) The strategies for scaling-up SLM practices in the central highlands of Ethiopia should shift towards more integrated soil fertility management, rather than focusing mainly on physical conservation practices. Especially, in this region, where land degradation severely threatens food security and the long-term productive capacity of the land, promoting integrated and diverse SLM practices is essential to promote and maintain healthy soils.

4) Government investments in creating an adequate enabling environment for scalingup SLM are urgently required. Many limitations at institutional level currently hinder the effectiveness of SLM efforts, and are a direct threat to the long-term sustainability of Ethiopian agriculture and food security. Action is required at all institutional levels to genuinely tackle land degradation. 


\section{Appendices}

\section{Appendix 1: Interview guides and survey questionnaire for Chapter 2}

\section{Field Observations/surveys}

Observations of the study watersheds were carried out before and during the study period. Prior to household surveys and interviews, I held field observations in the studied watersheds, in consultation with development agents and field assistants. Information about farmlands with stone bunds (coordinates of the farmland, elevation/altitude of the farmland), distance between farmlands with stone bunds implemented by own initiative and mass mobilization, and the implemented stone bunds (length of the stone bunds, distance between stone bunds) were obtained.

\section{Key informant interviews}

I conducted interviews with 10 farmers in the selected studied watersheds. The question included the following issues:

1. Perception on stone bunds implemented by own initiative and mass mobilization.

2. Perception on farmers' participation in mass mobilization?

3. Perception on the integration of stone bunds with other soil fertility management measures.

4. Perception towards stone bunds implemented by mass mobilization and own initiative in terms of suitability for farming, reduced erosion, and improve soil fertility and crop productivity.

\section{Household surveys}

Households surveys with the 80 farmers were carried out using structured and semistructured questionnaires. The questions included the following three issues:

\section{A. Perceived farmland characteristics}

1. Do you think that there is soil erosion problem in your area and farm land?

2. Do you perceive that soil erosion is a problem to your farmlands?

3. Do you perceive that there is loss of soil fertility on your farmland?

4. Do you have experience in protecting/managing your farmland from erosion problems?

5. Do you have experience in maintaining and replenishing soil fertility of your farmland?

6. The number of farm plots where you have implemented stone bunds?

7. Would you please tell us the characteristics of each of your farm plots where stone bunds have been implemented? 
B. Stone bund characteristics

1. Did mass mobilization construct stone bunds on your farmland?

2. Have you used and maintained stone bunds implemented by mass mobilization for the last five years?

3. Have you implemented stone bunds on your farm plots by your own initiative?

4. From where did you learn implementing stone bunds?

5. Do you maintain stone bunds that you have implemented by yourself?

6. Have you implemented stone bunds as you have seen/heard how, or in a modified form to fit to your farm plots?

7. Did you implement stone bunds integrating with soil fertility management measures?

8. What types of soil fertility management measures do you apply together with stone bunds?

C. Perceived effect of stone bunds

1. How do you rate the trend in soil erosion problems on your farmland after stone bunds have been implemented?

2. How do you rate the productivity of your farm land after you have started using stone bunds?

3. Has water availability/soil moisture on the field have increased since you have started implementing stone bunds?

4. How do you rate the productivity of crop yield since you have started implementing stone bunds?

5. If your response is ' Increasing' to $Q \# 4$, do you believe that your yield improvement is only due to implementation of stone bunds?

6. Do you apply improved inputs on your farmland in order to increase your crop yield?

\section{Appendix 2: Interview guides and survey questionnaire for Chapter 3}

\section{Open discussions with farmers}

I conducted open interviews with some selected farmers in the studied watersheds before making the questionnaire. This was to help identify factors in household characteristics that explain why some farmers spontaneously implemented stone bunds and other farmers did not. The following discussion points were used to help identify those possible factors.

1. Farmers views concerning integrated farm management practices (crop, livestock and soil management).

2. What are farmers' current farm management practices? Do farmers practice integrated crop, livestock and soil management practices on their own farmland? 
3. What is the role of stone bunds in the farmers' soil fertility management? What does it do? Why are farmers interested to implement stone bunds on their land?

4. Do farmers decide themselves to practice and experiment stone bunds integrating with soil fertility management measures on their own farmland?

5. Do farmers interested and capable to implement stone bunds integrated with soil fertility management on their own farm land?

6. Source of farmer's motivation to implement stone bunds integrating with soil fertility management measures on their own farmland? (work motivation, coercion/forced to do, expected benefits, expected support, etc.)

7. How have do farmers implement stone bunds on their own farmland

8. Types of farmers who have been implemented stone bunds integrating with soil fertility management measures on their farmland?

9. Perception towards stone bunds implemented by mass mobilization and own initiative in terms of suitability for farming, reduced erosion, and improve soil fertility and crop productivity.

10. Sense of ownership and responsibility to maintain stone bunds implemented by mass mobilization.

11. Perception on the benefits of farmers social learning and networking to gain knowledge on stone bunds implementation integrating with soil fertility management measures.

12. Perception on the sustainability aspects of stone bunds implemented by mass mobilization and own initiative.

\section{Household survey questionnaire}

Based on the results of open interviews, 32 possible factors that explain difference in farmers characteristics were identified and included in the survey questionnaire. Therefore, the socio-cultural, economic and policy/institutional characteristics of the 80 farmers were collected using open-ended and Likert-type scale.

\section{A. Socio-cultural characteristics}

1. Age of household head in years.

2. Education status of household head

3. Number of family members in the household.

4. Number of available family labor for farming activities at time of survey.

5. Household head social position in the community:

6. Household category in terms of wealth status

7. Do you have adequate knowledge about integrated crop, livestock and soil management practices?

8. Do you practice integrated crop, livestock and soil management practices on your farm land?

9. If 'Yes', indicate your level of agreement or disagreement concerning the following statements? ....

10. Do you have an annual plan to maintain and implement stone bunds in the rest of your plots currently untreated? 
11. Do you visit your own farmland mostly to recognize erosion problems and soil loss?

12. What is your views and prospects concerning the use of stone bunds to improve agricultural production and productivity, your household food security and living condition in the future?

13. Would you tell us the relation to and trust with other farmers, development agents and government officials

14. Would you tell us your perception towards implemented stone bunds on your farmland on the basis of the following statements raised?

15. Would you tell us your level of agreement or disagreement related to the responsibility and sense of ownership to maintain implemented stone bunds?

16. Would you tell us your sources of motivation to implement and maintain stone bunds

17. Would you tell us the level of agreement or disagreement related to your readiness and willingness to maintain and continually use stone bunds on your farm plots?

\section{B. Economic characteristics}

18. what is the total size of your farmland that you use currently?

19. What type of crops you cultivated and harvested in the year 2014/15 (2006/07 E.C.)?

20. Would you tell us the amount of crop products you sold out in quintals or Kgs and total income obtained?

21. Do you have farm oxen?

22. Would you tell us the types of livestock you have, their number and the total amount of income you obtained from sale of livestock and livestock products in the year 2014/15?

23. Would you tell us the total amount of income you obtained from sale of livestock and livestock products in the year 2014/15?

24. Do you or any of your household members engage in off-farm activities?

25. Do you have farm tools used for soil conservation activities?

\section{Policy/institutional characteristics}

26. Household category in terms of extension use

27. Have you contacted development agents and/or other agricultural experts on crop production, livestock production and soil management?

28. Have you participated in the following organization/institutions? Would you also tell us you level of participation and the role you have in the organization/institutions?

29. Indicate your level of agreement or disagreement concerning your ability to make decision on your own farmlands during the campaign works.

30. Did you obtained material support and technical assistance from extension workers during implementing stone bunds on your farmland?

31. Do you have a land certificate?

32. Do you have access to credit services?

33. Do you have access to local market in your area for your produce? 


\section{Appendix 3: Interview guides and survey questionnaire for Chapter 4}

\section{Group discussion}

The focus of this chapter was on a field experiment in which the adapted training approach was validated on a group of 26 farmers. Before doing the training, I developed the baseline information using group discussions with the $26 \mathrm{EF}$. The discussions covered the following main points:

1. Major environmental problems in the studied watershed

2. Existing farm management practices practiced by farmers in the studied watershed

3. SLM practices implemented through mass mobilisation in the studied watershed

4. Perception towards the level of community participation in the current mass mobilization campaign and sense of ownership of SLM practices implemented through mass mobilisation.

Again, after the training, I collected the end-line information using group discussions with the 26 trained farmers, and using the same discussion points as before the training.

\section{Household survey questionnaire}

I conducted household surveys with 52 farmers, 26 trained farmers and 26 non-trained farmers, using structured and semi-structured questionnaires. The questions included the following issues:

\section{A. Socio-economic characteristics}

1. Age of household head.

2. Family size including household head

3. Available family labor including household head

4. Did you attend formal schooling? (applicable for head of household)

5. Farming experience in years

6. The size of your farmlands in Timad

7. Would you tell us soil management technologies you have been using on each of your farm plots in 2015/16?

8. Would you tell us the type of crops you grow on each of your farm plots, amount of crop products you produced and income obtained in the year 2008/09 E.C. (2015/16)

9. Would you tell us the types of livestock you have, their number and income obtained from sale of livestock's in the year 2008/09 (2015/16)?

10. Would you tell us livestock products you produced, products sold to market and estimated income obtained from sale of livestock products in the year 2008/9 $(2015 / 16) ?$

11. Would you tell us about the type of off-farm activities you are engaged in and estimated income obtained in the year 2008/09 (2015/16)? 
B. Perception and opinion on integrated farm management

1. Do you have adequate awareness about integrating farming activities (crop production, livestock production, soil management and income generating activities?

2. Do you have a motivation to practice integrated farm management activities (crop production, livestock production, soil management and income generating activities) in your fields?

3. Did you implement soil erosion control technologies integrating with soil fertility management measures on your farm plots to improve crop and livestock production system?

4. How do you evaluate your attitude towards improving your farming activities by integrating cropland with livestock and soil management practices in the future?

\section{Perception and opinion on drought}

1. Do you know what drought means?

2. How do you perceive the effect of drought on your farming activities?

3. Do you believe that the effect of drought on farming activities can be reduced?

4. Do you feel responsible to control drought effects by integrating crop production, livestock production and soil management?

5. Do you have a plan to reduce the effect of drought using sustainable land management technologies in the future? If 'yes', please tell us your future plan to reduce drought risks?

\section{Appendix 4: Interview guides and survey questionnaire for Chapter 5}

\section{Key informant interview guide}

Interviews with policy makers and implementers at the three institutional levels were carried out to assess the policy and institutional environment for scaling-up SLM through the mass mobilization approach. The focus of this chapter was to identify important limitations, available opportunities/strengths and required conditions to speed-up the scaling-up of SLM through the mass mobilisation approach. The following questions were addressed to collect the required information.

1. Do you know SLM? If yes, how would you define it?

2. Do you know benefits of SLM? What benefits does SLM generate when implemented at the watershed level and at the level of individual farms?

3. Do you think that scaling-up SLM is currently done in the country? If yes, who is in charge of scaling-up SLM and how is it actually done? (please describe the process for scaling-up according to your knowledge or experience) 
4. Do you consider scaling-up SLM through the mass mobilisation campaign important in Ethiopia?

5. What are the available means presently available for institutions at the local, regional and national level to improve or enable scaling-up of SLM practices through the mass mobilisation campaign?

6. What is the role of the farmers and their local networks in scaling-up SLM?

7. Are locally available social networks such as idir, debo, mahiber, etc. are taken into account in scaling-up SLM? (Yes/No). If yes, how? What role do they play?

8. Who else is involved in scaling-up SLM? In what ways do these stakeholder contribute to scaling-up of SLM through the mass mobilisation?

9. What do you know about the national SLM policy in Ethiopia? What role does participation of local stakeholder play in it?

10. What are the key limitations for institutions at the local, regional and national level that hinder them in scaling-up SLM practices through the mass mobilisation? How can the limitations be addressed?

11. What should be the role of local authorities in organising the participation of local stakeholders in:

12. What should be the role of regional authorities in supporting local authorities in organising the participation of local stakeholders in scaling up SLM practices? How and what?

13. What should be the role of regional authorities in creating national policies, institutions and facilities that support local authorities in organising the participation of local stakeholders in scaling up SLM practices? How and what?

14. What should be the role of national authorities in supporting local authorities in organising the participation of local stakeholders in scaling up SLM practices? How and what?

15. What should be the role of national authorities in creating national policies, institutions and facilities that support local authorities in organising the participation of local stakeholders in scaling up SLM practices? How and what? 


\section{Literature cited}

Abate, H. 2014. Communication Protocol and Effective Program Planning of Agricultural Extension and Production Packages. Ethiopian Agricultural Transformation Agency, Geographic Implementation Support. Addis Ababa, Ethiopia.

Abdela, A. \& Derso, D. 2015. Analyzing factors affecting adoption of soil and water conservation practice in eastern Ethiopia. African Journal of Agricultural Science and Technology (AJAST), 3, 356-364.

Abdi, H. \& Williams, L. J. 2010. Principal component analysis: Overview. Wiley Interdisciplinary Reviews Computational Statistics, 2, 433-459.

Abebe, Z. D. \& Sewnet, M. A. 2014. Adoption of soil conservation practices in North Achefer District, Northwest Ethiopia. Chinese Journal of Population Resources and Environment, 12, 261-268.

Abi, M. 2012. Household Food Security Situation in Girar Jarso Woreda, North Shewa Zone of Oromiya National Regional State, Ethiopia. MSc Thesis. Addis Ababa University. http://etd.aau.edu.et/dspace/handle/123456789/4236.

Abi, M., Kessler, A., Oosterveer, P. \& Tolossa, D. 2018a. Adapting the current mass mobilization approach in Ethiopia to enhance its impact on sustainable land management: lessons from the Sago-kara watershed. Manuscript submitted.

Abi, M., Kessler, A., Oosterveer, P. \& Tolossa, D. 2018b. How farmers' characteristics influence spontaneous spreading of stone bunds in the highlands of Ethiopia: a case study in the Girar Jarso woreda. Environment, Development and Sustainability, https://doi.org/10.1007/s10668-018-0203-2.

Abi, M., Kessler, A., Oosterveer, P. \& Tolossa, D. 2018c. Understanding the Spontaneous Spreading of Stone Bunds in Ethiopia: Implications for Sustainable Land Management. Sustainability, 10 (8).

Abi, M. \& Tolossa, D. 2015. Household Food Security Status and its Determinants in Girar Jarso Woreda, North Shewa zone of Oromia Region, Ethiopia. Journal of Sustainable Development in Africa, 17, 118-137.

Adego, T., Simane, B. \& Woldie, G. A. 2018. Sustainability, institutional arrangement and challenges of community based climate smart practices in northwest Ethiopia. Agriculture \& Food Security, 7, 56.

Adesina, A. A. \& Zinnah, M. M. 1993. Technology characteristics, farmers' perceptions and adoption decisions: A Tobit model application in Sierra Leone. Agricultural Economics, 9, 297-311. 
Adimassu, Z. \& Kessler, A. 2015. Impact of the productive safety net program on farmers' investments in sustainable land management in the Central Rift Valley of Ethiopia. Environmental Development, 16, 54-62.

Adimassu, Z., Kessler, A. \& Hengsdijk, H. 2012. Exploring determinants of farmers' investments in land management in the Central Rift Valley of Ethiopia. Applied Geography, 35, 191-198.

Adimassu, Z., Kessler, A. \& Stroosnijder, L. 2013. Exploring co-investments in sustainable land management in the Central Rift Valley of Ethiopia. International Journal of Sustainable Development \& World Ecology, 20, 32-44.

Adimassu, Z., Kessler, A. \& Stroosnijder, L. 2014. Farmers' strategies to perceived trends of rainfall and crop productivity in the Central Rift Valley of Ethiopia. Environmental Development, 11, 123-140.

Adimassu, Z., Langan, S. \& Johnston, R. 2016. Understanding determinants of farmers' investments in sustainable land management practices in Ethiopia: review and synthesis. Environment, Development and Sustainability, 18, 1005-1023.

Ajzen, I. 1991. The theory of planned behavior. Organizational Behavior and Human Decision Processes, 50, 179-211.

Akhtar-Schuster, M., Thomas, R. J., Stringer, L. C., Chasek, P. \& Seely, M. 2011. Improving the enabling environment to combat land degradation: Institutional, financial, legal and science-policy challenges and solutions. Land Degradation \& Development, 22, 299312.

Alexiadou, N. 2001. Researching policy implementation: Interview data analysis in institutional contexts. International Journal of Social Research Methodology, 4, 51-69.

Amede, T., German, L., Rao, S., Opondo, C. \& Stroud, A. (eds.) 2006. Integrated Natural Resource Management in Practice: Enabling Communities to Improve Mountain Livelihoods and Landscapes. Proceedings of a conference held on October 12-15, 2004 at ICRAF Headquarters, Nairobi, Kenya. Kampala, Uganda: African Highlands Initiative.

Amjad, U., Ojomo, E., Downs, K., Cronk, R. \& Bartram, J. 2015. Rethinking Sustainability, Scaling Up, and Enabling Environment: A Framework for Their Implementation in Drinking Water Supply. Water, 7, 1497.

Amsalu, A. \& de Graaff, J. 2006. Farmers' Views of Soil Erosion Problems and their Conservation Knowledge at Beressa Watershed, Central Highlands of Ethiopia. Agriculture and Human Values, 23, 99-108.

Amsalu, A. \& de Graaff, J. 2007. Determinants of adoption and continued use of stone terraces for soil and water conservation in an Ethiopian highland watershed. Ecological Economics, 61, 294-302.

Amsalu, A., Stroosnijder, L. \& Graaff, J. d. 2007. Long-term dynamics in land resource use and the driving forces in the Beressa watershed, highlands of Ethiopia. Journal of Environmental Management, 83, 448-459. 
Amudavi, D. M., Khan, Z. R., Wanyama, J. M., Midega, C. A. O., Pittchar, J., Nyangau, I. M., Hassanali, A. \& Pickett, J. A. 2009. Assessment of technical efficiency of farmer teachers in the uptake and dissemination of push-pull technology in Western Kenya. Crop Protection, 28, 987-996.

Anley, Y., Bogale, A. \& Haile-Gabriel, A. 2007. Adoption decision and use intensity of soil and water conservation measures by smallholder subsistence farmers in Dedo District, Western Ethiopia. Land Degradation \& Development, 18, 289-302.

Araya, A. \& Stroosnijder, L. 2011. Assessing drought risk and irrigation need in northern Ethiopia. Agricultural and Forest Meteorology, 151, 425-436.

Ariti, A. T., van Vliet, J. \& Verburg, P. H. 2018. Farmers' participation in the development of land use policies for the Central Rift Valley of Ethiopia. Land Use Policy, 71, 129-137.

Ashoori, D., Allahyari, M. S. \& Damalas, C. A. 2017. Adoption of conservation farming practices for sustainable rice production among small-scale paddy farmers in northern Iran. Paddy and Water Environment, 15, 237-248.

Ashoori, D., Bagheri, A., Allahyari, M. S. \& Michailidis, A. 2016. Understanding the attitudes and practices of paddy farmers for enhancing soil and water conservation in Northern Iran. International Soil and Water Conservation Research, 4, 260-266.

Asrat, P., Belay, K. \& Hamito, D. 2004. Determinants of farmers' willingness to pay for soil conservation practices in the southeastern highlands of Ethiopia. Land Degradation \& Development, 15, 423-438.

Bamberger, M. 2009. Strengthening the evaluation of programme effectiveness through reconstructing baseline data. Journal of Development Effectiveness, 1:1, 37-59.

Bautista, S., Llovet, J., Ocampo-Melgar, A., Vilagrosa, A., Mayor, Á. G., Murias, C., Vallejo, V. R. \& Orr, B. J. 2017. Integrating knowledge exchange and the assessment of dryland management alternatives - A learning-centered participatory approach. Journal of Environmental Management, 195, 35-45.

Bekele, W. \& Drake, L. 2003. Soil and water conservation decision behavior of subsistence farmers in the Eastern Highlands of Ethiopia: a case study of the Hunde-Lafto area. Ecological Economics, 46, 437-451.

Bernard, H. R. 2011. Research methods in anthropology: Qualitative and quantitative approaches. 5th edition, AltaMira Press.

Beshah, T. 2003. Understanding farmers : Explaining soil and water conservation in Konso, Wolaita and Wello, Ethiopia. Doctoral Thesis. Wageningen University. The Netherlands. http://edepot.wur.nl/121378

Bewket, W. 2007. Soil and water conservation intervention with conventional technologies in northwestern highlands of Ethiopia: Acceptance and adoption by farmers. Land Use Policy, 24, 404-416.

Bhan, S. 2013. Land degradation and integrated watershed management in India. International Soil and Water Conservation Research, 1, 49-57. 
Binswanger, H. P. \& Aiyar, S. S. 2003. Scaling up community-driven development: theoretical underpinnings and program design implications. World Bank policy research working paper 3039.

Biswas, H., Raizada, A., Kumar, S. \& Morade, A. S. 2017. Integrated Natural Resource Management in India Through Participatory Integrated Watershed Management. In: Rakshit, A., Abhilash, P. C., Singh, H. B. \& Ghosh, S. (eds.) Adaptive Soil Management : From Theory to Practices. Singapore: Springer Singapore.

Blackstock, K. L., Ingram, J., Burton, R., Brown, K. M. \& Slee, B. 2010. Understanding and influencing behaviour change by farmers to improve water quality. Science of The Total Environment, 408, 5631-5638.

Bodnár, F. \& De Graaff, J. 2003. Factors influencing adoption of soil and water conservation measures in southern Mali. Land Degradation \& Development, 14, 515-525.

Borrás, S. \& Edquist, C. 2013. The choice of innovation policy instruments. Technological Forecasting and Social Change, 80, 1513-1522.

Branca, G., Lipper, L., McCarthy, N. \& Jolejole, M. C. 2013. Food security, climate change, and sustainable land management. A review. Agronomy for Sustainable Development, 33, 635-650.

Carter Jr, F. J., Jambulingam, T., Gupta, V. K. \& Melone, N. 2001. Technological innovations: a framework for communicating diffusion effects. Information \& Management, 38, 277 287.

Carter, S. E. \& Currie-Alder, B. 2006. Scaling-up natural resource management: insights from research in Latin America. Development in Practice, 16, 128-140.

CASCAPE 2014. Annual Report 2014. Period 1 January 2014 - 31 December 2014. CASCAPE (Capacity bulding for scaling-up of evidence-based best practices in Agricultural Production in Ethiopia) Project, Addis Ababa University.

Catley, A., Cullis, A. \& Abebe, D. 2016. El Niño in Ethiopia, 2015-2016: A Real-Time Review of Impacts and Responses. USAID/Ethiopia Agriculture Knowledge, Learning, Documentation and Policy Project.

Cavatassi, R., Lipper, L. \& Narloch, U. 2011. Modern variety adoption and risk management in drought prone areas: insights from the sorghum farmers of eastern Ethiopia. Agricultural Economics, 42, 279-292.

Chentanez, N., Barto, A. G. \& Singh, S. P. Intrinsically motivated reinforcement learning. Advances in neural information processing systems, 2004. 1281-1288.

Cholo, T., Fleskens, L., Sietz, D. \& Peerlings, J. 2018. Is Land Fragmentation Facilitating or Obstructing Adoption of Climate Adaptation Measures in Ethiopia? Sustainability, 10, 2120.

Cocklin, C., Mautner, N. \& Dibden, J. 2007. Public policy, private landholders: Perspectives on policy mechanisms for sustainable land management. Journal of Environmental Management, 85, 986-998. 
Conley, T. \& Udry, C. 2001. Social Learning through Networks: The Adoption of New Agricultural Technologies in Ghana. American Journal of Agricultural Economics, 83, 668-673.

Cook, S., Collier, R., Clarke, J. \& Lillywhite, R. 2009. Contribution of integrated farm management (IFM) to Defra objectives. Aspects of Applied Biology, 93, 131-138.

Cordingley, J. E., Snyder, K. A., Rosendahl, J., Kizito, F. \& Bossio, D. 2015. Thinking outside the plot: addressing low adoption of sustainable land management in sub-Saharan Africa. Current Opinion in Environmental Sustainability, 15, 35-40.

Cramb, R. A. 2005. Social capital and soil conservation: evidence from the Philippines. Australian Journal of Agricultural and Resource Economics, 49, 211-226.

Cramb, R. A., Garcia, J. N. M., Gerrits, R. V. \& Saguiguit, G. C. 1999. Smallholder adoption of soil conservation technologies: evidence from upland projects in the Philippines. Land Degradation \& Development, 10, 405-423.

CSA 2013. Population Projection of Ethiopia for All Regions At Wereda Level from 2014 2017. Addis Ababa: Federal Democratic Republic of Ethiopia Central Statistical Agency. CSA 2015. Key Findings of the 2014/2015 (2007 E.C.) Agricultural Sample Surveys. Addis Ababa: The Federal Democratic Republic of Ethiopia, Central Statistical Agency.

CSA 2016. Report on Crop and Livestock Product Utilization (Private Peasant Holdings, Meher Season): Agricultural Sample Survey: 2015/2016 (2008 E.C.). Addis Ababa: The Federal Democratic Republic of Ethiopia, Central Statistical Agency, Addis Ababa.

CSA 2018. Key Findings of the 2017/2018(2010 E.C): Agricultural Sample Surveys. Country Summary. The Federal Democratic Republic of Ethiopia, Central Statistical Agency, Addis Ababa.

Cullen, B., Tucker, J., Snyder, K., Lema, Z. \& Duncan, A. 2014. An analysis of power dynamics within innovation platforms for natural resource management. Innovation and Development, 4, 259-275.

Danano, D. (ed.) 2010. Sustainable Land Management Technologies and Approaches in Ethiopia. Sustainable Land Management Project (SLMP), Natural Resources Management Sector, Ministry of Agriculture and Rural Development of the Federal Democratic Republic of Ethiopia. Addis Ababa.

Dar, N. A., Lone, B. A., Alaie, B. A., Dar, Z. A., Gulzafar, Bahar, F. A., Haque, S. A. \& Singh, K. N. 2018. Integrated Farming Systems for Sustainable Agriculture. In: Sengar, R. S. \& Singh, A. (eds.) Eco-friendly Agro-biological Techniques for Enhancing Crop Productivity. Singapore: Springer Singapore.

Davis, K., Nkonya, E., Kato, E., Mekonnen, D. A., Odendo, M., Miiro, R. \& Nkuba, J. 2012. Impact of Farmer Field Schools on Agricultural Productivity and Poverty in East Africa. World Development, 40, 402-413.

de Graaff, J., Amsalu, A., Bodnár, F., Kessler, A., Posthumus, H. \& Tenge, A. 2008. Factors influencing adoption and continued use of long-term soil and water conservation measures in five developing countries. Applied Geography, 28, 271-280. 
de Souza, H. N., Cardoso, I. M., de Sá Mendonça, E., Carvalho, A. F., de Oliveira, G. B., Gjorup, D. F. \& Bonfim, V. R. 2012. Learning by doing: a participatory methodology for systematization of experiments with agroforestry systems, with an example of its application. Agroforestry Systems, 85, 247-262.

de Vente, J., Reed, M. S., Stringer, L. C., Valente, S. \& Newig, J. 2016. How does the context and design of participatory decision making processes affect their outcomes? Evidence from sustainable land management in global drylands. Ecology and Society, 21.

Deci, E. \& Ryan, R. M. 1985. Intrinsic motivation and self-determination in human behavior, Springer Science \& Business Media.

Deci, E. L. \& Ryan, R. M. 2012. Motivation, personality, and development within embedded social contexts: An overview of self-determination theory. In: Ryan, R. M. (ed.) The Oxford handbook of human motivation.

Defoer, T. 2002. Learning about methodology development for integrated soil fertility management. Agricultural Systems, 73, 57-81.

Dejene, A. 2003. Integrated natural resources management to enhance food security: The Case for Community-Based Approaches in Ethiopia. Rome: FAO.

Douthwaite, B., Beaulieu, N., Lundy, M. \& Peters, D. 2009. Understanding how participatory approaches foster innovation. International Journal of Agricultural Sustainability, 7, $42-$ 60 .

Douthwaite, B., Keatinge, J. D. H. \& Park, J. R. 2001. Why promising technologies fail: the neglected role of user innovation during adoption. Research Policy, 30, 819-836.

Dumanski, J. \& Peiretti, R. 2013. Modern concepts of soil conservation. International Soil and Water Conservation Research, 1, 19-23.

Duveskog, D., Friis-Hansen, E. \& Taylor, E. W. 2011. Farmer Field Schools in Rural Kenya: A Transformative Learning Experience. The Journal of Development Studies, 47, 15291544.

Enki, M., Belay, K. \& Dadi, L. 2001. Determinants of adoption of physical soil conservation measures in central highlands of Ethiopia the case of three districts of north Shewa. Agricultural Economics Research, Policy and Practice in Southern Africa, 40, 293-315.

EPA \& MEDC 1997. Environmental Policy. Environmental Protection Authority (EPA) in collaboration with the Ministry of Economic Development and Cooperation (MEDC). Federal Democratic Republic of Ethiopia. Addis Ababa.

Ervin, C. A. \& Ervin, D. E. C. F. p. d. A. 1982. Factors Affecting the Use of Soil Conservation Practices: Hypotheses, Evidence, and Policy Implications. Land Economics, 58, 277-292.

Everitt, S. L. a. B. S. 2004. A Handbook of Statistical Analyses using SPSS, Boca Raton London New York Washington, D.C., Chapman \& Hall/CRC Press LLC.

FAO 2016. El Niño and La Niña: Preparedness and Response. Situation Report - July 2016. Food and Agriculture Organization of the United Nations. 
FDRE 2005. Federal Democratic Republic of Ethiopia Rural Land Administration and Land Use Proclamation. Proclamation No. 456/2005. Federal Negarit Gazeta, 44(2005). 3133-3144.

FDRE 2010. Growth and Transformation Plan (2010/11-2014/15). Volume I: Main Text. Addis Ababa: Federal Democratic Republic of Ethiopia, Ministry of Finance and Economic Development.

FDRE 2011. Ethiopia's Climate-Resilient Green Economy. Green economy strategy. Federal Democratic Republic of Ethiopia.

FDRE 2013. National Policy and Strategy on Disaster Risk Management. The Federal Democratic Republic of Ethiopia. Addis Ababa.

FDRE 2016. Growth and Transformation Plan II (GTP II) (2015/16-2019/20). Volume I: Main Text. Addis Ababa: Federal Democratic Republic of Ethiopia, National Planning Commission.

Feder, G., Murgai, R. \& Quizon, J. B. 2004. The Acquisition and Diffusion of Knowledge: The Case of Pest Management Training in Farmer Field Schools, Indonesia. Journal of Agricultural Economics, 55, 221-243.

Feola, G., Lerner, A. M., Jain, M., Montefrio, M. J. F. \& Nicholas, K. A. 2015. Researching farmer behaviour in climate change adaptation and sustainable agriculture: Lessons learned from five case studies. Journal of Rural Studies, 39, 74-84.

Field, A. 2009. Discovering Statistics Using SPSS (and sex and drugs and rock ' $n$ ' roll), SAGE Publications Ltd.

Franzel, S., Denning, G. L., Lillesø, J. P. B. \& Mercado, A. R. 2004. Scaling up the impact of agroforestry: Lessons from three sites in Africa and Asia. Agroforestry Systems, 61, 329344.

Gagné, M. \& Deci, E. L. 2005. Self-determination theory and work motivation. Journal of Organizational Behavior, 26, 331-362.

Gebrehaweria, G., Dereje, A. A., Girmay, G., Giordano, M. \& Langan, S. 2016. An assessment of integrated watershed management in Ethiopia. IWMI Working Paper.

Gebrehiwot, T. \& van der Veen, A. 2013. Farm Level Adaptation to Climate Change: The Case of Farmer's in the Ethiopian Highlands. Environ Manage, 52, 29-44.

Gebrehiwot, T., van der Veen, A. \& Maathuis, B. 2011. Spatial and temporal assessment of drought in the Northern highlands of Ethiopia. International Journal of Applied Earth Observation and Geoinformation, 13, 309-321.

Gebremedhin, B. \& Swinton, S. M. 2003. Investment in soil conservation in northern Ethiopia: the role of land tenure security and public programs. Agricultural Economics, 29, 69-84.

Gebremichael, A., Yakob, G. \& Mekonnen, G. 2015. Assessment of farmers perception and adaptation mechanism to soil erosion problem in Shomba Kichib, Gimbo District, Kaffa Zone, South West Ethiopia. African Journal of Agricultural Research, 10, 2608-2616. 
Gebremichael, D., Nyssen, J., Poesen, J., Deckers, J., Haile, M., Govers, G. \& Moeyersons, J. 2005. Effectiveness of stone bunds in controlling soil erosion on cropland in the Tigray Highlands, northern Ethiopia. Soil Use and Management, 21, 287-297.

German, L., Mowo, J. \& Kingamkono, M. 2006. A methodology for tracking the "fate" of technological interventions in agriculture. Agriculture and Human Values, 23, 353-369.

Gete, Z., Menale, K., Pender, J. \& Mahmud, Y. Stakeholder analysis for sustainable land management (SLM) in Ethiopia: Assessment of opportunities, strategic constraints, information needs, and knowledge gaps. Second Draft. Environmental Economics Policy Forum for Ethiopia (EEPFE). International Food Policy Research Institute, Ethiopia. 2006.

Getenet, B. \& Tefera, B. 2017. Institutional Analysis of Environmental Resource Management in Lake Tana Sub-basin. In: Stave, K., Goshu, G. \& Aynalem, S. (eds.) Social and Ecological System Dynamics: Characteristics, Trends, and Integration in the Lake Tana Basin, Ethiopia. Cham: Springer International Publishing.

Greiner, R. \& Gregg, D. 2011. Farmers' intrinsic motivations, barriers to the adoption of conservation practices and effectiveness of policy instruments: Empirical evidence from northern Australia. Land Use Policy, 28, 257-265.

Gündel, S., Hancock, J. \& Anderson, S. 2001. Scaling-up strategies for research in natural resources management: A Comparative Review. Chatham, UK: The University of Greenwich.

Guo, M., Jia, X., Huang, J., Kumar, K. B. \& Burger, N. E. 2015. Farmer field school and farmer knowledge acquisition in rice production: Experimental evaluation in China. Agri. Ecosy. Environ., https://doi.org/10.1016/j.agee.2015.02.011, 100-107.

Gwandu, T., Mtambanengwe, F., Mapfumo, P., Mashavave, T. C., Chikowo, R. \& Nezomba, H. 2014. Factors Influencing Access to Integrated Soil Fertility Management Information and Knowledge and its Uptake among Smallholder Farmers in Zimbabwe. The Journal of Agricultural Education and Extension, 20, 79-93.

Hagmann, J. \& Chuma, E. 2002. Enhancing the adaptive capacity of the resource users in natural resource management. Agricultural Systems, 73, 23-39.

Haileslassie, A., Priess, J., Veldkamp, E., Teketay, D. \& Lesschen, J. P. 2005. Assessment of soil nutrient depletion and its spatial variability on smallholders' mixed farming systems in Ethiopia using partial versus full nutrient balances. Agriculture, Ecosystems \& Environment, 108, 1-16.

Haregeweyn, N., Berhe, A., Tsunekawa, A., Tsubo, M. \& Meshesha, D. T. 2012. Integrated Watershed Management as an Effective Approach to Curb Land Degradation: A Case Study of the Enabered Watershed in Northern Ethiopia. Environ Manage, 50, 1219 1233.

Haregeweyn, N., Tsunekawa, A., Nyssen, J., Poesen, J., Tsubo, M., Meshesha, D. T., Schuett, B., Adgo, E. \& Tegegne, F. 2015. Soil erosion and conservation in Ethiopia: A review. Progress in Physical Geography, 39, 750-774. 
Haregeweyn, N., Tsunekawa, A., Tsubo, M., Meshesha, D., Adgo, E., Poesen, J. \& Schutt, B. 2016. Analyzing the hydrologic effects of region-wide land and water development interventions: a case study of the Upper Blue Nile basin. Regional Environmental Change, 16, 951-966.

Hellin, J. \& Schrader, K. 2003. The case against direct incentives and the search for alternative approaches to better land management in Central America. Agriculture, Ecosystems \& Environment, 99, 61-81.

Hillman, M. \& Howitt, R. 2008. Institutional change in natural resource management in New South Wales, Australia: Sustaining capacity and justice. Local Environment, 13, 55-66.

Hishe, S., Lyimo, J. \& Bewket, W. 2018. Impacts of soil and water conservation intervention on rural livelihoods in the Middle Suluh Valley, Tigray Region, northern Ethiopia. Environment, Development \& Sustainability, https://doi.org/10.1007/s10668-0180152-9.

Hoang Fagerström, M. H., Messing, I. \& Wen, Z. M. 2003. A participatory approach for integrated conservation planning in a small catchment in Loess Plateau, China: Part I. Approach and Methods. Catena, 54, 255-269.

Hurni, H. 1993. Land degradation, famine, and land resource scenarios in Ethiopia. In: Pimentel, D. (ed.) World soil erosion and conservation. United States of America, New York: Cambridge University Press.

Hurni, H. 2000. Assessing sustainable land management (SLM). Agriculture, Ecosystems \& Environment, 81, 83-92.

Hurni, H., Abate, S., Bantider, A., Debele, B., Ludi, E., Portner, B., Yitaferu, B. \& Zeleke, G. 2010. Land degradation and sustainable land management in the highlands of Ethiopia. In: Hurni, H. \& Wiesmann, U. (eds.) Global Change and Sustainable Development : A Synthesis of Regional Experiences from Research. Geographica Bernesia.

IIRR. Going to scale: can we bring more benefits to more people more quickly. In: Gonsalves, J., ed. Workshop highlights presented by the CGIAR-NGO Committee and The Global Forum for Agricultural Research with BMZ, MISEREOR, Rockefeller Foundation, International Rice Research Institute (IRRI) and International Institute of Rural Reconstruction (IIRR) 2000. 10-14.

Imperial, M. T. 1999. Institutional Analysis and Ecosystem-Based Management: The Institutional Analysis and Development Framework. Environ Manage, 24, 449-465.

Karidjo, B., Wang, Z., Boubacar, Y. \& Wei, C. 2018. Factors Influencing Farmers' Adoption of Soil and Water Control Technology (SWCT) in Keita Valley, a Semi-Arid Area of Niger. Sustainability, 10, 288.

Kassahun, D. 2006. Towards the development of differential land taxation and its implications for sustainable land management. Environmental Science \& Policy, 9, 693697. 
Kassie, B. T., Hengsdijk, H., Rötter, R., Kahiluoto, H., Asseng, S. \& Van Ittersum, M. 2013. Adapting to Climate Variability and Change: Experiences from Cereal-Based Farming in the Central Rift and Kobo Valleys, Ethiopia. Environ Manage, 52, 1115-1131.

Kassie, M., Zikhali, P., Pender, J. \& Köhlin, G. 2010. The Economics of Sustainable Land Management Practices in the Ethiopian Highlands. Journal of Agricultural Economics, 61, 605-627.

Kato, E., Ringler, C., Yesuf, M. \& Bryan, E. 2011. Soil and water conservation technologies: a buffer against production risk in the face of climate change? Insights from the Nile basin in Ethiopia. Agricultural Economics, 42, 593-604.

Kessler, A. 2006a. Decisive key-factors influencing farm households' soil and water conservation investments. Applied Geography, 26, 40-60.

Kessler, A. 2006b. Moving People: Towards Collective Action in Soil and Water Conservation Experiences from the Bolivian Mountain Valleys, Wageningen University and Research Centre.

Kessler, C. A. 2008. Laying a solid foundation for sustainable development in Bolivian mountain villages. Environment, Development and Sustainability, 10, 233-247.

Kessler, C. A., van Duivenbooden, N., Nsabimana, F. \& van Beek, C. L. 2016. Bringing ISFM to scale through an integrated farm planning approach: a case study from Burundi. Nutrient Cycling in Agroecosystems, 105, 249-261.

Kilpatrick, S. 2000. Education and training: Impacts on farm management practice. The Journal of Agricultural Education and Extension, 7, 105-116.

Kiptot, E. \& Franzel, S. 2015. Farmer-to-farmer extension: opportunities for enhancing performance of volunteer farmer trainers in Kenya. Development in Practice, 25, 503 517.

Kiptot, E., Franzel, S., Hebinck, P. \& Richards, P. 2006. Sharing seed and knowledge: farmer to farmer dissemination of agroforestry technologies in western Kenya. Agroforestry Systems, 68, 167-179.

Kraaijvanger, R., Veldkamp, T. \& Almekinders, C. 2016. Considering change: Evaluating four years of participatory experimentation with farmers in Tigray (Ethiopia) highlighting both functional and human-social aspects. Agricultural Systems, 147, 38-50.

Kraaijvanger, R. G. \& Witteveen, L. 2018. Farmer responsibility and researcher learning: Two sides of the same coin? Reflecting on five years of involvement in participatory experimentation in Tigray, Northern Ethiopia. In: Extension, I. J. o. A. (ed.) International Conference - European Seminar on Extension Education. Greece: International Journal of Agricultural Extension.

Kumar, R. 2011. Research methodology: a step-by-step guide for beginners. 3rd edition. SAGE Publications Ltd. London.

Kuyvenhoven, A. 2004. Creating an enabling environment: policy conditions for less-favored areas. Food Policy, 29, 407-429. 
Lalani, B., Dorward, P., Holloway, G. \& Wauters, E. 2016. Smallholder farmers' motivations for using Conservation Agriculture and the roles of yield, labour and soil fertility in decision making. Agricultural Systems, 146, 80-90.

Lanckriet, S., Derudder, B., Naudts, J., Bauer, H., Deckers, J., Haile, M. \& Nyssen, J. 2015. A Political Ecology Perspective of Land Degradation in the North Ethiopian Highlands. Land Degradation \& Development, 26, 521-530.

Lapar, M. L. A. \& Pandey, S. 1999. Adoption of soil conservation: the case of the Philippine uplands. Agricultural Economics, 21, 241-256.

Leavy, P. 2017. Research design: Quantitative, qualitative, mixed methods, arts-based, and community-based participatory research approaches, Guilford Publications.

Leonard, M. 2004. Bonding and Bridging Social Capital: Reflections from Belfast. Sociology, 38(5), 927-944.

Leta, G., Kelboro, G., Stellmacher, T., Assche, K. V. \& Hornidge, A. K. 2018. Nikinake: the mobilization of labour and skill development in rural Ethiopia. Natural Resources Forum, 42, 93-107.

Liniger, H. P., Gurtner, M., Studer, R. M. \& Hauert, C. 2011. Sustainable land management in practice - Guidelines and best practices for Sub-Saharan Africa. TerrAfrica, World Overview of Conservation Approaches and Technologies (WOCAT) and Food and Agriculture Organization of the United Nations (FAO), Rome, Italy, FAO.

Ludi, E., Belay, A., Duncan, A., Snyder, K. A., Tucker, J., Cullen, B., Belissa, M., Oljira, T., Teferi, A. \& Nigussie, Z. 2013b. Rhetoric versus realities: A diagnosis of rainwater management development processes in the Blue Nile Basin of Ethiopia. Colombo, Sri Lanka: CGIAR Challenge Program on Water and Food (CPWF). 58p. (CPWF Research for Development (R4D) Series 5).

Luther, G. C., Mariyono, J., Purnagunawan, R. M., Satriatna, B. \& Siyaranamual, M. 2018. Impacts of farmer field schools on productivity of vegetable farming in Indonesia. Natural Resources Forum, 42, 71-82.

Mbaga-Semgalawe, Z. \& Folmer, H. 2000. Household adoption behaviour of improved soil conservation: the case of the North Pare and West Usambara Mountains of Tanzania. Land Use Policy, 17, 321-336.

McDonald, M. \& Brown, K. 2000. Soil and water conservation projects and rural livelihoods: options for design and research to enhance adoption and adaptation. Land Degradation \& Development, 11, 343-361.

Meijer, S. S., Catacutan, D., Ajayi, O. C., Sileshi, G. W. \& Nieuwenhuis, M. 2015. The role of knowledge, attitudes and perceptions in the uptake of agricultural and agroforestry innovations among smallholder farmers in sub-Saharan Africa. International Journal of Agricultural Sustainability, 13, 40-54.

Mengistu, D., Bewket, W. \& Lal, R. 2015. Conservation Effects on Soil Quality and Climate Change Adaptability of Ethiopian Watersheds. Land Degradation \& Development, 10.1002/ldr.2376, n/a-n/a. 
Mercer, D. E. 2004. Adoption of agroforestry innovations in the tropics: A review. Agroforestry Systems, 61, 311-328.

Miheretu, B. A. \& Yimer, A. A. 2017. Determinants of farmers' adoption of land management practices in Gelana sub-watershed of Northern highlands of Ethiopia. Ecological Processes, 6, 19.

Milder, J. C., Hart, A. K., Dobie, P., Minai, J. \& Zaleski, C. 2014. Integrated Landscape Initiatives for African Agriculture, Development, and Conservation: A Region-Wide Assessment. World Development, 54, 68-80.

Milestad, R. \& Darnhofer, I. 2003. Building Farm Resilience: The Prospects and Challenges of Organic Farming. Journal of Sustainable Agriculture, 22, 81-97.

Millar, J. \& Connell, J. 2010. Strategies for scaling out impacts from agricultural systems change: the case of forages and livestock production in Laos. Agriculture and Human Values, 27, 213-225.

MoA 2014. Project Implementation Manual for Sustainable Land Management Project-2 ( 2014-2018). Zero Draft. Federal Democratic Republic of Ethiopia, Ministry of Agriculture.

MoARD 2010. Ethiopian Strategic Investment Framework for Sustainable Land Management. The Federal Democratic Republic of Ethiopia, Ministry of Agriculture and Rural Development (MoARD). Addis Ababa.

MoFED 2003. Rural Development Policies and Strategies. Government of the Federal Democratic Republic of Ethiopia, Ministry of Finance and Economic Development, Economic Policy and Planning. Addis Ababa

Moges, D. M. \& Taye, A. A. 2017. Determinants of farmers' perception to invest in soil and water conservation technologies in the North-Western Highlands of Ethiopia. International Soil and Water Conservation Research, 5, 56-61.

Mulema, A. A., Lema, Z., Damtew, E., Adie, A., Ogutu, Z. \& Duncan, A. J. 2017. Stakeholders' perceptions of integrated rainwater management approaches in the Blue Nile Basin of the Ethiopian highlands. Natural Resources Forum, 41, 244-254.

Mutoko, M. C., Shisanyac, C. A. \& Hein, L. 2014. Fostering technological transition to sustainable land management through stakeholder collaboration in the western highlands of Kenya. Land Use Policy, 41, 110-120.

Mwangi, C. A. G. \& Bettencourt, G. M. 2017. A Qualitative Toolkit for Institutional Research. New Directions for Institutional Research, 2017, 11-23.

Napier, T. L. 1991. Factors affecting acceptance and continued use of soil conservation practices in developing societies: a diffusion perspective. Agriculture, Ecosystems \& Environment, 36, 127-140.

Nedessa, B., Yirga, A., Seyoum, L. \& Gebrehawariat, G. (eds.) 2015. A Guideline on Documentation of Sustainable Land Management Best Practices in Ethiopia. Ministry of Agriculture, Natural Resource Sector. Addis Ababa, Ethiopia, Addis Ababa, Ethiopia: Ministry of Agriculture, Natural Resource Sector. 
Neuman, W. L. 2014. Social research methods: Qualitative and quantitative approaches. 7th edition, Pearson Education Limited.

Nigussie, Z., Tsunekawa, A., Haregeweyn, N., Adgo, E., Cochrane, L., Floquet, A. \& Abele, S. 2018. Applying Ostrom's institutional analysis and development framework to soil and water conservation activities in north-western Ethiopia. Land Use Policy, 71, 1-10.

Noordin, Q., Niang, A., Jama, B. \& Nyasimi, M. 2001. Scaling up adoption and impact of agroforestry technologies: Experiences from western Kenya. Development in Practice, 11, 509-523.

North, D. C. 1990. Institutions, Institutional Change and Economic Performance, Cambridge University Press.

Ntshangase, N., Muroyiwa, B. \& Sibanda, M. 2018. Farmers' Perceptions and Factors Influencing the Adoption of No-Till Conservation Agriculture by Small-Scale Farmers in Zashuke, KwaZulu-Natal Province. Sustainability, 10, 555.

Nyagumbo, I., Nyamangara, J. \& Rurinda, J. 2011. Scaling Out Integrated Soil Nutrient andWater Management Technologies Through Farmer Participatory Research: Experiences fromSemi-arid Central Zimbabwe. In: al, A. B. e. (ed.) Innovations as Key to the Green Revolution in Africa. Springer Science+Business Media B.V.

Nyanga, A., Kessler, A. \& Tenge, A. 2016. Key socio-economic factors influencing sustainable land management investments in the West Usambara Highlands, Tanzania. Land Use Policy, 51, 260-266.

Nyssen, J., Poesen, J., Gebremichael, D., Vancampenhout, K., D’aes, M., Yihdego, G., Govers, G., Leirs, H., Moeyersons, J., Naudts, J., Haregeweyn, N., Haile, M. \& Deckers, J. 2007. Interdisciplinary on-site evaluation of stone bunds to control soil erosion on cropland in Northern Ethiopia. Soil and Tillage Research, 94, 151-163.

O'Rourke, N. \& Hatcher, L. 2013. A step-by-step approach to using SAS for factor analysis and structural equation modeling, Sas Institute.

Osman, M. \& Sauerborn, P. 2001. Soil and water conservation in Ethiopia. Journal of Soils and Sediments, 1, 117-123.

Ostrom, E. 1992. Crafting institutions for self-governing irrigation systems. Institute for Contemporary Studies San Francisco, California

Owen, N., Glanz, K., Sallis, J. F. \& Kelder, S. H. 2006. Evidence-Based Approaches to Dissemination and Diffusion of Physical Activity Interventions. American Journal of Preventive Medicine, 31, 35-44.

Pahl-Wostl, C. 2009. A conceptual framework for analysing adaptive capacity and multi-level learning processes in resource governance regimes. Global Environmental Change, 19, 354-365.

Papadopoulos, S., Karelakis, C., Zafeiriou, E. \& Koutroumanidis, T. 2015. Going sustainable or conventional? Evaluating the CAP's impacts on the implementation of sustainable forms of agriculture in Greece. Land Use Policy, 47, 90-97. 
Pender, J. \& Gebremedhin, B. 2008. Determinants of agricultural and land management practices and impacts on crop production and household income in the highlands of Tigray, Ethiopia. Journal of African Economies, 17, 395-450.

Peshin, R., Vasanthakumar, J. \& Kalra, R. 2009. Diffusion of Innovation Theory and Integrated Pest Management. In: Peshin, R. \& Dhawan, A. K. (eds.) Integrated Pest Management: Dissemination and Impact: Volume 2. Dordrecht: Springer Netherlands.

Phillips, N., Lawrence, T. B. \& Hardy, C. 2000. Inter-organizational collaboration and the dynamics of institutional fields. Journal of management studies, 37 (1), 23-43.

Pinto-Correia, T., Gustavsson, R. \& Pirnat, J. 2006. Bridging the Gap between Centrally Defined Policies and Local Decisions - Towards more Sensitive and Creative Rural Landscape Management. Landscape Ecology, 21, 333-346.

Posthumus, H., Zougmoré, R., Spaan, W. \& De Graaff, J. 2001. Incentives for soil and water conservation in semi-arid zones: a case study from Burkina Faso. Multidisciplinarity approaches to soil and water conservation strategies. Muncheberg, 11-13 May 2001.

Prager, K. \& Creaney, R. 2017. Achieving on-farm practice change through facilitated group learning: Evaluating the effectiveness of monitor farms and discussion groups. Journal of Rural Studies, 56, 1-11.

Prager, K. \& Posthumus, H. 2010. Socio-economic factors influencing farmers' adoption of soil conservation practices in Europe. In: Napier, T. L. (ed.) Human Dimensions of Soil and Water Conservation. New York: Nova Science Publishers, Inc.

Pregernig, M. 2001. Values of Forestry Professionals and their Implications for the Applicability of Policy Instruments. Scandinavian Journal of Forest Research, 16, 278288.

Quinn, C. E. \& Burbach, M. E. 2010. A Test of Personal Characteristics That Influence Farmers' Pro-Environmental Behaviors. Great Plains Research, 20, 193-204.

Raymond, C. M., Fazey, I., Reed, M. S., Stringer, L. C., Robinson, G. M. \& Evely, A. C. 2010. Integrating local and scientific knowledge for environmental management. J Environ Manage, 91, 1766-1777.

Reij, C. \& Garrity, D. 2016. Scaling up farmer-managed natural regeneration in Africa to restore degraded landscapes. Biotropica, 48, 834-843.

Rogers, E. M. 1983. Diffusion of Innovations, New York, The Free Press.

Rogers, E. M. 1995. Diffusion of Innovations, New York, The Free Press.

Rogers, E. M. 2002. Diffusion of preventive innovations. Addictive Behaviors, 27, 989-993.

Rojas, R. V., Achouri, M., Maroulis, J. \& Caon, L. 2016. Healthy soils: a prerequisite for sustainable food security. Environmental Earth Sciences, 75, 1-10.

Rose, D. C., Sutherland, W. J., Barnes, A. P., Borthwick, F., Ffoulkes, C., Hall, C., Moorby, J. M., Nicholas-Davies, P., Twining, S. \& Dicks, L. V. 2018. Integrated farm management for sustainable agriculture: Lessons for knowledge exchange and policy. Land Use Policy, 81 (2019), 834-842. 
Roseland, M. 2000. Sustainable community development: integrating environmental, economic, and social objectives. Progress in Planning, 54, 73-132.

Ryan, R. M. \& Deci, E. L. 2000a. Intrinsic and Extrinsic Motivations: Classic Definitions and New Directions. Contemporary Educational Psychology, 25, 54-67.

Ryan, R. M. \& Deci, E. L. 2000b. Self-Determination Theory and the Facilitation of Intrinsic Motivation, Social Development, and Well-Being. American psychologist, 55 (1), 68-78.

Ryan, R. M. \& Deci, E. L. 2017. Self-determination theory: Basic psychological needs in motivation, development, and wellness, Guilford Publications.

Sanginga, P. C., Kamugisha, R. N. \& Martin, A. M. 2010. Strengthening Social Capital for Adaptive Governance of Natural Resources: A Participatory Learning and Action Research for Bylaws Reforms in Uganda. Society \& Natural Resources, 23, 695-710.

Schwilch, G., Liniger, H. P. \& Hurni, H. 2014. Sustainable Land Management (SLM) Practices in Drylands: How Do They Address Desertification Threats? Environ Manage, 54, 9831004.

Seyoum, B. 2016a. Assessment of soil fertility status of Vertisols under selected three land uses in Girar Jarso District of North Shewa Zone, Oromia National Regional State, Ethiopia. Environmental Systems Research, 5, 18.

Seyoum, B. 2016b. Assessment of soil fertility status of Vertisols under selected three land uses in Girar Jarso District of North Shewa Zone, Oromia National Regional State, Ethiopia. Environmental Systems Research, 5, 1-16.

Shiferaw, B. \& Holden, S. 1999. Soil Erosion and Smallholders' Conservation Decisions in the Highlands of Ethiopia. World Development, 27, 739-752.

Shiferaw, B. \& Holden, S. T. 1998. Resource degradation and adoption of land conservation technologies in the Ethiopian Highlands: A case study in Andit Tid, North Shewa. Agricultural Economics, 18, 233-247.

Shiferaw, B. \& Holden, S. T. 2000. Policy instruments for sustainable land management: the case of highland smallholders in Ethiopia. Agricultural Economics, 22, 217-232.

Shiferaw, B. A., Okello, J. \& Reddy, R. V. 2009. Adoption and adaptation of natural resource management innovations in smallholder agriculture: Reflections on key lessons and best practices. Environment, Development and Sustainability, 11, 601-619.

Sietz, D. \& Van Dijk, H. 2015. Land-based adaptation to global change: What drives soil and water conservation in western Africa? Global Environmental Change, 33, 131-141.

Smithers, J. \& Furman, M. 2003. Environmental farm planning in Ontario: exploring participation and the endurance of change. Land Use Policy, 20, 343-356.

Snyder, K. A., Ludi, E., Cullen, B., Tucker, J., Zeleke, A. B. \& Duncan, A. 2014. Participation and Performance: Decentralised Planning and Implementation In Ethiopia. Public Administration and Development, 34, 83-95.

Sonneveld, B. G. J. S. \& Keyzer, M. A. 2003. Land under pressure: Soil conservation concerns and opportunities for Ethiopia. Land Degradation \& Development, 14, 5-23. 
Sterk, B., Christian, A. K., Gogan, A. C., Sakyi-Dawson, O. \& Kossou, D. 2013. Five Years After; the Impact of a Participatory Technology Development Programme as Perceived by Smallholder Farmers in Benin and Ghana. The Journal of Agricultural Education and Extension, 19, 361-379.

Straub, E. T. 2009. Understanding Technology Adoption: Theory and Future Directions for Informal Learning. Review of Educational Research, 79, 625-649.

Sturdy, J. D., Jewitt, G. P. W. \& Lorentz, S. A. 2008. Building an understanding of water use innovation adoption processes through farmer-driven experimentation. Physics and Chemistry of the Earth, Parts A/B/C, 33, 859-872.

Taddese, G. 2001. Land Degradation: A Challenge to Ethiopia. Environ Manage, 27, 815-824. Tadesse, M. \& Belay, K. 2004. Factors influencing adoption of soil conservation measures in Southern Ethiopia: The case of Gununo area. Journal of Agriculture and Rural Development in the Tropics and Subtropics, 105, 49-62.

Tamene, L. \& Vlek, P. L. G. 2008. Soil Erosion Studies in Northern Ethiopia. In: Braimoh, A. K. \& Vlek, P. L. G. (eds.) Land Use and Soil Resources. Dordrecht: Springer Netherlands. Tefera, T., Tesfay, G., Elias, E., and, M. D. \& Koomen, I. 2016. Drivers for adoption of agricultural technologies and practices in Ethiopia - A study report from 30 woredas in four regions. Addis Ababa/Wageningen: CASCAPE project.

Teklewold, H., Kassie, M. \& Shiferaw, B. 2013. Adoption of Multiple Sustainable Agricultural Practices in Rural Ethiopia. Journal of Agricultural Economics, 64 (3), 597-623.

Tesfahunegn, G. B. 2018. Farmers' perception on land degradation in northern Ethiopia: Implication for developing sustainable land management. The Social Science Journal, https://doi.org/10.1016/j.soscij.2018.07.004.

Teshome, A., de Graaff, J. \& Kassie, M. 2016a. Household-Level Determinants of Soil and Water Conservation Adoption Phases: Evidence from North-Western Ethiopian Highlands. Environtal Management, 57, 620-636.

Teshome, A., de Graaff, J. \& Kessler, A. 2016b. Investments in land management in the north-western highlands of Ethiopia: The role of social capital. Land Use Policy, 57, 215228.

Teshome, A., de Graaff, J., Ritsema, C. \& Kassie, M. 2016c. Farmers' Perceptions about the Influence of Land Quality, Land Fragmentation and Tenure Systems on Sustainable Land Management in the North Western Ethiopian Highlands. Land Degradation \& Development, 27, 884-898.

Thackway, R., Davey, S., Hoare, J. \& Cresswell, I. D. 2005. Strategies for an Integrated Approach to Ecologically Sustainable Land Management. Australasian Journal of Environmental Management, 12, 66-76.

Thomas, R., Reed, M., Clifton, K., Appadurai, N., Mills, A., Zucca, C., Kodsi, E., Sircely, J., Haddad, F., Hagen, C., Mapedza, E., Woldearegay, K., Shalander, K., Bellon, M., Le, Q., Mabikke, S., Alexander, S., Leu, S., Schlingloff, S., Lala-Pritchard, T., Mares|, V. \& Quiroz, 
R. 2018. A framework for scaling sustainable land management options. Land Degradation \& Development, 29, 3272-3284.

Tiwari, K. R., Sitaula, B. K., Nyborg, I. L. P. \& Paudel, G. S. 2008. Determinants of Farmers' Adoption of Improved Soil Conservation Technology in a Middle Mountain Watershed of Central Nepal. Environ Manage, 42, 210-222.

Tolossa, D., Senbeta, F., Tesfaye, B., Gemachu, B., Zeleke, B., Tariku, M., Yasin, S. \& Mengist, S. 2015. Participatory Rural Appraisal Report: Girar Jarso Woreda, North Shewa Zone, Central Oromia Region. Addis Ababa: Addis Ababa University/CASCAPE Project.

Tukahirwa, J., Fungo, B., Kamugisha, R., Wagoire, W. \& Gorfu, B. 2013a. Significance of social networks in sustainable land management in central Ethiopia and eastern Uganda. African Crop Science Journal, 21, 735-750.

Tukahirwa, J., Mowo, J., Tanui, J., Kamugisha, R. \& Masuki, K. 2013b. Scaling Sustainable Land management Innovations: The African Highland Initiative Devolution Model. African Crop Science Journal, 21, 705-722.

Uvin, P., Jain, P. S. \& Brown, L. D. 2000. Think Large and Act Small: Toward a New Paradigm for NGO Scaling Up. World Development, 28, 1409-1419.

Van den Berg, H. \& Jiggins, J. 2007. Investing in Farmers-The Impacts of Farmer Field Schools in Relation to Integrated Pest Management. World Development, 35, 663-686. Vancampenhout, K., Nyssen, J., Gebremichael, D., Deckers, J., Poesen, J., Haile, M. \& Moeyersons, J. 2006. Stone bunds for soil conservation in the northern Ethiopian highlands: Impacts on soil fertility and crop yield. Soil and Tillage Research, 90, 1-15.

Vanclay, F. 2004. Social principles for agricultural extension to assist in the promotion of natural resource management. Australian Journal of Experimental Agriculture, 44, 213 222.

Viste, E., Korecha, D. \& Sorteberg, A. 2013. Recent drought and precipitation tendencies in Ethiopia. Theoretical and Applied Climatology, 112, 535-551.

Wall, E. \& Smit, B. 2005. Climate Change Adaptation in Light of Sustainable Agriculture. Journal of Sustainable Agriculture, 27, 113-123.

Ward, A., Minja, E., Blackie, M. \& Edwards-Jones, G. 2007. Beyond Participation - Building Farmer Confidence. Outlook on AGRICULTURE, 36, 259-266.

Wejnert, B. 2002. Integrating Models of Diffusion of Innovations: A Conceptual Framework. Annual Review of Sociology, 28, 297-326.

Weldemariam, D., Kebede, M., Taddesse, M. \& Gebre, T. 2013. Farmers' perceptions' and participation on Mechanical soil and water conservation techniques in Kembata Tembaro Zone: the Case of Kachabirra Woreda, Ethiopia. International Journal of Advanced Structures and Geotechnical Engineering, 2, 118-131.

Werner, M., Wauters, E., Bijttebier, J., Steinmann, H.-H., Ruysschaert, G. \& Knierim, A. 2017. Farm level implementation of soil conservation measures: farmers' beliefs and intentions. Renewable Agriculture and Food Systems, 32, 524-537. 
Wigboldus, S., Klerkx, L., Leeuwis, C., Schut, M., Muilerman, S. \& Jochemsen, H. 2016. Systemic perspectives on scaling agricultural innovations. A review. Agronomy for Sustainable Development, 36, 46.

Willock, J., Deary, I. J., Edwards-Jones, G., Gibson, G. J., McGregor, M. J., Sutherland, A., Dent, J. B., Morgan, O. \& Grieve, R. 1999. The Role of Attitudes and Objectives in Farmer Decision Making: Business and Environmentally-Oriented Behaviour in Scotland. Journal of Agricultural Economics, 50, 286-303.

WOCAT 2007. Where the land is greener - case studies and analysis of soil and water conservation initiatives worldwide., Bern, Centre for Development and Environment (CDE).

Wolancho, K. W. 2015. Evaluating watershed management activities of campaign work in Southern nations, nationalities and peoples' regional state of Ethiopia. Environmental Systems Research, 4, 1-13.

Wolka, K. 2014. Effect of Soil and Water Conservation Measures and Challenges for its Adoption: Ethiopia in Focus. Journal of Environmental Science and Technology, 7, 185199.

Wood, D. J. \& Gray, B. 1991. Collaborative alliances: Moving from practice to theory. The Journal of Applied Behavioral Science, 27, 139-162.

Wossena, T., Bergera, T., Mequaninte, T. \& Alamirew, B. 2013. Social network effects on the adoption of sustainable natural resource management practices in Ethiopia. International Journal of Sustainable Development \& World Ecology, 20, 477-483.

Yimer, M. 2015. The effect of sustainable land management (SLM) to ensure food security; local evidences from Tehuledere Woreda, ANRS, Northern Ethiopia. Scientific Journal of Crop Science, 4, 1-27.

Yirga, C., Waithaka, M., Kyotalimye, M. \& Gorfu, B. 2014. Community participatory sustainable land management byelaw formulation in the highlands of central Ethiopia. African Crop Science Journal, 22, 9-20.

Zeweld, W., Van Huylenbroeck, G., Tesfay, G. \& Speelman, S. 2017. Smallholder farmers' behavioural intentions towards sustainable agricultural practices. J Environ Manage, 187, 71-81.

Zougmoré, R., Mando, A. \& Stroosnijder, L. 2010. Benefits of integrated soil fertility and water management in semi-arid West Africa: an example study in Burkina Faso. Nutrient Cycling in Agroecosystems, 88, 17-27. 


\section{English summary}

In Ethiopia's struggle to enhance agricultural production and attain food security, combating land degradation remains a huge challenge; particularly in the highlands of the country where the large majority of the population is dependent on subsistence agriculture for their living. Sustainable Land Management (SLM) is therefore crucial, and over the past decades, massive investments have been made in Ethiopia to promote and scale-up SLM practices. However, large-scale adoption of these practices by smallholder farmers has so far been limited. Nevertheless, there are examples of farmers who have spontaneously adopted SLM practices. These farmers - using their own knowledge and capacity - often adapt practices to make them fit to their particular farming system, and integrate them with other land management measures. The overall aim of this study was to analyze this process of spontaneous spreading (i.e. the adoption and implementation of measures by farmers on their own initiative) and learn lessons that could contribute to developing the way forward in scaling-up SLM in the Central Highlands of Ethiopia.

Chapter 2 deals with the comparison between stone bunds that were spread spontaneously versus stone bunds implemented by mass mobilization campaigns. The results show that farmers who spontaneously implement stone bunds prefer to construct them on farmlands located nearby the homestead, often with a poor to medium soil fertility status, where erosion is perceived as moderate to severe, and which have moderate to steep slope gradients. This means that stone bunds spontaneously spread mainly where they were most needed. Farmers with spontaneously implemented stone bunds perceive a reduction in soil erosion, increase in soil moisture, better soil productivity and higher crop yields on these farmlands. These positive effects are the result of the fact that stone bunds of the spontaneous adopting farmers are well-maintained and integrated with the use of fertilizer, compost and manure. The lesson learned from this chapter is that SLM activities undertaken by mass mobilization should become more integrated and participatory, as learning and testing innovations by farmers enhances adoption of SLM practices.

Following up on the previous chapter, Chapter 3 focuses on the characteristics of farmers that spontaneously implement stone bunds and farmers who do not. Using Principal Component Analysis, the study identified five key-factors that explain the differences between farmers who spontaneously implement stone bunds and those who do not. These include readiness to change, available resources, social capital, type of family and commitment. The results show that farmers who spontaneously implemented stone bunds are: 1) young farmers committed to soil conservation, 2) intrinsically motivated dynamic 
farmers ready to change their future and improve productivity and food security, and 3) farmers with relatively limited productive resources such as farmland, labor and livestock, but with more willingness to improve their agricultural production, relying on available resources and social capital. This implies that government extension programs aiming to sustainably increase agricultural production and achieve food security of smallholder farmers in Ethiopia should be more focused on triggering farmers' "readiness to change", and foster their intrinsic motivation to implement SLM. Likewise, the results show that implementation of SLM relies more on farmers having a positive attitude and commitment, rather than having the resources available like labor forces and money. Hence, changing farmers' mind-set through training and learning is crucial to foster SLM in Ethiopia.

Chapter 4 explores the effect of an adapted (more participatory and more integrated) mass mobilization training approach on farmers' motivation to practice integrated farming. This study was based on the results of a one-year field experiment carried out in the Central Highlands of Ethiopia. The results show that the adapted training approach enhanced awareness of farmers, created intrinsic motivation for integrated farm management and fostered implementation of SLM practices in the field. It also reveals that farmers who followed the training are better able to plan for future drought mitigation and are more aware of the possible effects of drought on their farming activities. The results imply that agricultural extension programs that aim at scaling-up of resilient farming to watershed and landscape levels should start with capacity building by means of participatory training methods, and by empowering and motivating farmers for integrated SLM.

Chapter 5 focuses on the policy and institutional environment of Ethiopia required to speedup the scaling-up of SLM. It identifies perceived limitations at the national, regional and local level hindering the scaling-up of SLM practices, and finds that these relate to the process of policy formulation and implementation, the available institutional capacity, and collaboration between institutions. Particularly limiting are the top-down approaches used for planning, implementing and monitoring; these neglect farmers' knowledge and their priority needs. However, lack of capacity within institutions to scale-up SLM practices is another crucial issue: decision-makers have very limited knowledge about SLM practices and measures, while extension workers and officials do not transfer their knowledge and have to deal with high staff turnover. Furthermore, there is often poor coordination, collaboration and communication between different institutional levels, which also hinders a more effective and structured scaling-up of SLM practices. Changing the policy and institutional environment of Ethiopia is therefore urgently required, by means of creating supportive policies, building the institutional capacity, and strengthening institutional collaboration and networking. 
Chapter 6 presents a synthesis of the previous chapters. It provides answers to the research questions, and discusses the major findings of the study. It also presents the extension and policy implications, scientific contributions of the thesis, and suggestions for future research. The main insight from this thesis is that a shift towards a more participatory and integrated approach for SLM is urgently required to genuinely tackle land degradation in the highlands of Ethiopia. Participatory approaches empower farmers to make decisions themselves and enable them to invest in diverse SLM practices that they think can solve their priority problems such as low soil fertility. Likewise, promoting SLM technologies in a more integrated manner contributes to increased food production, and diversified production and higher incomes. Furthermore, Chapter 6 presents the general conclusions drawn from the findings of the study. The chapter concludes that:

- In order to sustainably enhance the productive capacity of smallholder farmers and increase their food security, more focus on training and enhancing farmers' intrinsic motivation to improve their livelihood is necessary.

- More focus on participatory planning and learning in the mass mobilisation strategy is crucial, as this improves farmers' sense of ownership of SLM practices and increases their motivation to participate in conservation activities.

- The strategies for scaling-up SLM practices in the central highlands of Ethiopia should shift towards more integrated soil fertility management, rather than focusing mainly on physical conservation practices.

- Government investments in creating an adequate enabling environment for scalingup SLM are urgently required, as many limitations at institutional level currently hinder the spreading and effectiveness of SLM efforts. 


\section{Acknowledgements}

Above all, my greatest gratitude reaches to the almighty God for giving me the courage and patience to see the fruit of my effort. Of course, the completion of this PhD journey would not have been possible without a kind contribution and support from various people and organizations in different aspects. In the following, for the time being, I express my sincere gratitude to some of them who have made a significant contribution to this journey.

First, I would like to express my sincere and heartfelt gratitude to my promoter Prof Peter Oosterveer for his guidance, encouragement and support over the past five years. We spent several invaluable hours in discussions, from the time of proposal development through the final write-up of this thesis. Peter, you are really kind, helpful and positive. I say thank you for your unreserved comments and suggestions to improve the quality of this thesis. I am pleased to have you as a promoter!

Next, I would like to extend my earnest thanks to my daily supervisor Dr Aad Kessler for his guidance, supervision, support and patience through the entire period of my study. He deserves appreciation and gratitude for his invaluable and critical comments, tireless support and invaluable inputs towards the shaping up of this $\mathrm{PhD}$ thesis. I really appreciate his critical comments and suggestions on the contents and structure of the thesis chapters. Aad, this thesis would not have been the same without your constructive feedback and challenges throughout the entire writing process, I say thank you so much. To be honest, it was such a relief to be able to receive invaluable input and feedback on drafts of my writings. I greatly-value your patience while correcting those silly mistakes or grammatical errors, and providing the much needed editorial works throughout the thesis writing. I consider it my privilege to have you as a daily supervisor!

Special thanks to my local supervisor Dr Degefa Tolossa for his kind advice, constructive comments and encouragement through the entire period of my study. Degefa, I greatly value your thoughts and critical comments on my papers. I feel privileged to work with you, I say thank you for everything you have done for me.

I would like to extend my sincere thanks to staff and PhD students at the Soil Physics and Land Management Group. Special thanks for the staff members: Coen, Violette, Jerry, Jantiene, Piet, Jos and Demie at Wageningen University for their moral support during my study in Wageningen. I am also indebted to thank my friends from the "Atlas Gang", particularly Kaveh, Coleen, Corjan, Ammar, Karrar, Raoul, Celia, Vera, Ricardo, Carlos, Pop, 
Fabio, Nickolas, Mulatie, Selamawit, Walle, Samuel A., Samuel T., Tesfaye, Xiaomei, Lingtong, Yoeling, Miao and many others for their friendship. SLMers, I benefitted a lot from our discussions during the coffee breaks and lunch times. My heartfelt thanks also go to Marnella, Esther, Henny and Siawash for facilitating the administrative and financial matters during my study at Wageningen University, as well as Addis Ababa University. Special thanks and appreciation to Marnella for her support in terms of booking tickets, arranging taxis, facilitating a room to stay in Wageningen. I say thank you for your invaluable contribution during my PhD journey. My gratitude to Klaas Oostindie for his precious assistance in outlining and editing my thesis book.

Many thanks to Ethiopian friends in Wageningen. Special thanks to Solomon, Delelegne, Mikinay and Tariku. Thanks a lot for keeping our Sunday evening walking program part of our weekly routines, and for the time and traditional meals we had together.

Carrying-out this PhD study would not have been possible without the financial support from the Capacity building for Scaling-up of evidence-based best practices in Agricultural Production in Ethiopia (CASCAPE) project, and the study leave grant with a half salary payment from Addis Ababa University, College of Development Studies (CDS). I wish to acknowledge the CASCAPE project and CDS for this. I am very grateful to all CDS staff for their kind academic advice, unreserved moral support and encouragements during my study period. My heartfelt thanks go to Bechaye, Dr Messay, Dr Temesgen, Dr Solomon, Dr Desalegn, Dr Abebe, Dr Amare, Dr Dilu, Dr Terefe, Dula, Emebet, Chalachewu, Tariku, Abiot, Dr Belay, Dr Tesfaye and Gebeyawu. I thank Dr Ermias for his technical support in mapping the study area. A special thank you to Dr Feyera for his thoughtful advice, encouragements and support during my study. He also read and commented on my dissertation chapters.

In Girar Jarso woreda, I thank Mr. Tesfaye Hailu for facilitating my field work and allowing me to use office facilities. I would also like to thank all staff members of Girar Jarso Woreda Agriculture Office for their continuous moral support. Special thanks go to my field assistants Mr. Negatu Tadesse and Mr. Tesfaye Tefera for their assistance during data collections and field experiment. I also indebted special gratitude to all Development Agents and kebele administrators for their valuable assistance, time, information and hospitality during my field work. I am grateful for that. Last, but not least, I am greatly indebted to all farmers who participated in this research.

Finally, I would like to thank my parents for all their affection, unconditional support, encouragement, prayers and blessing for my progress and success. Special thanks to my father Abi Teka, mother Shewaye Adugna, brothers Fekadu, Hailu, Samuel and Tibebu and sisters Sintayehu, Fikir, Lensa, Obse and Demme. Finally yet importantly, I would like to 
express my heartfelt thanks to my grandmother Emahow Alemayehu Mengiste for her blessings and keeping me in her prayers throughout my life. 


\section{About the author}

Meskerem Abi Teka was born on September 25, 1984 in North Shewa Zone of Oromia region, Ethiopia. She obtained her BSc degree in Agricultural Resource Economics and Management from Hawassa University in July 2007. She was employed in Girar Jarso Woreda Agriculture Office as an expert of planning in September 2007. In December 2009, she continued her MSc study at Addis Ababa University and received her MSc degree in Food Security Studies in July 2011. Her Master thesis focused on household food security in the Girar Jarso woreda, Oromia region. After completing her MSc study, she continued working as an expert of planning in the agriculture office. In September 2012, she was employed in Addis Ababa University as Lecturer in the Center for Food Security studies, where she also served as a Head of the Center.

In October 2013, she joined Soil Physics and Land Management Group to pursue her PhD study at Wageningen University. The PhD project was funded by the project "Capacity building for Scaling-up of evidence-based best practices in Agricultural Production in Ethiopia (CASCAPE)". Meskerem Abi Teka conducted an interdisciplinary research in the field of sustainable land management. This dissertation presents the results of her PhD study, which also comprises published, peer-reviewed and submitted articles in scientific journals.

\section{Scientific Publications}

\section{Peer reviewed articles}

Abi, M., Kessler, A., Oosterveer, P. \& Tolossa, D. 2018. Understanding the Spontaneous Spreading of Stone Bunds in Ethiopia: Implications for Sustainable Land Management. Sustainability, 10 (8).

Abi, M., Kessler, A., Oosterveer, P. \& Tolossa, D. 2018. How farmers' characteristics influence spontaneous spreading of stone bunds in the highlands of Ethiopia: a case study in the Girar Jarso woreda. Environment, Development and Sustainability, https://doi.org/10.1007/s10668-018-0203-2.

Abi, M. \& Tolossa, D. 2015. Household Food Security Status and its Determinants in Girar Jarso Woreda, North Shewa zone of Oromia Region, Ethiopia. Journal of Sustainable Development in Africa, 17, 118-137.

Abi, M., Kessler, A., Oosterveer, P. \& Tolossa, D. Adapting the current mass mobilization approach in Ethiopia to enhance its impact on sustainable land management: lessons from the Sago-kara watershed. Journal of Environmental Management, under review 
Abi, M., Kessler, A., Oosterveer, P. \& Tolossa, D. Towards an enabling policy and institutional environment for scaling-up sustainable land management practices in the central highlands of Ethiopia. Land use policy. Submitted.

Master thesis

Abi, M. 2012. Household Food Security Situation in Girar Jarso Woreda, North Shewa Zone of Oromiya National Regional State, Ethiopia. MSc Thesis. Addis Ababa University. http://etd.aau.edu.et/dspace/handle/123456789/4236. 


\section{Certificate of the Netherlands Research School for the Socio-economic and Natural Sciences of the Environment (SENSE)}




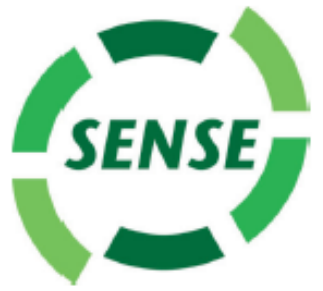

Netherlands Research School for the

Socio-Economic and Natural Sciences of the Environment

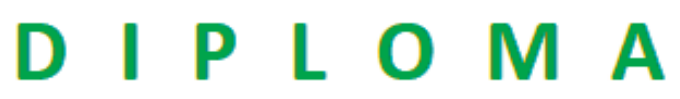

For specialised PhD training

The Netherlands Research School for the

Socio-Economic and Natural Sciences of the Environment

(SENSE) declares that

\section{Meskerem Abi Teka}

born on 25 September 1984 in North Shewa Zone, Ethiopia

has successfully fulfilled all requirements of the

Educational Programme of SENSE.

Wageningen, 12 June 2019

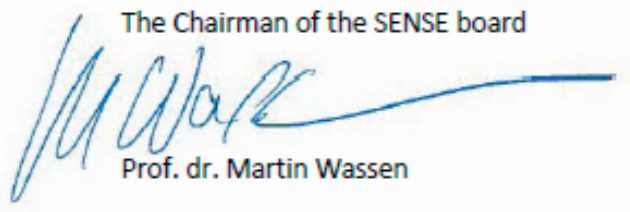

the SENSE Director of Education

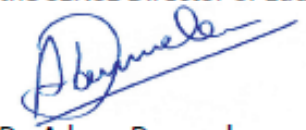

Dr. Ad van Dommelen

The SENSE Research school has been accredited by the Royal Netherlands Academy of Arts and Sciences (KNAW)

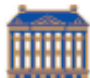

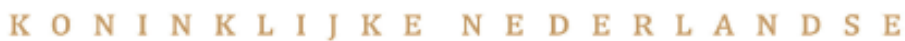

A K A D E M I E V A N W E T E N S C H A P P E N 


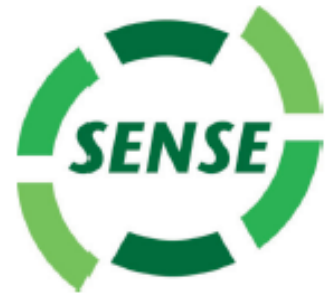

The SENSE Research School declares that Meskerem Abi Teka has successfully fulfilled all requirements of the Educational PhD Programme of SENSE with a work load of $34.9 \mathrm{EC}$, including the following activities:

\section{SENSE PhD Courses}

- Basic statistics (2014)

- Research Methodology: From Topic to Proposal (2014)

- Environmental research in context (2014)

- Research in context activity: "Co-organizing and chairing two days training workshop on 'Scaling-up sustainable land management Practices through integrated and participatory approach', organized in the Sago-Kara watershed, Central Highland of Ethiopia' (2016)

\section{Other PhD and Advanced MSc Courses}

- Interpersonal communication, Wageningen Graduate schools (2014)

- Scientific writing, Wageningen Graduate schools (2016)

- Reviewing a Scientific Paper, Wageningen Graduate schools (2017)

- Scientific Publishing, Wageningen Graduate schools (2017)

- Mobilizing Scientific Network, Wageningen Graduate schools (2017)

- Career Perspective, Wageningen Graduate schools (2017)

- Effective behaviour in professional surrounding, Wageningen Graduate schools (2018)

\section{Selection of Oral and poster Presentations}

- Scaling-up best practices for sustainable land management in the highlands of Ethiopia: The case of Girar Jarso Woreda, Oromia Region. CASCAPE symposium, 9-13 February 2015, Dire Dawa, Ethiopia

- How farmers' characteristics influence spontaneous spreading of stone bunds in the highlands of Ethiopia. Wageningen Soil Conference, 27-31 August 2017, Wageningen, The Netherlands

- Sustainable land management practices through integrated farm management approach: Lessons from the Sago-Kara Watershed, Ethiopia. Soil contamination: Scope, advances and challenges, 1 September 2017, Wageningen, The Netherlands

SENSE Coordinator PhD Education

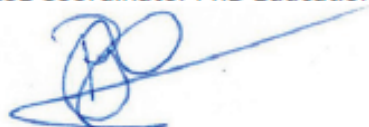

Dr. Peter Vermeulen 


